\title{
Configuration and Technology Implications of Potential Nuclear Hydrogen System Applications
}

prepared by

Nuclear Engineering Division and

Decision and Information Sciences Division

Argonne National Laboratory 


\begin{abstract}
About Argonne National Laboratory
Argonne is managed by The University of Chicago for the U.S. Department of Energy under contract W-31-109-Eng-38. The Laboratory's main facility is outside Chicago, at 9700 South Cass Avenue, Argonne, Illinois 60439. For information about Argonne and its pioneering science and technology programs, see www.anl.gov.
\end{abstract}

\title{
Availability of This Report
}

This report is available, at no cost, at http://www.osti.gov/bridge. It is also available on paper to U.S. Department of Energy and its contractors, for a processing fee, from:

U.S. Department of Energy

Office of Scientific and Technical Information

P.O. Box 62

Oak Ridge, TN 37831-0062

phone (865) 576-8401

fax (865) 576-5728

reports@adonis.osti.gov

\section{Disclaimer}

This report was prepared as an account of work sponsored by an agency of the United States Government. Neither the United States Government nor any agency thereof, nor The University of Chicago, nor any of their employees or officers, makes any warranty, express or implied, or assumes any legal liability or responsibility for the accuracy, completeness, or usefulness of any information, apparatus, product, or process disclosed, or represents that its use would not infringe privately owned rights. Reference herein to any specific commercial product, process, or service by trade name, trademark, manufacturer, or otherwise, does not necessarily constitute or imply its endorsement, recommendation, or favoring by the United States Government or any agency thereof. The views and opinions of document authors expressed herein do not necessarily state or reflect those of the United States Government or any agency thereof, Argonne National Laboratory, or The University of Chicago. 


\section{Configuration and Technology Implications of Potential Nuclear Hydrogen System Applications}

by

Bilge Yildiz and Mark C. Petri

Nuclear Engineering Division, Argonne National Laboratory

Guenter Conzelmann

Decision and Information Sciences Division, Argonne National Laboratory

Charles Forsberg

Oak Ridge National Laboratory

July 31,2005


Argonne National Laboratory is managed by

The University of Chicago for the U.S. Department of Energy 


\title{
Configuration and Technology Implications of Potential Nuclear Hydrogen System Applications
}

\author{
Summary
}

\section{Introduction - Nuclear-Generated Hydrogen}

Nuclear technologies have important distinctions and potential advantages for large-scale generation of hydrogen for U.S. energy services. Nuclear hydrogen requires no imported fossil fuels, results in lower greenhouse-gas emissions and other pollutants, lends itself to large-scale production, and is sustainable. The technical uncertainties in nuclear hydrogen processes and the reactor technologies needed to enable these processes, as well waste, proliferation, and economic issues must be successfully addressed before nuclear energy can be a major contributor to the nation's energy future. In order to address technical issues in the time frame needed to provide optimized hydrogen production choices, the Nuclear Hydrogen Initiative (NHI) must examine a wide range of new technologies, make the best use of research funding, and make early decisions on which technology options to pursue. For these reasons, it is important that system integration studies be performed to help guide the decisions made in the NHI.

In framing the scope of system integration analyses, there is a hierarchy of questions that should be addressed:

- What hydrogen markets will exist and what are their characteristics?

- Which markets are most consistent with nuclear hydrogen ?

- What nuclear power and production process configurations are optimal?

- What requirements are placed on the nuclear hydrogen system?

\section{Study Objectives}

The intent of the NHI system studies is to gain a better understanding of nuclear power's potential role in a hydrogen economy and what hydrogen production technologies show the most promise. This work couples with system studies sponsored by DOE-EE and other agencies that provide a basis for evaluating and selecting future hydrogen production technologies. This assessment includes identifying commercial hydrogen applications and their requirements, comparing the characteristics of nuclear hydrogen systems to those market requirements, evaluating nuclear hydrogen configuration options within a given market, and identifying the key drivers and thresholds for market viability of nuclear hydrogen options.

\section{Nuclear Energy for Hydrogen Production}

Different methods for hydrogen production have different characteristics. For nuclear-generated hydrogen those characteristics include (1) economics that favor large-scale centralized production of hydrogen, (2) the co-production of oxygen as a byproduct, and (3) the availability 
Summary

July 31, 2005

of low-cost heat. Hydrogen production technologies that use renewable energy generally involve smaller scale and dispersed production facilities.

Each existing and potential market for hydrogen also has distinct characteristics that will favor particular methods of hydrogen production - even if each technology produces hydrogen at similar production costs. The size, location, and hydrogen product requirements will determine whether a production method will be cost effective. A large centralized demand for hydrogen can be supplied by a nuclear hydrogen system without the need for an expensive infrastructure of pipelines for hydrogen delivery as compared to meeting a dispersed demand. It can also supply large quantities of byproduct oxygen that is required for some applications. Nuclear hydrogen must also be competitive with alternative technologies in terms of cost, risk, operability, and environmental impact, which in turn will depend on the needs of the specific hydrogen market being considered. As these markets evolve, nuclear hydrogen's ability to compete will change. This study attempts to align these characteristics to understand implications for nuclear hydrogen development priorities.

\section{Synergisms with Other Primary Energy Sources}

Nuclear hydrogen and heat can transform coal and tar sands into liquid fuels for transportation, making coal and tar sands more environmentally acceptable and providing a means for nuclear energy to contribute to the transportation sector. The infrastructure developed through these markets may eventually lead to the direct use of hydrogen as a transportation fuel.

The development of nuclear hydrogen technologies may contribute to the adoption of other primary energy sources, as well. Plant configurations that allow switching between electricity and hydrogen production could provide the backup power needed to make intermittent renewable energy sources such as sunlight and wind viable. Although this configuration could impose additional capital costs for the plant, with the right choice of technologies the nuclear-renewable arrangement could significantly improve the market attractiveness of the renewable options.

The complexities of such integrated and synergistic markets need to be considered in assessing the most economically favorable configurations for nuclear hydrogen production and the technologies employed. Such complexities will be examined in the broader DOE hydrogen program system studies. The work sponsored here by the Nuclear Hydrogen Initiative will make an important contribution to that overall effort.

\section{Hydrogen Markets and Characteristics}

The current market for hydrogen is already significant and rapidly growing. Near-term markets for nuclear hydrogen include those currently being supplied from steam methane reforming, but new markets are likely to develop. The figure below summarizes the major markets and their characteristics. 
Summary

July 31, 2005

\section{Markets}

- Current and near-term

- Oil refining

- Ammonia (fertilizer) industry

- Methanol industry

- Merchant H2 customers (chemicals, metals, food, etc.)

- Tar sands

- Mid-term

- Power peaking

- Coal liquefaction

- Far-term

- Remote power

- Transportation

\section{Characteristics}

- Current market size

- By region, state, customer

- By product/market type

- Projected market size

- Main growth drivers

- Potential market inhibitors/threats

- Marketing/business models

- Product requirements

- Delivery characteristics

- Distribution needs

- Nuclear competitors

\section{Comparison of Nuclear Hydrogen Characteristics and Potential Market Requirements}

Nuclear hydrogen applications are linked to the attributes of nuclear power. These systems will be large and centralized, but may have customized hydrogen production capacities. Existing markets for hydrogen include ammonia and methanol production and conversion of heavy oil, tar sands, and other heavy hydrocarbons into liquid transport fuels (gasoline, diesel, and jet fuel). Large quantities of hydrogen are required by these facilities in the conversion processes.

Most existing refineries and other fuel production facilities do not use significant quantities of oxygen in fuel production. If nuclear hydrogen technology is developed and used, low-cost oxygen becomes available. The co-production and use of hydrogen and oxygen could (1) significantly improve refinery economics, (2) reduce releases of greenhouse gases from these fuel production facilities, and (3) increase liquid transport fuel yields per unit of heavy oil, tar sands, oil shale, or coal. In this context, there are potential advantages for using nuclear hydrogen with co-produced oxygen to minimize carbon dioxide releases from these facilities.

The following table summarizes current and potential hydrogen markets and the implication for nuclear hydrogen technologies: 
Summary

July 31, 2005

\begin{tabular}{|c|c|c|c|c|c|}
\hline Hydrogen Market & $\begin{array}{c}2003 \text { U.S. } \\
\text { Market Size } \\
(1000 \text { tonnes H2) }\end{array}$ & Outlook & $\begin{array}{l}\text { Hydrogen Production } \\
\text { Implications }\end{array}$ & $\begin{array}{l}\text { Nuclear Technology } \\
\text { Implications }\end{array}$ & $\begin{array}{l}\text { Nuclear } \\
\text { Hydrogen } \\
\text { Technology } \\
\text { Options }\end{array}$ \\
\hline Oil Refining & 4,084 & Strong growth. & $\begin{array}{l}\text { Market suitable to dedicated } \\
\text { hydrogen production at local } \\
\text { sites. }\end{array}$ & $\begin{array}{l}\text { Standardized nuclear reactor } \\
\text { with fixed-capacity hydrogen } \\
\text { plant customized for site; } \\
\text { excess electricity for site or } \\
\text { grid sales. }\end{array}$ & $\begin{array}{l}\text { Thermochemical or } \\
\text { electrolysis with co- } \\
\text { generation. }\end{array}$ \\
\hline Ammonia Industry & 2,616 & \begin{tabular}{|l|} 
Market stalled by \\
high natural gas \\
and hydrogen costs.
\end{tabular} & $\begin{array}{l}\text { Market suitable to dedicated } \\
\text { hydrogen production at local } \\
\text { sites. }\end{array}$ & $\begin{array}{l}\text { Standardized nuclear reactor } \\
\text { with fixed-capacity hydrogen } \\
\text { plant customized for site; } \\
\text { excess electricity for site or } \\
\text { grid sales. }\end{array}$ & $\begin{array}{l}\text { Thermochemical or } \\
\text { electrolysis with co- } \\
\text { generation. }\end{array}$ \\
\hline Methanol Industry & 393 & $\begin{array}{l}\text { Market stalled by } \\
\text { high natural gas } \\
\text { and hydrogen costs } \\
\text { and MTBE phase- } \\
\text { out. }\end{array}$ & $\begin{array}{l}\text { Market suitable to dedicated } \\
\text { hydrogen production at local } \\
\text { sites, but possibly shrinking } \\
\text { market. }\end{array}$ & $\begin{array}{l}\text { Co-generation plant to switch } \\
\text { to electricity if methanol } \\
\text { demand falls. }\end{array}$ & Electrolysis. \\
\hline Other Industries & & Modest growth. & $\begin{array}{l}\text { Market suitable to scaleable } \\
\text { regional production centers. }\end{array}$ & $\begin{array}{l}\text { Dedicated or co-generation } \\
\text { plant that can be scaled for } \\
\text { market growth. }\end{array}$ & Electrolysis. \\
\hline $\begin{array}{l}\text { - Edible fats and oils } \\
\text { - Metals } \\
\text { - Electronics } \\
\text { - Other }\end{array}$ & $\begin{array}{l}22 \\
48 \\
14 \\
11\end{array}$ & & & & \\
\hline Tar Sands & $\begin{array}{c}(515 \text { in Alberta in } \\
\text { 2004) }\end{array}$ & $\begin{array}{l}\text { Strong growth } \\
\text { (Canada). }\end{array}$ & $\begin{array}{l}\text { Market suitable to dedicated } \\
\text { hydrogen production at local } \\
\text { sites. }\end{array}$ & $\begin{array}{l}\text { Standardized nuclear reactor } \\
\text { with fixed-capacity hydrogen } \\
\text { plant customized for site; heat } \\
\text { for process steam. }\end{array}$ & $\begin{array}{l}\text { Thermochemical or } \\
\text { electrolysis with } \\
\text { process heat } \\
\text { generation. }\end{array}$ \\
\hline $\begin{array}{l}\text { Coal Liquefaction and } \\
\text { Shale Oil }\end{array}$ & $\begin{array}{l}\text { Medium-to-long } \\
\text { term }\end{array}$ & $\begin{array}{l}\text { Potentially } \\
\text { significant. }\end{array}$ & $\begin{array}{l}\text { Market suitable to dedicated } \\
\text { hydrogen production at local } \\
\text { sites. }\end{array}$ & $\begin{array}{l}\text { Standardized nuclear reactor } \\
\text { with fixed-capacity hydrogen } \\
\text { plant customized for site; } \\
\text { excess electricity for site or } \\
\text { grid sales. }\end{array}$ & $\begin{array}{l}\text { Thermochemical or } \\
\text { electrolysis with co- } \\
\text { generation. }\end{array}$ \\
\hline Peak Electricity & $\begin{array}{l}\text { Medium-to-long } \\
\text { term }\end{array}$ & $\begin{array}{l}\text { Potentially } \\
\text { significant. }\end{array}$ & $\begin{array}{l}\text { Market suitable to dedicated } \\
\text { hydrogen production at local } \\
\text { sites. }\end{array}$ & $\begin{array}{l}\text { Standardized nuclear reactor } \\
\text { with fixed-capacity } \\
\text { hydrogen/oxygen plant } \\
\text { customized for site. }\end{array}$ & $\begin{array}{l}\text { Thermochemical or } \\
\text { electrolysis. }\end{array}$ \\
\hline Transportation & Long term & $\begin{array}{l}\text { Potentially } \\
\text { significant. }\end{array}$ & $\begin{array}{l}\text { Depending on market } \\
\text { scenario, may be suitable to } \\
\text { scaleable regional production } \\
\text { centers. }\end{array}$ & $\begin{array}{l}\text { Dedicated or co-generation } \\
\text { plant that can be scaled for } \\
\text { market growth. }\end{array}$ & Electrolysis. \\
\hline
\end{tabular}

\section{Observations and Conclusions}

\section{Potential Roles for Nuclear Hydrogen}

- Nuclear-produced hydrogen matches the requirements of the major near-term hydrogen markets for liquid fuels and chemical products. 
- Refining production represents good opportunities for domestic hydrogen production. Hydrogen needs for Canadian tar sands are large and are growing rapidly. In the mid term, coal liquefaction may represent another growing hydrogen consumer. Nuclear energy is possibly the most suitable option for these large-scale, centralized, captive markets.

- Nuclear hydrogen production costs today through low-temperature electrolysis are high compared to those for steam methane reforming. Advances in low-temperature electrolysis and growing concerns about greenhouse gas emissions may make this an attractive option, especially for distributed, small-scale applications.

- Some markets would benefit from nuclear power's flexibility in producing electricity, process heat, hydrogen, and oxygen. Further analysis is required to explore these complex synergies.

- There are compelling synergies between nuclear base-load hydrogen production systems and intermittent renewable energy systems that enable the combination of energy sources to be more economic and deployed earlier.

- The oxygen co-product from nuclear hydrogen production may provide a path to improved manufacture of liquid transportation fuels. Analysis is required to determine the economic advantages of using nuclear hydrogen co-produced oxygen for conversion of heavy feedstocks (heavy oil, shale oil, coal) to transportation fuels.

\section{Nuclear Hydrogen Production Technologies}

- Nuclear energy can be used to make hydrogen using conventional electrolysis for some early applications. The timing and ultimate market penetration of this approach will be influenced by several factors, including the availability of cost-effective off-peak electricity supplies in the future from nuclear sources. Advances in electrolyzers will also increase the level of use of this technology.

- The advanced production technologies (thermochemical cycles and high-temperature steam electrolysis) have the potential to improve the economics by about 30 to $50 \%$ over today's low-temperature electrolysis technology, if development is successful.

- Thermochemical methods use cheaper energy (heat), but require higher temperature reactors than are now available. Research and development into ways to use lower temperatures could determine the ultimate level of use of thermochemical cycles if very high temperature gas-cooled reactor economics are not favorable.

- Steam electrolysis also requires high temperatures and, therefore, new reactor designs, but only about $25 \%$ of the energy is in the form of heat with the rest in the form of electricity. A single $600 \mathrm{MWt}$ VHTR could provide heat for a multi-GW nuclear steam electrolysis plant that consumes electricity from other sources on the grid.

- Nuclear plants capable of co-generating electricity and hydrogen allow additional flexibility within different hydrogen markets. For instance, co-generation allows for standardization of the nuclear unit, but with customized hydrogen production capacity to meet a consumer's needs. Some markets would benefit from hydrogen technologies that can readily be scaled (e.g., through modularity) as hydrogen demand grows. 


\section{Other Economic Observations}

- Historically the U.S. has had some of the lowest natural gas prices in the industrial world. Today the U.S. has some of the highest prices. This is driving hydrogen-intensive industries with shippable products (such as fertilizers) offshore to areas with low-cost natural gas. Growing natural gas demand in the U.S. and Canada (in part due to increasing hydrogen demands) will exacerbate this problem. Domestic sources of lowcost hydrogen not subject to natural gas price volatility could revive these industries.

- Cost of peak power from natural gas turbines has increased proportionately with the price of natural gas. This creates incentives to consider nuclear hydrogen and oxygen for production of peak electricity. It may also create incentives for co-generation plants as a method to vary electricity and hydrogen production and thus maximize peak electricity production.

- High prices for oil and issues of domestic energy security are renewing interest in coal liquefaction. Two major cost inputs into coal liquefaction are hydrogen and oxygen (for the gasification option). Nuclear hydrogen can generate centralized hydrogen and oxygen on a scale to match coal liquefaction.

\section{Next Steps}

In FY 2006, the nuclear hydrogen system integration studies will investigate the likelihood of success for nuclear hydrogen technologies in evolving markets. In this effort the overall economics of nuclear hydrogen will be further investigated and a cost framework will be developed for understanding the relationships between, say, capital costs and the cost of produced hydrogen. Four questions will be addressed with the goal of providing a means to assess nuclear hydrogen technology options:

1. Are there improvements in key technical/cost parameters and components that future research should focus on because of their strong influence on market viability?

2. What are the potential tradeoffs in performance improvements and increased capital costs due to increased system complexity?

3. How will nuclear hydrogen evolve under a number of different futures (low/high hydrogen market demand, low/high natural gas prices, etc.)?

4. What are synergistic relationships between nuclear hydrogen, renewables, and fossil fuels (coal liquefaction, shale oil, etc.) and are there specific requirements that are imposed on nuclear hydrogen systems to maximize total benefits.

The answers will be coordinated with the process designers for the nuclear hydrogen systems. The results of this work can provide feedback for the cost and efficiency of each technology configuration required to be viable in a given market. Consequently, the process designers should judge whether or how those threshold requirements for the market viability of the process can be achieved both from technical and economic aspects. 
Summary

July 31,2005

The market analysis will be integrated into a larger DOE-EE study on hydrogen infrastructure and markets. The ultimate objective of the DOE-EE project is to indicate the role of different technologies in a successful transition to a hydrogen production and delivery infrastructure by using agent-based modeling tools. For validation and verification purposes, under the DOE-EE project a conventional hydrogen infrastructure analysis framework already developed at ANL will be used to develop a baseline scenario for hydrogen market penetration of competing technologies. 


\section{Table of Contents}



1.1 Relationship of Nuclear Power to Energy Currencies and Services........................... 2

2. Objectives of the Nuclear Hydrogen System Integration Studies ................................ 8

2.1 Relationship of this Analysis to the DOE-EE Project ........................................ 9



3.1 Near-Term Hydrogen Markets............................................................................ 17

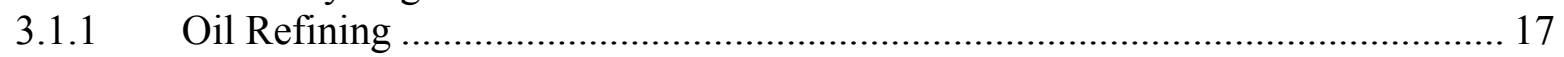







3.2 Mid- and Long-Term Markets .......................................................................... 27











4. Characteristics of Nuclear Hydrogen Production Technologies ................................. 32

4.1 Candidate Nuclear Reactor Technologies and Power Conversion Systems ................ 33

4.2 Hydrogen Production Technologies Using Nuclear Energy..................................... 34

4.2.1 Thermochemical Processes .............................................................................. 34

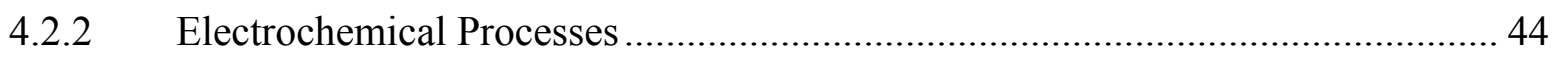

4.2.3 Hybrid Thermochemical Cycles ................................................................ 47

5. Properties and Market Implications of Nuclear Hydrogen Production Plant



5.1 Configurations for Thermochemical Processes .................................................... 55

5.2 Configurations for Low-Temperature Electrolysis ................................................ 56

5.3 Configurations for High-Temperature Steam Electrolysis ...................................... 57

5.4 Configurations for the Westinghouse Hybrid Sulfur Process................................... 61



5.6 Summary of the Implications for Nuclear Hydrogen Plant Configurations ................ 66

6. Observations on Hydrogen Markets and Nuclear Technologies..................................6 68



6.2 Observations on Nuclear Hydrogen Production Options.......................................... 71

6.3 Next Steps and Goals for the Nuclear Hydrogen System Studies ............................. 72

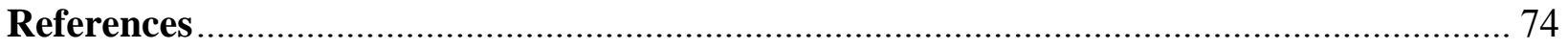

Appendix A












3.2 Carbon Dioxide Neutral Liquid Fuels.............................................................. 91

3.3 Hydrogen Auto and Truck Transport System ........................................................ 94

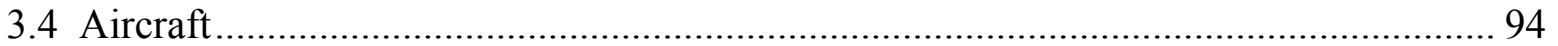

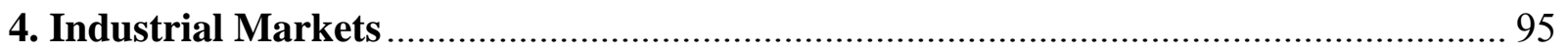

4.1 Ammonia and Other Chemical Applications ..................................................... 95





5.1 Energy Storage for Intermediate and Peak Electrical Production ............................. 96

6. Commercial Hydrogen Markets ............................................................................ 99















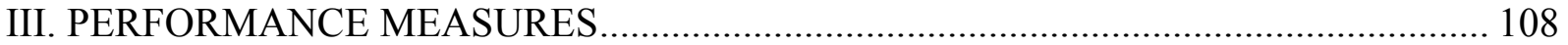

III.A Commodities Inventory and Equipment Count.................................................... 108

III.B Material Properties ........................................................................................ 109





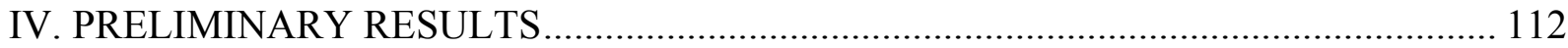

IV.A Low-Cost Product Plant .................................................................................... 112

IV.B Temperatures and Efficiency with Load Change................................................. 113

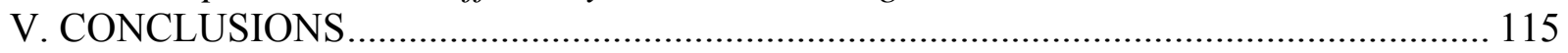






\title{
Configuration and Technology Implications of Potential Nuclear Hydrogen System Applications
}

\author{
Bilge Yildiz, ANL \\ Guenter Conzelmann, ANL \\ Mark C. Petri, ANL \\ Charles Forsberg, ORNL
}

July 31,2005

\section{Introduction}

Nuclear-generated hydrogen has important potential advantages over other sources that will be considered for a growing hydrogen economy. Nuclear hydrogen requires no imported fossil fuels, results in lower greenhouse-gas emissions and other pollutants, lends itself to large-scale production, and is sustainable. These advantages do not ensure that nuclear hydrogen will prevail, however, especially given strong competition from other hydrogen sources. There are technical uncertainties in nuclear hydrogen processes, certainly, which need to be addressed through a vigorous research and development effort. Equally important, though, are the lifecycle environmental and economic issues that could end nuclear energy's prospects, regardless of the technical viability. Moreover, the limited budget of the Nuclear Hydrogen Initiative (NHI) will require early decisions on which technology options to pursue. For these reasons, it is important that system integration studies be performed to help guide the decisions made in the NHI.

In framing the scope of system integration analyses, there is a hierarchy of questions that should be addressed:

- What markets will exist within a changing hydrogen economy?

- $\quad$ In which markets can nuclear power compete?

- What nuclear power configurations are optimal?

- What requirements are placed on the nuclear hydrogen system?

Through the system integration studies sponsored by NHI, the program will gain a better understanding of nuclear power's potential role in a hydrogen economy and what hydrogen production technologies show the most promise and are worth pursuing. This work couples with system studies sponsored by other agencies and with NHI efforts to standardize the assessment of hydrogen production efficiencies.

After a discussion of the role hydrogen can play in the relationship between energy sources and energy services and a review of the objectives and framework of the nuclear hydrogen system integration studies, this report assesses existing U.S. hydrogen markets and their prospects (Chapter 3). Emerging and anticipated markets are also considered. Chapter 4 describes candidate nuclear hydrogen production technologies and their characteristics that will affect their 
ability to meet the needs of potential markets. Not all alternatives are discussed. Rather, the discussion covers a sampling of high-temperature and low-temperature processes, including electrolysis, thermochemical, and hybrid options. Chapter 5 extends this discussion by considering various plant configurations that could improve the economics or operational flexibility of a given hydrogen generation process. Chapter 6 ties these assessments together and presents observations about the match between individual market needs and the characteristics of nuclear hydrogen technologies and their configuration options.

\subsection{Relationship of Nuclear Power to Energy Currencies and Services}

In thinking about specific energy technologies to pursue, one should consider the end uses of the energy (i.e., the services that the energy provides), how that energy is delivered (i.e., what energy currencies are employed), and what primary energy sources are available. In addition, one should consider overarching national goals and whether there are barriers that prevent the primary energy sources from meeting them.

The U.S. hydrogen program is founded on three national interests: independence from foreign energy sources, environmental sustainability, and abundant and affordable energy-based services (figure 1.1).

National Interests:


Figure 1.1. National Interests for the U.S. Hydrogen Program

The last goal is worth clarifying. Low-cost energy sources and currencies are not the primary concern. Rather, the concern is the cost of the services that those energy sources and currencies provide, be they transportation, illumination, heating, or other services. Consumers say, for instance, that they worry about high gasoline prices, but their real concern is the cost of traveling to and from the office five days a week. Abundant and affordable transportation is the real issue. Note, though, that most consumers have a high implicit discount rate when accounting for longterm expenses.

The three national interests can be linked to different primary energy sources. Some do a better job than others in addressing the individual goals (figure 1.2). 
July 31, 2005

National Interests:

Primary Energy Sources:



National Interests:

Primary Energy

Sources:



Figure 1.2. Relationship Between National Interests and Oil and Nuclear Fuel as Primary Energy Sources

Relying on oil, for instance, does little to promote energy independence or environmental sustainability. These barriers are marked as a solid line segment in the figure above for oil. Nuclear fuel, in contrast, has the potential to help meet these two goals. Questions about its cost effectiveness, however, may prove to be a barrier to nuclear fuel's ability to provide affordable energy-based services. Moreover, nuclear energy's role, so far, has been limited to the production of electricity, a valuable currency, but one that has not found widespread use in the transportation service sector. These uncertainties are indicated by a dashed line segment in the figure above for nuclear fuel.

A fuller picture of primary energy sources, energy currencies (that is, energy carriers), and services is shown on the following page (figure 1.3). Barriers may exist that prevent the energy sources from being translated into specific energy currencies, which in turn may have barriers to their being able to supply specific services. Some primary energy sources, such as natural gas, also act as currencies that can provide services (e.g., heating) directly. As currencies, electricity and hydrogen can be made from any primary energy source (but at different costs). 
Potential Nuclear Hydrogen System Applications

Argonne National Laboratory

July 31, 2005

National Interests:


Figure 1.3. A More Comprehensive Set of Energy Sources, Currencies, and Services

Hydrogen has another use, though, aside from its role as an energy carrier. As a chemical product, hydrogen can be used to manufacture other chemicals and products, including other energy currencies. This opens a new opportunity for nuclear-generated hydrogen: It can transform other (domestic) primary energy sources into a new set of energy currencies in an environmentally sustainable way. In this way, otherwise existing barriers can be overcome (figure 1.4). 




Figure 1.4. Nuclear Hydrogen Used Synergistically with Other Primary Energy Sources

In this example, nuclear hydrogen and heat can transform coal and tar sands into liquid fuels for transportation, making coal and tar sands more environmentally acceptable and providing a means for nuclear energy to contribute to the transportation sector. The infrastructure developed through these markets may eventually serve as stepping stones to the direct use of hydrogen as a 
transportation fuel, as long as needed modifications to the physical layout in this transitioning can be limited.

The development of nuclear hydrogen technologies may contribute to the adoption of other primary energy sources, as well (figure 1.5). Plant configurations that allow switching between electricity and hydrogen production could provide the backup power needed to make intermittent renewable energy sources such as sunlight and wind viable. A major limitation of these renewable energy sources is their inconsistency in power production depending on light levels in the one case and wind speed in the other. With a dual-purpose nuclear power plant, makeup electricity can be provided during times of low output from the renewable sources. This arrangement would alter the market attractiveness of the renewable options. However, relatively higher investment requirements for either of the components may limit the application of the backup configuration, depending on the technologies employed.

The complexities of such integrated and synergistic markets need to be considered in assessing the most economically favorable configurations for nuclear hydrogen production and the technologies employed. Such complexities will be examined in the broader DOE hydrogen program system studies. The work sponsored here by the Nuclear Hydrogen Initiative will make an important contribution to that overall effort. 
Potential Nuclear Hydrogen System Applications

Argonne National Laboratory

July 31, 2005

National Interests:


Nuclear power can switch from hydrogen production to electricity

to support intermittent power sources such as solar and wind

Primary Energy

Sources:

Energy Currencies:



\section{Objectives of the Nuclear Hydrogen System Integration Studies}

The goal of the Nuclear Hydrogen Initiative is to develop and promote nuclear-based hydrogen production technologies that make full use of their inherent advantages over other potential production pathways. These advantages include low greenhouse gas (GHG) emissions, flexibility in facility size to meet both small- and large-scale $\mathrm{H} 2$ production needs, and long-term sustainability. It is essential that the limited research and development resources be spent on the technology options that have the best potential to achieve this goal.

The objective of the NHI system integration studies is to provide information to DOE-NE to help them make programmatic decisions concerning technology paths for producing hydrogen from nuclear power. Technical feasibility is insufficient to guarantee the adoption of a hydrogen production process into the market. The process must also be competitive with alternative technologies in terms of cost, risk, operability, and environmental impact, which in turn will depend on the needs of the specific hydrogen market being considered. As these markets evolve, nuclear hydrogen's ability to compete will change. Fortunately, the NHI can tap into much larger efforts at DOE-EE to understand the evolution of hydrogen markets. The NHI-sponsored work will contribute to these efforts by providing data specific to nuclear hydrogen options.

Two broad categories of methods are being explored by DOE-NE: thermochemical water cracking and high-temperature electrolysis. Each category, and the options within each category, has merits that warrant further research. Within the limited budget and timeframe of the DOENE program, however, decisions will have to be made as to which technologies to pursue. Those decisions will need to be based on the potential for the technologies to meet a range of criteria that would make their use in a hydrogen economy attractive. These features would include safety, thermal efficiency, capital and production costs, pollution and waste streams, and ease and reliability of operation. Moreover, consideration will have to be made as to the accessibility of the produced hydrogen to the users in the economy. For instance, where must the production plants be located with respect to pipeline infrastructure or the regional users or distributors of the hydrogen? It is clear, then, that an understanding of the potential evolution of a hydrogen economy, and nuclear power's role in it, is important in setting priorities for the technologies pursued by the national program.

The system integration studies for nuclear hydrogen will help identify the key components, subsystems, and aspects of candidate hydrogen production technologies that most affect their market viability. The components of the NHI studies include the following:

1. Identifying commercial hydrogen applications, their requirements, and the implications for nuclear hydrogen options.

2. Assessing the elements of each nuclear hydrogen option in terms of their effect on the cost of the hydrogen produced. Such an assessment would consider the uncertainties of the cost estimates. One key parameter would be the economic scaling factor for the option, since this would affect the optimal size of a hydrogen production facility and the cost of increasing output from a single facility as the market grows. 
July 31,2005

3. Assessing configuration options for each nuclear hydrogen method within a given market. For example, nuclear power can be designed to produce hydrogen at a dedicated facility or to produce other energy products such as electricity, water, oxygen, and heat. This flexibility may open unique markets for nuclear power that cannot be met through other technologies.

4. Feeding nuclear hydrogen data to the DOE-EE studies, which will use agent-based modeling tools to indicate the expected range of market adoption for the various technologies. With input from the NHI work, the DOE-EE project will combine the results from performance assessments of nuclear hydrogen production technologies with cost, risk, and policy analyses to develop consistent market forecasts for individual nuclear hydrogen production plant configurations of interest.

5. Identifying the key parameters and their thresholds for market viability of nuclear hydrogen options. Such parameters could include hydrogen production and delivery costs, construction times, hydrogen output, and hydrogen/electricity production efficiency. In addition, if multi-product options are considered, storage costs will have to be included.

6. Identifying customers and partners for the most promising avenues for nuclear hydrogen.

This work will highlight the advantages and disadvantages of alternative integrated plant designs in existing and emerging hydrogen markets. It will provide the basis for informed decisions regarding resources and policies to promote the further development of nuclear hydrogen production technologies in a way that will allow nuclear hydrogen to be competitive in a growing hydrogen economy.

A total system study of the evolution of the nuclear energy based hydrogen systems is underway to understand the impacts of the different issues involved. A first step of the system analysis has been to identify the different markets for such energy system followed by a market penetration analysis of this energy system based on the different technologies and the need to compete with other possible sources of energy. In the September 2004 NHI System Study report [Petri, et al.] the different market applications of nuclear hydrogen were identified as near-term, long-term, and transitional applications. Methodologies that can be applied to study the market penetration and the economic viability of the different markets were described.

\subsection{Relationship of this Analysis to the DOE-EE Project}

Under a new project funded by DOE-EE, Argonne, in collaboration with several partners ${ }^{1}$, will analyze the evolution of the hydrogen infrastructure using an existing traditional market equilibrium model as well as a new complex adaptive systems approach using agent-based modeling and simulation (ABMS) techniques. ABMS is a modeling approach that is well-suited to understanding the development of a large-scale hydrogen infrastructure as it lends itself to address the question of how the hydrogen supply infrastructure and hydrogen demand markets

\footnotetext{
${ }^{1}$ Partners include AirProducts, Ford, BP, RCF Consulting, University of Michigan, and World Resources Institute.
} 
need to co-evolve, each incrementally supporting and promoting the growth of the other. The purpose of this new hydrogen transition ABMS model is to identify the key factors that either promote or inhibit the growth of the hydrogen infrastructure and to test strategies for that growth.

The ABMS tool will be used to model the individual stages of the hydrogen supply chain infrastructure (feedstock acquisition, processing/storage, and dispensing/retailing) in terms of the physical processes and the financial variables that drive decisions to invest in alternative forms of production and delivery infrastructure. Specifically, ABMS simulates the decision rules that agents (stakeholders) follow, and their behavior as they interact with each other and with their environment. An ABMS analysis allows the agents to adapt their decision rules as they learn which behaviors enhance the achievement of their objectives and which result in undesirable outcomes. This learning and adaptation process allows the agents to find solutions that cannot be determined by traditional modeling and simulation techniques.

In an ABMS framework, agent decisions based on finance and economics are interwoven with technical factors and various constraints. The model includes objects that simulate the behavior of a diverse set of self-directed entities that make decisions under uncertainty. These autonomous decisions are made with only limited information about the actions and strategies of other entities that participate in the energy markets. Strategic interactions among hydrogen market agents are an essential component of decision-making processes. The ABMS model will contain modules of basic energy system processes and economic decision-making units to provide realistic



Figure 2.1. Decision Framework of Hydrogen Market Agents

behaviors for pricing and investment decisions within the overall energy system. It will contain a variety of plausible behavioral rules that would be applicable for modeling agent behaviors within the energy sector. Hydrogen market agents will utilize historical data and a stream of new information that will be used to generate stochastic projections of future conditions in the system. These projections are, in turn, used in individual decision strategies by the agents. Elements from decision analysis and real-option theory may be incorporated to model how uncertainty and risk influences the market entry decisions of the agents (Figure 2.1).

This alternative approach is designed to address some of the key limitations of traditional simulation and optimization tools, such as the assumption of a single decision-maker with a 
single objective (e.g., maximization of social welfare), perfect foresight, rational decision making, and energy markets in equilibrium. The DOE NHI initiative will leverage the DOE-EE project activities by strengthening the nuclear technology representation and understanding in the EE modeling efforts and supporting additional nuclear hydrogen production market simulations. In particular, the ABMS framework will address uncertainties and risks involved in making nuclear hydrogen production investment decisions.

The DOE-EE project began in July 2005 and is expected to last three years. The first year will concentrate on traditional market equilibrium modeling. In the second year a base-case, business-as-usual market scenario will be analyzed using the new ABMS tools. In the third year alternate market scenarios will be analyzed. 


\section{Hydrogen Markets and Characteristics}

A variety of potential technologies and applications for nuclear hydrogen have been proposed. Chapters 4 and 5 of this report discuss the nuclear hydrogen production technologies and potential technology implications. The purpose of this chapter is to present a broader context for nuclear hydrogen, survey existing and future hydrogen markets, such as liquid-fuel refining, industrial applications, oil and tar sand processing, mobile fuel cells applications, and others, and to identify key requirements that may affect the market uptake of nuclear hydrogen as well as particular nuclear technology choices.

The hydrogen supply chain and the potential production of nuclear hydrogen cannot be analyzed in isolation. Rather, both need to be embedded in the overall energy system analysis to capture the feedbacks and interactions with other market segments (Figure 3.1). Given the complexities and dynamics involved in the emergence of a new hydrogen economy, and its relevance to the opportunities for nuclear hydrogen, an integrated systems analysis approach is needed to determine the role nuclear hydrogen might play in this environment. The market characterization in this section will describe various factors and dynamics that may



Figure 3.1. Nuclear and Hydrogen Markets as Part of the Overall Energy System affect the potential role nuclear can play in supplying the hydrogen needs in the various segments (e.g., size of markets, market trends, competing sources, location issues, etc.). This should be understood, however, as just one piece of the puzzle and a necessary precursor to a full system study of nuclear hydrogen.

The market adoption of a technology is driven by a number of factors, such as performance, costs, prices, and resulting profitability, as well as the competitive position of a certain technology vis-à-vis alternative suppliers. In addition, today's volatile energy markets illustrate the importance of considering risk in deciding if and when to enter a particular market, as well as in deciding what choice of technology to pursue.

Regional considerations are equally important. The market size for hydrogen will clearly vary substantially across the country, and this variation will change over time. If the transition is successful, the initial demand centers around large industrial facilities (e.g., petroleum refineries) will give way to a more geographically dispersed consumption pattern focused on larger metropolitan areas. Similarly, on the supply side, differences in regional resource and technology infrastructure availability across the country may favor one technology over another. This may be particularly significant for the early to mid stages of the transition when one might envision 
pockets of hydrogen production and consumption that are to some degree isolated given the technical and economic challenges of large-scale, long-distance transportation of hydrogen. In this type of situation, noticeable differences in the market price of hydrogen can be expected with a direct impact on the competitiveness of alternative hydrogen production technologies.

This chapter provides an overview of different hydrogen markets. Markets are distinguished into current or near-term, mid-term, and long-term. Near-term markets are those that could be expected to grow over the next five years. Mid-term markets could develop over the next five to ten years, with far-term markets developing after that. Each of the end-use markets may have significantly different needs and characteristics. It is important to understand these differences as they will impact the outlook for particular production technologies and should be used in guiding future technology research and development. We use a variety of attributes to describe current and future hydrogen markets. Figure 3.2 lists a summary of the attributes we

\section{Markets}

- Current and near-term

- Oil refining

- Ammonia (fertilizer) industry

- Methanol industry

- Merchant H2 customers (chemicals, metals, food, etc.) - Tar sands

- Mid-term

- Power peaking

- Coal liquefaction

- Far-term

- Remote power

- Transportation

Figure 3.2. Hydrogen Markets, Characteristics, and Attributes

\section{Characteristics}

- Current market size

- By region, state, customer By product/market type

- Projected market size

- Main growth drivers

- Potential market inhibitors/threats

- Marketing/business models

- Product requirements

- Delivery characteristics

- Distribution needs

- Nuclear competitors consider. Not all of the information is available for each of the markets. For existing markets, the description typically starts out with the current volume of the market with breakdowns by location and product type (e.g., liquid or gaseous), market type (e.g., captive or merchant), and recent and projected trends. We will try to identify some of the main drivers behind the growth in each market segment as well as any potential market inhibitors or threats. If available, the market description will discuss specific business models used in selling hydrogen and present specific product and delivery requirements. Similar information is provided for mid- and long-term markets.

Some of the markets represent large-scale consumers with an already established and relatively centralized demand distribution (e.g., industry and refineries), whereas other markets such as transportation will slowly develop over time and potentially have much lower demand densities. This will directly affect the timing of the nuclear hydrogen potential. Large, current markets, often in the form of captive consumers, may present early opportunities for nuclear hydrogen if nuclear production can meet or exceed the benchmarks for technical and financial performance needed to compete with established technologies. Developing markets will present challenges and hurdles that nuclear will only be able to overcome as markets mature into more densely concentrated demand centers. This applies equally to current merchant-type hydrogen markets with their relatively small consumers mostly relying on distributed production and delivery.

Worldwide hydrogen consumption is approximately 50 million tonnes per year [Shell, 2004a], including intentionally produced hydrogen as well as hydrogen that is produced as a by-product 
in the petrochemical industry and consumed on site. Table 3.1 shows how the 2003 global consumption of intentionally produced hydrogen of 41.09 million tonnes breaks down by sector and region. Worldwide, ammonia production accounts for $57 \%$ of total hydrogen demand, followed by oil refining (27\%) and methanol (10\%). The U.S. consumes about $19 \%$ of the total global hydrogen production. About $95 \%$ of the total demand is captive; that is, the hydrogen is produced at the site of consumption [AirProducts, 2004]. The remainder is produced as merchant hydrogen.

Table 3.1. 2003 Global Consumption of Intentionally Produced and Merchant Hydrogen (million tonnes)

\begin{tabular}{|l|c|c|c|c|c|}
\hline & $\begin{array}{c}\text { United } \\
\text { States }\end{array}$ & $\begin{array}{c}\text { Western } \\
\text { Europe }\end{array}$ & Japan & $\begin{array}{c}\text { Rest of } \\
\text { World }\end{array}$ & Total \\
\hline Captive Users & & & & & \\
\hline Ammonia & 2.59 & 1.78 & 0.23 & 19.02 & 23.63 \\
\hline Refineries & 3.19 & 2.81 & 1.17 & 4.10 & 11.26 \\
\hline Methanol & 0.39 & 0.31 & 0 & 3.29 & 3.99 \\
\hline Other & 0.35 & 0.03 & 0.09 & $\mathrm{Na}$ & 0.47 \\
\hline Merchant Users & & & & & \\
\hline Pipeline or on-site & 1.16 & 0.44 & 0.03 & $\mathrm{Na}$ & 1.63 \\
\hline Cylinder and bulk & 0.05 & 0.06 & 0.01 & $\mathrm{Na}$ & 0.12 \\
\hline Total & $\mathbf{7 . 7 4}$ & $\mathbf{5 . 4 2}$ & $\mathbf{1 . 5 3}$ & $\mathbf{2 6 . 4 1}$ & $\mathbf{4 1 . 0 9}$ \\
\hline Source: SRI, 2004 & & & & \\
\hline
\end{tabular}

In the U.S., 2003 hydrogen consumption totaled 7.74 million tonnes with 53\% used in oil refining, 34\% for ammonia production, $5 \%$ in the methanol industry, and the remainder used in a variety of industrial applications. Only a small portion (4-6\%) of the merchant demand consumes liquid hydrogen; the remainder is compressed gas demand [IG, 2005]. Although liquid merchant hydrogen is a premium product that commands higher prices, it is important to note that demand densities are such that production facilities are typically smaller, with the largest current size at about 20,000 tonnes per year (with a median of 10,000 tonnes per year).

Table 3.2 describes the U.S. hydrogen markets discussed in more detail in the following sections. The table summarizes current market volumes (total and regional), typical consumer size, and size range of individual demand centers, and presents an overview of recent trends, outlook, and growth drivers and threats for each of the market segments. 
July 31, 2005

Table 3.2. Overview of U.S. Hydrogen Markets

\begin{tabular}{|c|c|c|c|}
\hline Market & $\begin{array}{c}\text { Current (2003) Market } \\
\text { Volume and Regional } \\
\text { Distribution }\end{array}$ & Typical $\mathrm{H}_{2}$ Consumer Size & $\begin{array}{l}\text { Recent Trends, Outlook, } \\
\text { Growth Drivers, Threats }\end{array}$ \\
\hline Oil Refining & $\begin{array}{l}\text { 4,084 kt total; captive } \\
\text { demand of } 3,192 \mathrm{kt} \text { at } 55 \\
\text { locations and merchant gas of } \\
892 \mathrm{kt} \text { at } 57 \text { locations. } \\
\text { Captive demand: PADD-III } \\
(1,379 \mathrm{kt}), \text { PADD-V (1,270 } \\
\text { kt), PADD-II ( } 386 \mathrm{kt}) \text {, } \\
\text { PADD-IV ( } 89 \mathrm{kt}), \text { PADD-I } \\
\text { ( } 68 \mathrm{kt}) .\end{array}$ & $\begin{array}{l}\text { Captive: Size range of } 1,000 \\
\text { to } 225,000 \mathrm{t} / \mathrm{yr} \text { and median of } \\
25,500 \mathrm{t} / \mathrm{yr} ; 20 \text { locations with } \\
\text { demand at or above } 60,000- \\
70,000 \mathrm{t} / \mathrm{yr} \text {. } \\
\text { Merchant Compressed Gas: } \\
\text { Size range of } 8 \text { to } 91,000 \mathrm{t} / \mathrm{yr} \\
\text { and median of } 1,090 \mathrm{t} / \mathrm{yr} ; 6 \\
\text { locations with demand at or } \\
\text { above } 60,000-70,000 \mathrm{t} / \mathrm{yr} \text {. }\end{array}$ & $\begin{array}{l}1999-2003 \text { AAGR } 4.5 \% \\
\text { overall; merchant gas growing } \\
\text { at } 9.8 \% \text {; captive demand } \\
\text { forecast to grow by } 2 \% \text { until } \\
2008 \text { while merchant gas may } \\
\text { grow } 10-15 \% \text { per year until } \\
2008 \text {. }\end{array}$ \\
\hline $\begin{array}{l}\text { Ammonia } \\
\text { Industry }\end{array}$ & $\begin{array}{l}2,616 \mathrm{kt} \text { total; } 2,592 \mathrm{kt} \\
\text { captive and } 24 \mathrm{kt} \text { merchant } \\
\text { gas at } 24 \text { locations. } \\
\text { Consumption in } 21 \text { states: } \\
\text { LA, OK, and AK account for } \\
51 \% \text {; top } 3 \text { cities account for } \\
43 \% \text { of total demand. }\end{array}$ & $\begin{array}{l}\text { Size range of } 4,000 \text { to } 604,000 \\
\text { t/yr and median of } 109,000 \\
\text { t/yr; } 16 \text { locations with demand } \\
\text { over } 60,000 \text { t/yr. }\end{array}$ & $\begin{array}{l}\text { 1999-2003 AAGR }-2.5 \% \text {, } \\
\text { domestic ammonia capacity } \\
\text { idled or shutdown due to high } \\
\text { natural gas prices; } \mathrm{H}_{2} \\
\text { consumption projected to } \\
\text { remain about constant until } \\
2008 \text {. }\end{array}$ \\
\hline $\begin{array}{l}\text { Methanol } \\
\text { Industry }\end{array}$ & $\begin{array}{l}393 \text { kt total; all captive gas. } \\
\text { Consumption in } 6 \text { states: } \\
\text { TX }(55 \%), \text { FL }(20 \%), \text { WY } \\
(13 \%), \mathrm{TN}(7 \%), \mathrm{DE}(2 \%) \text {, } \\
\text { OK }(2 \%) \text {; regional } \\
\text { breakdowns are for } 2001 \text {. }\end{array}$ & $\begin{array}{l}\text { Size range of } 11,000 \text { to } \\
121,000 \mathrm{t} / \mathrm{yr} \text {, median of } 61,000 \\
\mathrm{t} / \mathrm{yr} ; 5 \text { locations with demands } \\
\text { of } 79,000 \mathrm{t} / \mathrm{yr} \text { and up. }\end{array}$ & $\begin{array}{l}\text { 1999-2003 AAGR -14.4\%, } \\
\text { domestic methanol capacity } \\
\text { idled or shutdown owing to } \\
\text { high natural gas prices and } \\
\text { MTBE phase-out. }\end{array}$ \\
\hline $\begin{array}{l}\text { Other } \\
\text { Industries }\end{array}$ & $\begin{array}{l}\text { Edible fats and oils: } 22.1 \mathrm{kt} \\
\text { total (16.2 kt captive, } 3.9 \mathrm{kt} \\
\text { merchant gas, } 2.1 \mathrm{kt} \\
\text { merchant liquid). } \\
\text { Metals: } 47.8 \mathrm{kt} \text { total }(1.3 \mathrm{kt} \\
\text { captive, } 31.7 \mathrm{kt} \text { merchant gas, } \\
14.7 \text { merchant liquid). } \\
\text { Electronics: } 13.7 \mathrm{kt} \text { total ( } 3.4 \\
\text { merchant gas, } 10.3 \text { merchant } \\
\text { liquid). } \\
\text { Others (Government/NASA, } \\
\text { float glass, public utilities, } \\
\text { other): } 11.3 \mathrm{kt} \text { total. }\end{array}$ & $\begin{array}{l}\text { No detailed information is } \\
\text { available. Also, total demand } \\
\text { in each sector is typically too } \\
\text { small to add value to this } \\
\text { report. }\end{array}$ & $\begin{array}{l}\text { Edible fats and oils: } 1999- \\
2003 \text { AAGR 0.2\%. } \\
\text { Metals: 1999-2003 AAGR } \\
\text { 5.6\% (merchant gas 7.1\%, } \\
\text { merchant liquid 3.1\%). } \\
\text { Electronics: 1999-2003 } \\
\text { AAGR -1.3\%. } \\
\text { Others: 1999-2003 AAGR - } \\
\text { 7.9\% (merchant gas 6.4\%, } \\
\text { merchant liquid -11.9\%). }\end{array}$ \\
\hline Tar Sands & $\begin{array}{l}\text { Near-to-medium term; } \\
\text { current demand in Alberta of } \\
515 \mathrm{kt} .\end{array}$ & $\begin{array}{l}\text { Median surface mining } \\
\text { operation with } 50,000 \mathrm{~b} / \mathrm{d} \text { oil } \\
\text { production requires } \mathrm{H}_{2} \text { of } \\
\text { about } 46,300 \mathrm{t} / \mathrm{yr} \text {. }\end{array}$ & $\begin{array}{l}\text { Projected to grow rapidly to } \\
1,919 \mathrm{kt}(2010), 2,860 \mathrm{kt} \\
(2015) \text {, and } 3,187 \mathrm{kt}(2020) .\end{array}$ \\
\hline
\end{tabular}


July 31, 2005

\begin{tabular}{|l|l|l|l|}
\hline \multicolumn{1}{|c|}{ Market } & $\begin{array}{c}\text { Current (2003) Market } \\
\text { Volume and Regional } \\
\text { Distribution }\end{array}$ & \multicolumn{1}{|c|}{ Typical H2 Consumer Size } & \multicolumn{1}{|c|}{$\begin{array}{l}\text { Recent Trends, Outlook, } \\
\text { Growth Drivers, Threats }\end{array}$} \\
\hline $\begin{array}{l}\text { Coal } \\
\text { Liquefaction } \\
\text { and Shale Oil }\end{array}$ & Medium-to-long term & $\begin{array}{l}370,000 \text { t/yr for a 100,000 bpd } \\
\text { coal liquefaction facility. }\end{array}$ & $\begin{array}{l}\text { Replacing the entire current } \\
\text { U.S. crude oil imports with } \\
\text { synthetic crude oil from coal } \\
\text { liquefaction would require } \\
\text { 37.7 Mt of hydrogen. }\end{array}$ \\
\hline $\begin{array}{l}\text { Peak } \\
\text { Electricity }\end{array}$ & Medium-to-long term & $\begin{array}{l}\text { 250,000 to 500,000 t/year } \\
\text { driven by economics of scale } \\
\text { for underground } \mathrm{H}_{2} \text { storage. }\end{array}$ & $\begin{array}{l}\text { Potential to replace expensive } \\
\text { natural gas for production of } \\
\text { peak electricity. }\end{array}$ \\
\hline Transportation & Long term & $\begin{array}{l}\text { Many market scenarios are } \\
\text { conceivable; most analysts } \\
\text { expect transition through } \\
\text { small-scale distributed } \mathrm{H}_{2} \text { in } \\
\text { initial stages while demand is } \\
\text { low, with a transition to } \\
\text { larger-scale production once } \\
\text { demand picks up. }\end{array}$ & $\begin{array}{l}\text { Following NRC assumptions, } \\
\text { market might develop slowly } \\
\text { starting in 2015, with 1.8 Mt } \\
(2020), 5.4 \text { Mt (2025), 16.2 } \\
\text { Mt (2030), 35.6 Mt (2035), } \\
67.1 \text { Mt (2024), 89.8 Mt } \\
(2045), \text { and 100 Mt (2050). }\end{array}$ \\
\hline Others & Long term; see Appendix A & See Appendix A & See Appendix A \\
\hline
\end{tabular}

b/d: barrels per day

kt: $\quad 1000$ metric tonnes

Mt: million metric tonnes

t/yr: tonnes per year

PADD: Petroleum defense district administration

AAGR: Annual average growth rate 
Potential Nuclear Hydrogen System Applications

Argonne National Laboratory

July 31,2005

\subsection{Near-Term Hydrogen Markets}

\subsubsection{Oil Refining}

U.S. oil refineries consumed about 4.08 million tonnes of hydrogen in 2003 . The refinery demand is driven by the need to produce cleaner transportation fuel to meet environmental regulations (e.g., low sulfur requirements) while the input slate continually shifts toward processing heavier crude oils. This upward trend is expected to continue and already accounts for a large part of the growth in hydrogen sales experienced by the major producers, such as AirProducts, Praxair, etc. Refineries have captive hydrogen demand; that is, the hydrogen is produced either on site or in facilities located nearby. But they also rely on merchant hydrogen to meet their needs. Of the 145 refineries, 62 have on-site,



Figure 3.3. U.S. Oil Refining Captive $\mathrm{H}_{2}$ Consumption in 2003 by State captive hydrogen production facilities totaling about 3.19 million tonnes per year. Figure 3.3 shows that the steam methane reformers used to meet captive hydrogen demand are located in 22 states with total state-wide consumption ranging from as low as 1,000 tonnes per year in West Virginia to about 1.11 million tons per year in California. Combined, Texas and California account for $64 \%$ of the total captive hydrogen



Figure 3.4. 2003 Hydrogen Consumption at U.S. Refineries By Location (1000 tonnes) 
Potential Nuclear Hydrogen System Applications

Argonne National Laboratory

July 31, 2005

production. On a regional basis, Petroleum Administration Defense Districts (PADDs) III and $\mathrm{V}$ account for $83 \%$ of the total demand. An additional 0.89 million tonnes of compressed merchant gas is consumed at a total of 67 refineries. Figure 3.4 gives the geographical distribution of consumption and also shows the extent of 2003 hydrogen consumption by location for both captive and merchant demand.

Individual captive demand for the 62 facilities at 55 locations ranges from less than 1,000 tonnes to over 225,000 tonnes per year as shown in Figure 3.5, with the median size at about 25,500 tonnes per year. Of the 67 facilities at 57



Figure 3.5. U.S. Oil Refining Captive $\mathrm{H}_{2}$ Consumption in 2003 by Location locations that supply the compressed merchant hydrogen gas to oil refineries, the size variation is more noticeable. The median of those facilities is much lower, at about 1,090 tonnes per year, with the largest demand at 91,000 tonnes (Figure 3.6). Recent facilities by AirProducts and Praxair are in the range of 90,000 tonnes per year (or about $100 \mathrm{MMscfd)}$ ). This is important to note as discussions on nuclear production facilities assume hydrogen outputs of around 60-70,000 tonnes per year for $600 \mathrm{MWth}$ reactors [WSRC, 2004], which would indicate a reasonable fit in terms of facility sizing in the oil refining industry. There are about 20 captive locations in this size range or above and about 6 merchant facilities. Using a plant size similar to the proposed Secure Transportable Autonomous Reactor (STAR) design [Wade, et al., 2004] that is expected to produce about 37,000 tonnes per year [Doctor, et al., 2003], the number of current refining locations with an appropriate size would increase to 36 .



Figure 3.6. U.S. Oil Refining Merchant
Compressed $\mathrm{H}_{2}$ Consumption in
2003 by Location

Refinery merchant hydrogen facilities are often based on a build-own-operate (BOO) type business scheme with the demand mostly supplied through long-term supply contracts. This allows both the consumer and producer to manage their risk. On the production side, it provides stable revenue projections and easier access to financing. Construction times are short and hydrogen producers have streamlined the design process of their facilities to minimize the risk of costly construction delays. The annual hydrogen production profile is continuous and steadystate, even though gasoline production has seasonal variations. However, on-site refined product storage of up to several months provides a balancing mechanism and a means to stabilize 
monthly production levels. Product requirements in the industry call for moderate hydrogen purity in this market segment.

Hydrogen demand in the oil industry is projected to grow fairly rapidly in the medium term. Expected annual growth rates range from $4 \%$ [IG, 2005] to about 5.5\% [BCC, 2003]. The merchant part of the market is projected to grow at more than those rates; that is, at about $8 \%$ per year [BCC, 2003] and up to 10-15\% out to 2008 [SRI, 2004].

\subsubsection{Ammonia Industry}

Ammonia is an intermediate product used in the manufacturing of a variety of nitrogen fertilizer materials and industrial products. Fertilizer, by far, is the largest end-use market of ammonia, with up to $90 \%$ of the annual $\mathrm{NH}_{3}$ production going toward that purpose. Most of the global ammonia is produced by catalytically reacting hydrogen coming from natural gas reforming with atmospheric nitrogen under elevated temperature and pressure.

World ammonia production in 2003 was 132.1 million tonnes $\mathrm{NH}_{3}$ and consumed about 11.7 million tonnes of $\mathrm{H}_{2}$. U.S. production of ammonia in 2003 was about 8.8 million tonnes, consuming about 2.62 million tonnes of hydrogen. Less than $1 \%$ of this $(24.1 \mathrm{kt})$ was merchant compressed gas; the rest of it was captive demand. Hydrogen consumption in this market is relatively concentrated. Figures 3.7 and 3.8 show that there are currently 31 ammonia production facilities in 24 locations in 18 states consuming $\mathrm{H}_{2}$. The top three states, Louisiana, Oklahoma, and Alaska, account for $51 \%$ of the total $\mathrm{H}_{2}$ consumption, or 1.33 million tonnes. Several locations have multiple ammonia production facilities, including Donaldsonville, LA (5 facilities), Kenai, AK (2 facilities), Verdigris, OK (2 facilities), and Dumas, TX (2 facilities). As a result, three cities account for $43 \%$ of the total demand:

- Donaldsonville (LA): $\quad 604,000$ tonnes/year or $23.1 \%$

- Kenai (AK): 292,000 tonnes/year or $11.2 \%$

- Verdigris (OK): $\quad 226,000$ tonnes/year or $8.6 \%$



Figure 3.7. U.S. Ammonia $\mathrm{H}_{2}$ Consumption in 2003 by State



Figure 3.8. U.S. Ammonia $\mathrm{H}_{2}$ Consumption in 2003 by Location 
Facilities are fairly large sized in terms of $\mathrm{H}_{2}$ demand. At half of the 24 locations, consumption exceeds 109,000 tonnes per year and 16 locations have an annual $\mathrm{H} 2$ demand of over 60,000 tonnes. The size in $\mathrm{H}_{2}$ consumption by location ranges from 4,000 to 604,000 tonnes (due to multiple facilities at one location). Figure 3.9 shows the location and hydrogen consumption of the various ammonia production locations.



Figure 3.9. 2003 Hydrogen Consumption for Ammonia Production (1000 tonnes)

U.S. demand for ammonia has remained relatively constant over the last 15 years (15.1 million tonnes in 1990 and 14.9 million tonnes in 2002). Consumption dropped about $10 \%$ in 2003 to 13.8 million tonnes and is projected to stay at that level until 2008 [SRI, 2004]. While consumption is relatively stable, domestic production, and along with it, associated hydrogen consumption, has declined noticeably over the last few years. This drop in domestic production and the accompanying shift to imported $\mathrm{NH}_{3}$ is primarily due to the recent run-up in domestic natural gas prices. The ammonia industry is very sensitive to natural gas price fluctuations, as gas may account for up to $70-90 \%$ of ammonia production costs. As a result, ammonia-related hydrogen consumption has dropped almost 10\% between 1999 and 2003 from 2.9 to 2.62 million tonnes $\mathrm{H}_{2}$.

The shift toward more ammonia imports is expected to stabilize. Domestic $\mathrm{NH}_{3}$ production in 2008 is projected to be about the same as in 2003, that is, about 8.8 million tonnes. Similarly, it is expected that in the medium term, hydrogen consumption of the sector will remain at 2003 levels. Given its cost structure, the U.S. ammonia industry will continue to be sensitive to 
July 31,2005

domestic natural gas price volatility. This exposure to price volatility will remain even if the current rush toward liquefied natural gas (LNG) will eventually lead to a global natural gas market with converging natural gas prices that would reduce current production cost advantages of off-shore ammonia producers. A shift to a technology with less feedstock price volatility may be attractive to the U.S. ammonia industry from a risk mitigation perspective. Also, with its concentrated demand and continuous hydrogen production profile (as the finished product is stored for several months to accommodate fluctuating fertilizer demand), the ammonia industry lends itself to large hydrogen production facilities.

\subsubsection{Methanol Industry}

The global methanol industry operated about 100 facilities worldwide [SenterNovem, 2002], manufactured 30.1 million tonnes of product in 2001, and consumed approximately 5.65 million tonnes of hydrogen coming largely from natural gas reforming. Methanol is primarily an intermediate product used in the manufacturing of a variety of materials. Worldwide, the largest end-use for methanol is the production of formaldehyde $(35 \%)$, which finds extensive use in the construction industry, followed by methyl tertiary-butyl ether or MTBE $(25 \%)$ used as an oxygenate in reformulated gasoline, acetic acid $(9 \%)$, and a variety of other products.

U.S. methanol consumption in 2001 totaled about 8.52 million tonnes. The production capacity in that year was 5.79 million tonnes, but actual production was only 3.25 million tonnes. Almost two-thirds of domestic methanol consumption was imported (5.43 million tonnes), as the industry, in reaction to rising natural gas prices ${ }^{2}$, idled or shut a number of production facilities. About 1.57 million tonnes of capacity was put on standby and 1.37 million tonnes permanently closed between early 1999 and beginning 2001 [IG, 2002]. This trend continued for the next two years. As a result, the sector's hydrogen consumption has significantly declined:

- 1999 H2 consumption: $731 \mathrm{kt}$

- $2001 \mathrm{H} 2$ consumption: $608 \mathrm{kt}$

- 2003 H2 consumption: 393 kt

In 2001, there were 10 methanol production facilities operating in the U.S. with hydrogen consumption ranging from 11,000 to 121,000 tonnes (Figure 3.10). Half of the plants consumed 79,000 tonnes or more. Texas alone accounted for $55 \%$ (336,000 tonnes) of the methanol-related hydrogen consumption, followed by Florida with $20 \%$ (121,000 tonnes) as shown in Figure 3.11. Figure 3.12 shows the location and hydrogen consumption of the various methanol production locations.



Figure 3.11. U.S. Methanol $\mathrm{H}_{2}$ Consumption in 2001 by State

${ }^{2}$ Natural gas may account for up to $55-65 \%$ of methanol production costs. 




Figure 3.12. 2001 Hydrogen Consumption for Methanol (1000 tonnes)

The largest end-use for methanol in 2001 in the United States was MTBE, accounting for 37\% of total demand, with formaldehyde coming in at second with $23 \%$. Current legislative actions on the state (e.g., California and 19 other states) and federal level may either severely limit, or ban



Figure 3.10. U.S. Methanol $\mathrm{H}_{2}$ Consumption in 2001 by Location altogether, the use of MTBE in reformulated gasoline, with ethanol being the alternative choice. While other methanol end-uses are expected to grow in the mid term, the MTBE phase-out is projected to lead to an overall decline in U.S. methanol consumption to around 8.10-8.31 million tonnes by 2005 with an estimated drop in hydrogen consumption to about $380-384 \mathrm{kt}$.

New potential growth areas for methanol include methanol fuel cells, methanol for stationary power generation, methanol for portable power generation, methanol wastewater denitrification (already 200 treatment plants in the U.S. use methanol

and more states are adopting regulations promoting denitrification), and methanol in biodiesel (12-15\% of biodiesel is methanol by volume). The second and third largest end-uses of 
Potential Nuclear Hydrogen System Applications Argonne National Laboratory

July 31,2005

methanol, formaldehyde and acetic acid, are used as adhesives and bonding agents in construction materials, and as such are dependent on growth in the construction industry.

Figure 3.13 shows the 2003 hydrogen consumption by state for the three current major U.S. hydrogen markets (oil refining, ammonia, and methanol). The top five major regional markets include Texas (25\%), California (18\%), Louisiana (14\%), Oklahoma (7\%), and Mississippi (5\%). These regions might provide more favorable conditions for larger, centralized hydrogen production technologies. Figure 3.14 shows a mapping of these markets by location.

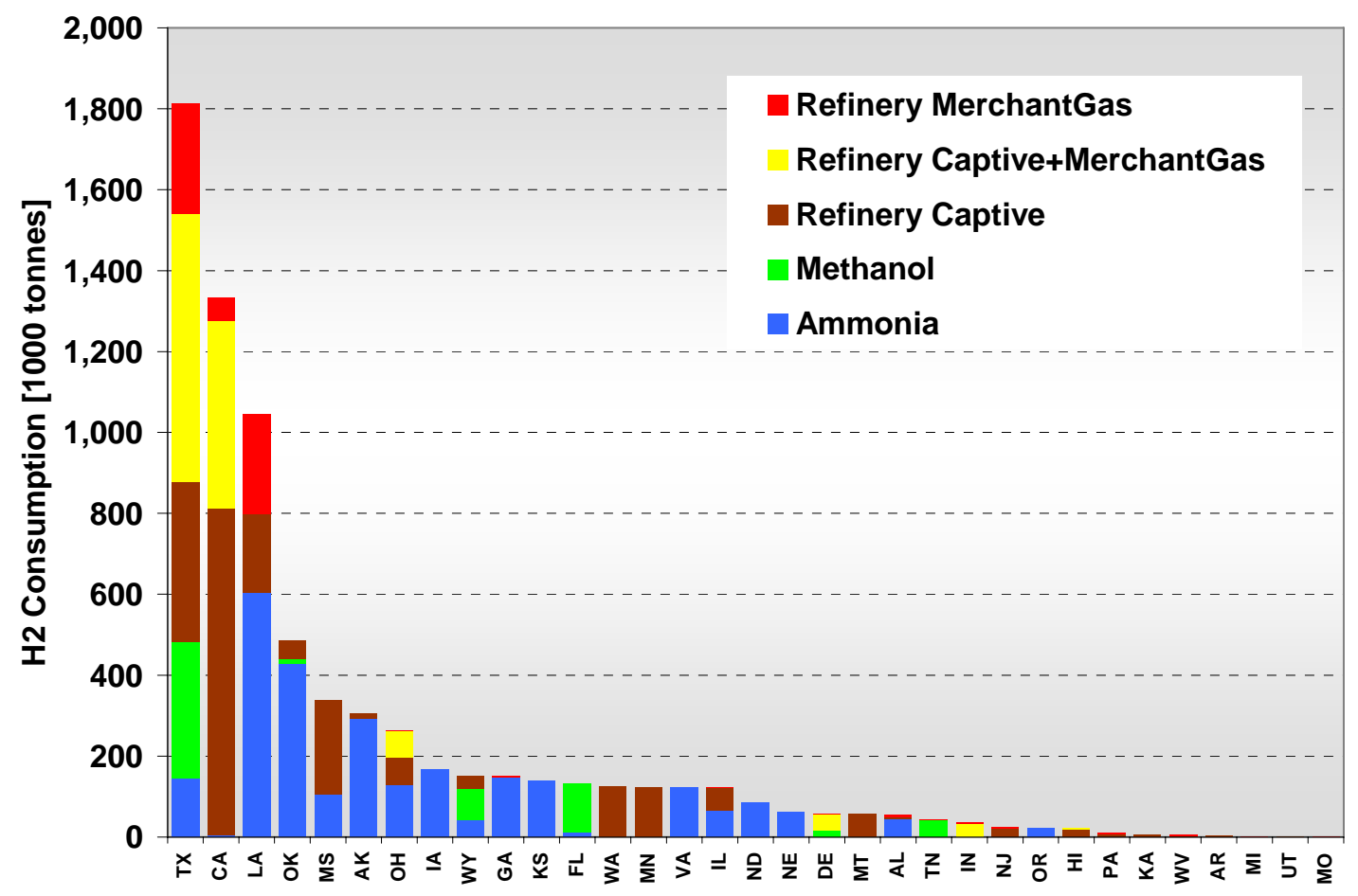

Figure 3.13. U.S. Hydrogen Consumption in 2003 by State 


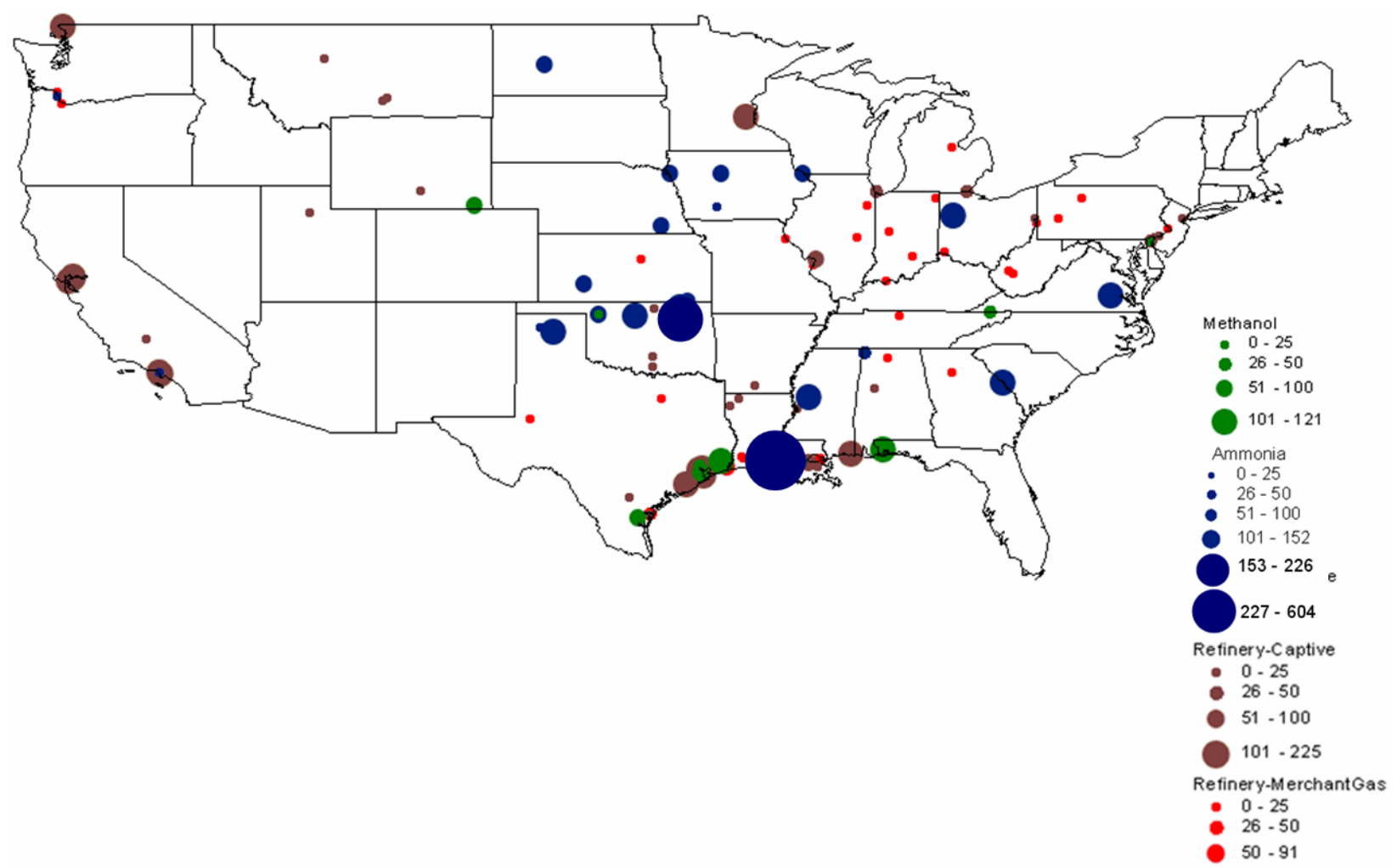

Figure 3.14. Location and Hydrogen Consumption for Oil Refining and the Production of Ammonia and Methanol (1000 tonnes)

\subsubsection{Oil or Tar Sands}

The two largest deposits of oil sands are located in Canada and Venezuela. In Canada, the bulk of the deposits are found in four regions in Alberta, including Athabasca, Wabasha, Cold Lake, and Peace River (Figure 3.15). Canada's proven oil sand reserves total about 179 billion barrels, second only to Saudi Arabia's petroleum reserves of 259 billion barrels [Manor, 2005]. Oil sand production in 2003 reached 964,000 b/d with 64\% coming from surface mining, 23\% from insitu thermal extraction, and the remainder from other techniques. Oil sand production in 2003 was substantially above Canada's 629,000 b/d of conventional oil production. Over the last 10 years, oil companies have heavily invested in Canada's oil sand resources (US\$24 billion between 1996 and 2002) and are making major commitments in the near-to-mid term with investment announcements totaling over US\$70 billion until 2020 [EUB, 2004].

Oil or tar sand deposits consist of bitumen (10-12\%), mineral matter such as sand and clay (80$85 \%$ ), and water (4-6\%). Bitumen is a heavy, black, molasses-like, viscous oil that must be treated before it can be further processed. Whereas in conventional crude oil extraction the 
Potential Nuclear Hydrogen System Applications Argonne National Laboratory

July 31,2005

product flows either naturally out of the ground or is pumped out, oil sand recovery is different and depends on the depth of the deposits:

1. Near-surface deposits representing about $20 \%$ of Canada's oil sands are mined in an open-pit operation. The oil sands are dug up by shovels and moved by trucks to crushers/sizers that break up larger pieces and remove rocks. The crushed sand is mixed with hot water in cyclofeeders to form a thick slurry that is then pumped by means of hydrotransport through a pipeline to a processing plant. Here the bitumen is separated from the sands in separation vessels where the bitumen floats at the top and can be skimmed off and sent for further treatment in centrifuges to remove water and solids. The material is then sent to an upgrader facility where the bitumen is converted into synthetic crude oil through coking, desulphurization, and the addition of hydrogen.

2. Bitumen in oil sand reservoirs too deep to be economically extracted with surface mining operations (75 meters or deeper, or about $80 \%$ of total deposits) are extracted using a variety of different in-situ techniques, including (1) cold heavy oil production with sand or CHOPS (used for $11 \%$ of oils sand extraction in 2003), (2) thermal in-situ recovery using cyclic steam stimulation, and (3) steamassisted gravity drainage. In both thermal in-situ techniques, steam softens the bitumen, dilutes and separates it from the sand, and allows the diluted oil to flow to the wells (Figure 3.16). In cyclic steam stimulation, steam is injected for several weeks, the bitumen is allowed
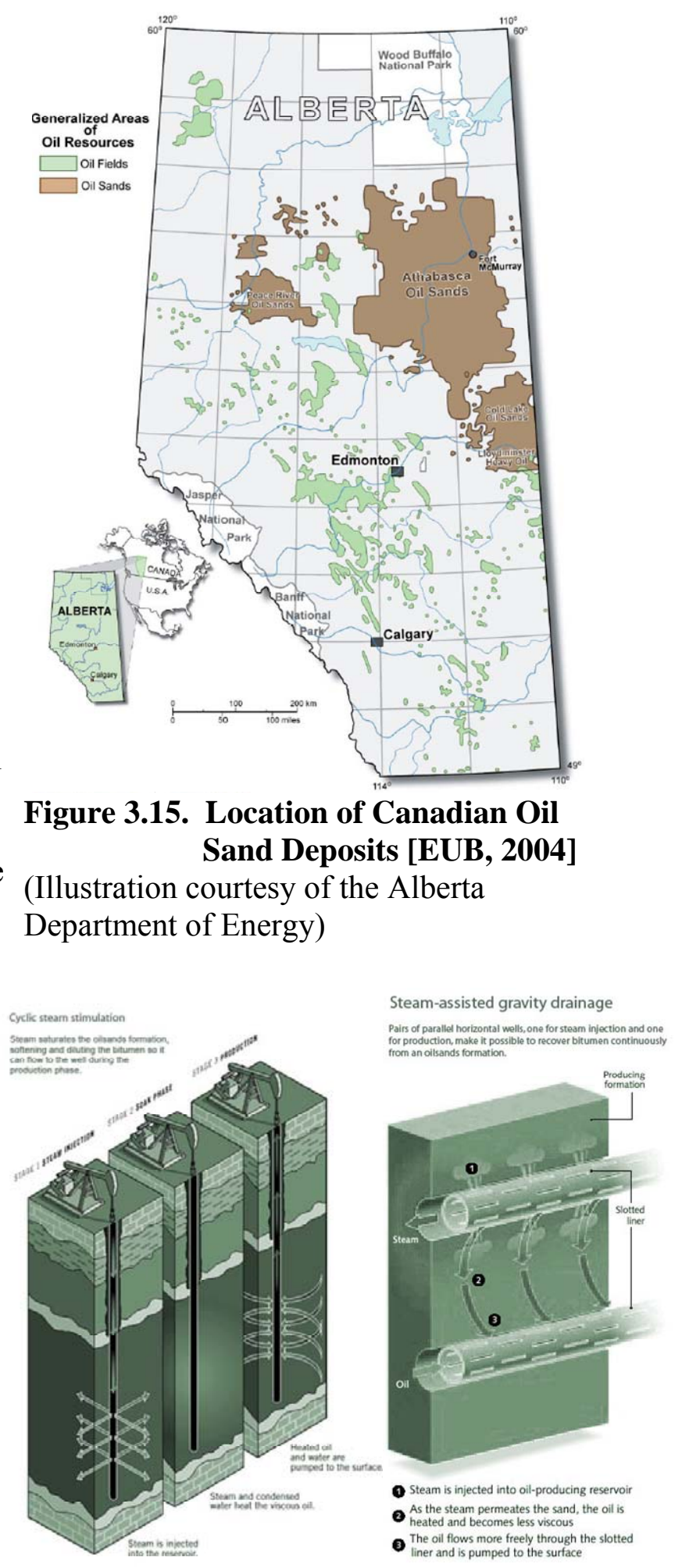

Figure 3.16. In-situ Oil Sand Recovery [CEC, 2005]

(Illustration courtesy of the Canadian Centre for Energy Information) 
July 31, 2005

to soak for several weeks, and then the oil is pumped out for several weeks through the same injection well. Once production declines, the process is repeated. With gravity drainage, steam is injected continuously into the upper of two horizontal wells, while the oil drains into the lower well and is constantly pumped out. Bitumen recovered through in-situ production is diluted and currently shipped without further treatment or upgrading to refineries.

Current in-situ techniques rely mostly on natural-gas-fired steam boilers to provide the steam needs. The process is very water and energy intensive, requires a large amount of hydrogen for upgrading the bitumen, and typically recovers between $25 \%$ to over $60 \%$ of the bitumen in the sand deposits.

Oil sand production is forecast to grow substantially to as much as 3 million b/d by 2020 as shown in Table 3.3.

Table 3.3. Projected Oil Production from Canada's Oil Sands (1000 barrels)

\begin{tabular}{|c|c|c|c|c|}
\hline Bitumen from Oil Sands & 2003 & 2010 & 2015 & 2020 \\
\hline Oil Sands Mining & 615 & 1,178 & 1,828 & 2,037 \\
\hline Oil Sands In-Situ & 218 & 707 & 864 & 963 \\
\hline Total & $964^{1}$ & 1,884 & 2,692 & 3,000 \\
\hline \multicolumn{5}{|c|}{$\begin{array}{l}{ }^{1} \text { Total includes } 105 \mathrm{kbpd} \text { of primary production and } 26 \mathrm{kbpd} \text { of other bitumen } \\
\text { production. } \\
\text { Source: CAPP (2005), CEC (2005) }\end{array}$} \\
\hline
\end{tabular}

Using the data in Table 3.3 as well as values provided by the Alberta Chamber of Resources (2004) on specific natural gas consumption factors per barrel of oil produced from oil sands, the total gas consumption and hydrogen requirements can be estimated over this time period. The estimated annual hydrogen demands are as follows:

- 2003: 0.51 million tonnes

- 2010: 1.92 million tonnes

- 2015: 2.86 million tonnes

- 2020: 3.19 million tonnes

The projected hydrogen consumption in 2020 would be the same as the current captive hydrogen consumption in the entire U.S. refining sector. Surface mining operations typically range from 13,000 to 274,000 b/d with the median around 50,000 b/d [Alberta Department of Energy, 2004]. This means that half of the oil sand production facilities may have hydrogen requirements of around 46,000 tonnes/yr, which could be easily supplied by a medium-sized centralized hydrogen production facility. 
The oil sand projections presented in Table 3.3 would lead to a significant increase in natural gas consumption. According to Natural Resources Canada (2004), oil sand production consumed about 220 Bcf of natural gas in 2003. Table 3.4 shows projections for natural gas consumption in the oil sand industry. By 2020, Canada is projected to use almost 1,100 Bcf of natural gas in the production of synthetic crude oil from oil sands. For perspective, this is equivalent to $35 \%$ of Canada's total 2003 gas demand. The share of $\mathrm{H}_{2}$-related gas consumption increases over time as the share of surface mining oil sands increases as projected by CAPP (2004). The increase in gas demand is of concern, and the Alberta Chamber of Commerce (2004) has started looking into alternative technologies to provide the steam and hydrogen, including coal gasification and nuclear power. Regarding nuclear options, the report concluded that for a 150,000 barrel per day in-situ facility, advanced nuclear reactor technology appears to be competitive at a natural gas price of $\$ 4$ per Giga-Joule. However, at a 150,000 bpd facility, steam needs to be distributed over a larger area, possibly rendering a single-source steam configuration uneconomic.

\section{Table 3.4. Projected Natural Gas Consumption for Canada's Oil Sands Production by Type of Extraction Method (Bcf)}

\begin{tabular}{|l|c|c|c|c|}
\hline & $\mathbf{2 0 0 3}$ & $\mathbf{2 0 1 0}$ & $\mathbf{2 0 1 5}$ & $\mathbf{2 0 2 0}$ \\
\hline Steam production & 139 & 370 & 493 & 550 \\
\hline Hydrogen production & 81 & 303 & 451 & 503 \\
\hline Total & $\mathbf{2 2 0}$ & $\mathbf{6 7 3}$ & $\mathbf{9 4 5}$ & $\mathbf{1 , 0 5 3}$ \\
\hline \multicolumn{2}{|l}{ Based on: CAPP (2005), CEC (2005), Larsen, et al. (2004). } \\
\hline
\end{tabular}

\subsection{Mid- and Long-Term Markets}

\subsubsection{Coal Liquefaction}

The U.S. has substantial coal reserves (Figure 3.17) that are currently estimated at 244 billion tonnes [NMA, 2004] that could be increasingly used as a liquid transportation fuel source to supplement dwindling and ever more expensive supplies of conventional oil. There are two basic processes for liquefying coal: indirect and direct liquefaction. Using direct liquefaction, coal is partially dissolved at high pressure and temperature in a liquid solvent. As coal is hydrogendeficient, converting solid coal into a liquid form requires the addition of hydrogen. Hydrogen is added under pressure to the coal and solvent mixture at temperatures up to $450^{\circ} \mathrm{C}$. Using a catalyst brings down process temperatures and pressures. Producing $100 \mathrm{~kg}$ of synthetic crude oil through direct hydrogenation from $110 \mathrm{~kg}$ of coal requires $7.4 \mathrm{~kg}$ of hydrogen [Williams, 2003]. This synthetic crude requires further refining to take the hydrogen-to-carbon ratio from 1.6 to approximately 2.0 for finished liquid fuel products.

Indirect liquefaction is a two-stage process. In the first stage, coal is heated in the presence of steam and oxygen to produce a mixture of carbon monoxide and hydrogen, or synthesis gas. Because of the low hydrogen content of coal, an additional source of hydrogen is required. This 
is usually supplied through the watergas-shift reaction of carbon monoxide and water, with the resultant carbon dioxide being removed from the product stream. Nuclear hydrogen would represent a $\mathrm{CO}_{2}$-free alternative. In the second stage, the synthesis gas contacts a catalyst and is converted to a synthetic liquid fuel. Alternatively, utilizing a different catalyst and reactor setup, the synthesis gas can be converted to alcohols, such as methanol or ethanol. The conventional indirect liquefaction is based on the Fischer-Tropsch process. The process was invented in 1923 and was used in Germany to produce close to 700,000 tonnes of petroleum products per year by 1941 for a total production of about 4 million tonnes.



Figure 3.17. Coal Bearing Areas of the United States Reserves [EIA, 1997]

(Illustration courtesy of the Energy Information Administration, U.S. Coal Reserves: 1997 Update)

For full-scale commercial deployment, however, substantial work is still needed to improve both process stages. The first process stage requires the use of an oxygen plant for making the synthesis gas. About $30-50 \%$ of the total investment requirements of a coal liquefaction plant are associated with the oxygen plant. This typically limits Fischer-Tropsch plants to very large operations, in the order of $100,000 \mathrm{~b} / \mathrm{d}$ or more. Improved catalysts would make the process more economic. The combined production of hydrogen and oxygen, both needed for coal liquefaction through gasification, make nuclear technologies a potential candidate for this market.

Based on the specific hydrogen requirements referenced above, we estimate the hydrogen requirements for a coal indirect-liquefaction plant with an output of 100,000 barrels of synthetic crude oil per day to be around 370,000 tonnes per year. This means that if the U.S. were to replace all its current net crude oil imports of 9.65 million $\mathrm{b} / \mathrm{d}$ with synthetic crude produced from coal liquefaction it would require about 97 such facilities consuming about 37.7 million tonnes of hydrogen. That quantity is equivalent to about four-and-a-half times the current U.S. hydrogen consumption. Simultaneously, the coal indirect-liquefaction plant would consume much of the oxygen byproduct of hydrogen production.

\subsubsection{Oil Shale}

Total global shale oil resources have been estimated to be around 2.6 trillion barrels, 2 trillion of which are located in the United States. The economically most attractive resources in the U.S. are found in Colorado, Utah, and Wyoming (Figure 3.18). These resources compare well in terms of richness, that is, liquid hydrocarbon yield per tonne of oil shale. More than 700 billion 
barrels of oil shale resources are found in concentrations that exceed the oil sands currently processed in Canada. Oil shale also compares highly favorably on another scale, that is, resource density. For example, Colorado oil shale can exceed 1 million barrels per acre, as compared to about 100,000 barrels/acre for Alberta's oil sands and about 65 barrels per acre for Alaskan north slope oil.

Unlike the bitumen derived from oil sands, the organic compounds in oil shale are solid and do not melt and are not soluble. To convert oil shale into liquids, the hydrocarbons must be converted from a solid to a liquid state. There are two conventional approaches to do this. In one, the shale is fractured in-situ and heated to obtain gases and liquids at wells. The second is by mining, transporting, and heating the shale to about $450^{\circ} \mathrm{C}$, adding hydrogen to the

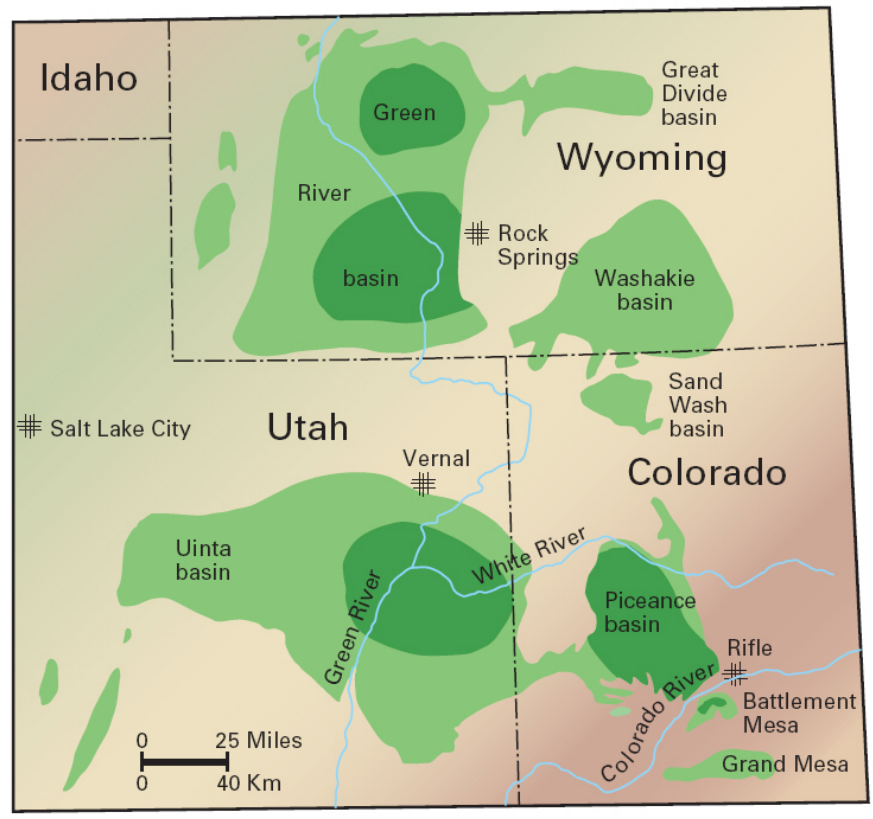
\begin{tabular}{|ll|}
\hline Area underlain by the Green River & Area underlain by oil shale more than \\
formation in which the oil shale is & $10 \mathrm{ft}$ thick, which yields 25 gal or more \\
unappraised or low grade. & oil per ton of shale. \\
\hline
\end{tabular}

Figure 3.18. Location of U.S. Shale Oil Resources [Bunger et al., 2004] (Illustration courtesy of the Oil and Gas Journal) resulting product, and disposing of and stabilizing the waste.

Full commercial-scale oil shale processing plants will likely be in the $150-200,000 \mathrm{~b} / \mathrm{d}$ range. A significant barrier to developing this resource, though, is a concern about waste streams and environmental damage from shale oil development.

\subsubsection{Transportation}

Hydrogen use in transportation might eventually be the main application for hydrogen production from nuclear energy. The full development of the use of hydrogen in transportation with the associated infrastructure is expected to take several decades, as different technological advancements in fuel cell design and storage and transportation of hydrogen will be needed. This application may involve both centralized centers of hydrogen production that use a number of nuclear plants or regional single-plant sites for local consumption. Owing to the inherent transition problems away from an established petroleum-based infrastructure, most analysts expect this transition to occur incrementally, with an initial focus on small-scale distributed hydrogen production (mostly natural gas based) to avoid the need for a new large-scale distribution infrastructure. 
Current hydrogen production facilities that are often near major population centers, such as oil refineries (as well as ammonia and methanol plants), as documented in the previous sections, could serve to jump-start this transition, such as the envisioned "mini-network and lighthouse concept" proposed by Shell [Shell, 2004]. Hydrogen production in those facilities could be increased incrementally to serve a small, but growing, transportation hydrogen demand. Once demand reaches a critical level in larger metropolitan areas, more centralized production technologies might take a hold in the market.

Because of the long-term nature of this market development, hydrogen demand scenarios for transportation are highly speculative. Nevertheless, using the underlying hydrogen demand scenario used in the report on the hydrogen economy by the National Academy of Sciences [NAE/NRC, 2004], one can estimate the growing hydrogen demand (Table 3.5). The report bases its market forecast on an S-curve penetration rate. S-curves have been used for decades to forecast prospective market shares based on the introduction of new technologies aimed at large consumer markets. When applied to measuring market growth potential, an S-curve assumes that (1) the time required to gain a $10 \%$ market share is approximately the same as that required to move from a $10 \%$ to a $90 \%$ penetration rate and (2) the shift from a concave to convex curve represents a diminishing growth rate in a rising, competitive mass consumer market. Many analysts, therefore, contend that the issue in this market is not full-scale development into a mature market, but rather, that the difficulties lie in how to reach the threshold of $10 \%$ penetration.

Table 3.5. Hydrogen Demand Scenario for Transportation

\begin{tabular}{|l|c|c|c|c|c|c|c|}
\hline & $\mathbf{2 0 2 0}$ & $\mathbf{2 0 2 5}$ & $\mathbf{2 0 3 0}$ & $\mathbf{2 0 3 5}$ & $\mathbf{2 0 4 0}$ & $\mathbf{2 0 4 5}$ & $\mathbf{2 0 5 0}$ \\
\hline $\begin{array}{l}\mathrm{H}_{2} \text { demand for transport } \\
\text { (million tonnes) }\end{array}$ & 1.8 & 5.4 & 16.2 & 35.6 & 67.1 & 89.8 & 100.0 \\
\hline
\end{tabular}

\subsubsection{Peak Electricity}

The peak electricity generation market is concerned with making use of variation of electricity demand daily, weekly, and seasonally. As a result of demand variation, the market price of electricity differs by an order of magnitude as a function of time. To meet peak demands, the utilities buy lower-capital-cost peaking power units, typically gas turbines that burn natural gas. In addition, utilities have developed storage devices so that they can buy electricity during times of low demand and low cost and sell the electricity from the storage devices during times of high demand and high prices. The volatility of the price of electricity could create a hydrogen market aimed at producing electrical power at those times of day when the price of electricity is at its maximum. Thus, plants that are able to produce hydrogen (and optionally oxygen) to produce more electricity at times of high demand are likely to maximize the profitability of the facility. Nuclear plants equipped with hydrogen production, hydrogen storage, and hydrogen-toelectricity conversion technologies could accomplish this objective. More information on these 
markets and a qualitative system configuration for a peak electricity nuclear system (PENS) can be found in Appendix A.

\subsubsection{Other Hydrogen Markets}

Other potential long-term markets for nuclear hydrogen include the production of carbondioxide-neutral liquid fuels through direct atmospheric fuel production, biomass conversion, or the production of a chemical hydrogen carrier for use in transportation; hydrogen for air transportation; and hydrogen for direct reduction of iron ore.

Using external energy in the form of electricity and hydrogen, liquid fuels can be manufactured from water and carbon dioxide that may either come from the atmosphere or the oceans. A variety of indirect fuel processes could be available to convert the carbon dioxide and hydrogen into liquid fuels. When using biomass to produce liquid fuels, such as ethanol, roughly one-third of the carbon in the biomass is emitted to the atmosphere in form of $\mathrm{CO}_{2}$, whereas only one-third ends up in the fuel itself. Using hydrogen from nuclear technologies, the $\mathrm{CO}_{2}$ from the bio-fuel factory could be collected and converted into additional fuel liquids.

One alternative for avoiding a large-scale compressed gas or liquid hydrogen distribution infrastructure could involve the use of a chemical hydrogen carrier, such as metal amines, or some type of calcium oxide bed. Several studies have been conducted on using liquid hydrogen for a variety of different aircraft, including commercial jets. The direct reduction iron process typically relies on the use of natural gas for its syngas needs, but could be replaced by nuclear hydrogen. 


\section{Characteristics of Nuclear Hydrogen Production Technologies}

The potential near-, mid-, and long-term hydrogen markets that the nuclear-supported hydrogen production technologies can contribute to was described in Chapter 3 . The objective of this section is to discuss the technical challenges of the various hydrogen production processes that can affect whether those technologies can satisfy the performance and economic threshold criteria for making them viable in the hydrogen markets.

Hydrogen can be produced by thermochemical, electrochemical, and hybrid (electrothermochemical) processes using nuclear energy as the primary thermal energy source. The hydrogen production process properties determine the types of reactors that can appropriately be coupled to the relevant hydrogen production technology. The first important design requirement for both thermochemical and electrochemical hydrogen production is the relatively high temperature needed for achieving high thermal-to-hydrogen energy efficiency. This is an important factor in the economics of the technologies, though the relative magnitude of importance can differ from process to process. Another important design objective is attaining high thermal-to-electrical power conversion efficiency, which is essential for the efficiency and economics of electrochemical and hybrid hydrogen production. Other general requirements are enabling effective heat transfer to the chemical plant with minimum temperature losses, minimizing the pressure losses in the primary loop (or intermediate loop if one is used), ensuring safety through chemically inert coolants, reducing the potential for power-to-flow mismatches in the reactor, and optimizing the capital cost with product demand. Because of their hightemperature capability, gas cooled reactors, heavy metal cooled reactors, and molten salt cooled reactors, all with gas power cycles (in the cases where electricity is also needed), are candidate technologies to be coupled to a hydrogen plant [LaBar 2002, Forsberg 2003]. Near-term hydrogen markets, however, would have to rely on available light or heavy water cooled nuclear reactors with low-temperature water electrolysis for hydrogen production.

Each hydrogen production process, and the nuclear system supporting it, has technological features that can significantly influence the economic compatibility of the system in the hydrogen markets. It is important to understand such technical features of the nuclear hydrogen production technologies for determining the thresholds of their cost and performance to be viable. In the first phase of this study, we evaluate the major issues for a range of nuclear hydrogen production processes, their margins for improvements, performance goals, and their influence on the performance and economic competitiveness on the specific configuration. The feedback from the larger DOE-EE/DOE-NE market studies to the hydrogen production process designers will be the thresholds of those factors for the particular process and plant configuration to be viable in a given market. It will then be left to the process designers to judge whether those performance and cost thresholds can be achieved for the specified technology. 
July 31,2005

\subsection{Candidate Nuclear Reactor Technologies and Power Conversion Systems}

A range of nuclear reactors can support nuclear hydrogen production technologies. They can vary from the currently available reactors to Generation-IV advanced reactors. Candidate nuclear technologies for hydrogen production include:

- $\quad$ Light Water Reactor (LWR - PWR and BWR);

- Supercritical Water Cooled Reactor (SCWR);

- Advanced Pressurized Water Reactor (APWR);

- Simplified Boiling Water Reactor (SBWR);

- CANDU or Advanced CANDU;

- Pebble Bed or Prismatic Modular Helium Reactor (MHR);

- Advanced High Temperature Reactor (AHTR);

- Advanced Gas Reactor (AGR);

- Gas Fast Reactor (GFR);

- Sodium or Pb/Pb-Bi Cooled Fast Reactors (SFR, LFR);

- Molten Salt Reactor (MSR).

A comprehensive evaluation of most of the advanced technologies, including their economic features such as the overnight cost distributions is found at the GenIV Roadmap website (http://gif.inel.gov/roadmap/). The configurations in which these reactors can support the hydrogen production processes and their achievable peak temperatures determine the performance of the processes.

For processes that require electricity input in addition to thermal energy, or for plant configurations that co-generate hydrogen and electricity, an efficient and economical power conversion system has to support the nuclear reactor. The following technologies show potential for the near- and long-term applications:

- Steam turbine power conversion systems;

- Helium gas turbine power conversion system [LaBar, 2002];

- Supercritical $\mathrm{CO}_{2}\left(\mathrm{~S}-\mathrm{CO}_{2}\right)$ gas turbine power conversion system [Dostal, 2002].

The steam turbine Rankine cycle is a current technology, but its efficiency is relatively low ( $\sim 33 \%$ with the current LWRs). The advanced $\mathrm{He}$ and $\mathrm{S}-\mathrm{CO}_{2}$ turbine power conversion systems can provide higher efficiency and can contribute to supporting advanced hydrogen production systems. The higher efficiencies would also be beneficial to low-temperature water electrolysis. 
July 31, 2005

\subsection{Hydrogen Production Technologies Using Nuclear Energy}

Nuclear energy can be used in hydrogen production mainly in three ways:

- By using the electricity from the nuclear plant for conventional liquid water electrolysis.

- By using both the high-temperature heat and electricity from the nuclear plant for steam electrolysis or hybrid processes.

- By using the heat from the nuclear plant for pure thermochemical processes.

The technology options for the production of hydrogen using nuclear energy are presented in this section. Up to now, no consensus has been reached on the efficiency and cost of these technologies. All candidate technologies, the leading ones being high-temperature steam electrolysis and the high-temperature thermochemical water-splitting cycles, have margins for improvement in their efficiency and cost. Nevertheless, efficiency improvements may come at the price of higher complexity and capital cost.

Table 4.1 presents an overview of nuclear hydrogen production technologies. Water electrolysis coupled to an LWR is the least energy efficient, but it is a well commercialized and non-GHG emitting technology and can yield high efficiencies if supported by advanced power conversion systems. It is the only currently available technology for producing hydrogen without GHG release and without the burden of $\mathrm{CO}_{2}$ capture and sequestration.

\subsubsection{Thermochemical Processes}

Thermochemical processes for hydrogen production involve thermally assisted chemical reactions that release the hydrogen from hydrocarbons or water. The most widespread thermochemical process for hydrogen production is steam methane reforming (SMR). Although this technology is the most economic today, it yields considerable carbon dioxide emissions. The currently commercial steam methane reforming technology can be coupled to a nuclear source for near-term applications to reduce the overall production of carbon dioxide. This technology poses a higher near-term implementation potential owing to the proven operation of the method, but with the disadvantage of $\mathrm{CO}_{2}$ emissions. 
Table 4.1. Overview of Nuclear Hydrogen Production Processes

\begin{tabular}{|c|c|c|c|c|}
\hline \multirow{2}{*}{ Feature } & \multicolumn{2}{|c|}{ Electrochemical } & \multicolumn{2}{|c|}{ Thermochemical } \\
\hline & $\begin{array}{l}\text { Water } \\
\text { Electrolysis }\end{array}$ & $\begin{array}{l}\text { High Temperature } \\
\text { Steam Electrolysis }\end{array}$ & $\begin{array}{l}\text { Steam-Methane } \\
\text { Reforming }\end{array}$ & $\begin{array}{l}\text { Thermochemical } \\
\text { Water Splitting }\end{array}$ \\
\hline $\begin{array}{l}\text { Required } \\
\text { temperature, }{ }^{\circ} \mathrm{C}\end{array}$ & $<100$, at $\mathrm{P}_{\mathrm{atm}}$ & $>500$, at $\mathrm{P}_{\mathrm{atm}}$ & $>700$ & $\begin{array}{c}>800 \text { for } \mathrm{S}-\mathrm{I} \text { and WSP } \\
>700 \text { for } \mathrm{UT}-3 \\
>600 \text { for } \mathrm{Cu}-\mathrm{Cl}\end{array}$ \\
\hline $\begin{array}{l}\text { Efficiency of the } \\
\text { process, } \%\end{array}$ & $85-90$ & $90-95$ (at $\left.\mathrm{T}>800{ }^{0} \mathrm{C}\right)$ & $\begin{array}{l}>60, \text { depending } \\
\text { on temperature }\end{array}$ & $\begin{array}{l}>40 \text {, depending on } \mathrm{TC} \\
\text { cycle and temperature }\end{array}$ \\
\hline $\begin{array}{l}\text { Energy efficiency } \\
\text { coupled to LWR, } \\
\text { or ALWR } \%\end{array}$ & $\sim 27$ & $\sim 30$ & Not Applicable & Not Feasible \\
\hline $\begin{array}{l}\text { Energy efficiency } \\
\text { coupled to MHR, } \\
\text { ALWR, ATHR, } \\
\text { or S-AGR, \% }\end{array}$ & $>40$ & $\begin{array}{l}>45 \text {, depending on } \\
\text { power cycle and } \\
\text { temperature }\end{array}$ & $\begin{array}{l}>60, \text { depending } \\
\text { on temperature }\end{array}$ & $\begin{array}{l}>40 \text {, depending on } \mathrm{TC} \\
\text { cycle and temperature }\end{array}$ \\
\hline Advantage & $\begin{array}{l}+ \text { Proven } \\
\text { technology }\end{array}$ & $\begin{array}{l}+ \text { High efficiency } \\
+ \text { Can be coupled to } \\
\text { reactors operating at } \\
\text { intermediate } \\
\text { temperatures } \\
+ \text { Eliminates } \mathrm{CO}_{2} \\
\text { emission }\end{array}$ & $\begin{array}{l}+ \text { Proven } \\
\text { technology } \\
+ \text { Reduces } \mathrm{CO}_{2} \\
\text { emission }\end{array}$ & $\begin{array}{l}+ \text { Potential for } \\
\text { high efficiency } \\
+ \text { Eliminates } \mathrm{CO}_{2} \\
\quad \text { emissions }\end{array}$ \\
\hline Disadvantage & $\begin{array}{l}\text { - Low energy } \\
\text { efficiency } \\
\text { in the near } \\
\text { term }\end{array}$ & $\begin{array}{l}\text { - Requires development } \\
\text { of durable, large scale } \\
\text { HTSE units }\end{array}$ & $\begin{array}{l}\text { - } \mathrm{CO}_{2} \text { emissions } \\
\text { - Dependent on } \\
\text { methane prices }\end{array}$ & $\begin{array}{l}\text { +Aggressive } \\
\text { chemistry } \\
\text { +Requires very high } \\
\text { temperature reactors } \\
\text { +Requires } \\
\text { development at } \\
\text { large scale }\end{array}$ \\
\hline
\end{tabular}

Alternative thermochemical processes are those that do not have hydrocarbon feedstock, but that split water into hydrogen and oxygen through a series of thermally driven chemical reactions. The purpose is to generate hydrogen at lower temperatures than that for pyrolysis of water, which takes place at temperatures greater than $2500^{\circ} \mathrm{C}$. A screening study [Besenbruch, 2000] identified two thermochemical water splitting cycles as with the highest commercialization potential and with practical applicability to nuclear heat sources. These were the sulfur-iodine (SI) and calcium-bromine-iron (UT-3) cycles. SI cycle development is being investigated in the U.S., France, and Japan. The UT-3 cycle, which was named in recognition of its origins at the University of Tokyo, has been investigated by JAERI. A lower-temperature version of this cycle that eliminates the use of iron is being developed at Argonne National Laboratory (ANL). ANL is also working on achieving thermochemical water splitting processes at still lower temperatures. In particular, ANL is investigating the copper-chlorine $(\mathrm{Cu}-\mathrm{Cl})$ thermochemical cycle [Lewis 2003]. 
July 31,2005

Thermochemical processes can involve stringent heat transfer requirements and challenges. The first one is that effective heat transfer be accomplished at high temperature, since operating temperature is the dominant factor in process efficiency. The second is maintaining the operating peak temperature of the hydrogen plant sufficiently close to the reactor exit temperature while trying to achieve a bulk temperature in the thermochemical decomposer as high as possible. This can help to attain more uniform temperature distributions in the decomposer for more homogeneous and faster reaction rates and to decrease energy losses. Consequently, it is necessary to develop and use durable materials suitable for these operating conditions.

In the following sections, alternative thermochemical processes that can use nuclear energy as the primary heat source, their potential economics and related uncertainties, and technological barriers are discussed.

\section{(a) Steam methane reforming (SMR)}

Steam methane reforming, SMR, is currently the primary commercial technology for hydrogen production. The SMR process requires high process temperatures, which are usually provided by burning natural gas. The process is as follows:

Reforming: $\mathrm{CH}_{4}+\mathrm{H}_{2} \mathrm{O} \rightarrow \mathrm{CO}+3 \mathrm{H}_{2}$, endothermic, $\left(750-800^{\circ} \mathrm{C}\right)$

Shift: $\quad \mathrm{CO}+\mathrm{H}_{2} \mathrm{O} \rightarrow \mathrm{CO}_{2}+\mathrm{H}_{2}$, exothermic, $\left(350^{\circ} \mathrm{C}\right)$

High-temperature reactors can substitute for the natural gas burning furnaces as a heat source. This approach can reduce $\mathrm{CO}_{2}$ emissions by 30\% [Hori 2003]. Nevertheless, owing to the nature of the chemical reforming and shifting processes, there is still a need for natural gas feedstock, which ultimately results in $\mathrm{CO}_{2}$ emissions.

The steam-to-carbon ratio $(\mathrm{St} / \mathrm{C})$ is an important factor affecting the total thermal energy supplied for SMR. The ideal value of $\mathrm{St} / \mathrm{C}$ is 2 . However, most reformers run at larger values of $\mathrm{St} / \mathrm{C}$ in order to prevent coking and enhance the reaction progress. Consequently, the increased $\mathrm{St} / \mathrm{C}$ enhances the process efficiency at medium temperatures and decreases the efficiency at higher temperatures compared to the efficiency with $\mathrm{St} / \mathrm{C}=2$. The theoretical efficiency of this process as a function of temperature and $\mathrm{St} / \mathrm{C}$ as calculated by Lutz, et al., [2003a and 2003b] is shown in Figure 4.1. This figure indicates that temperatures above $700^{\circ} \mathrm{C}$ are required for favorable efficiency values. 


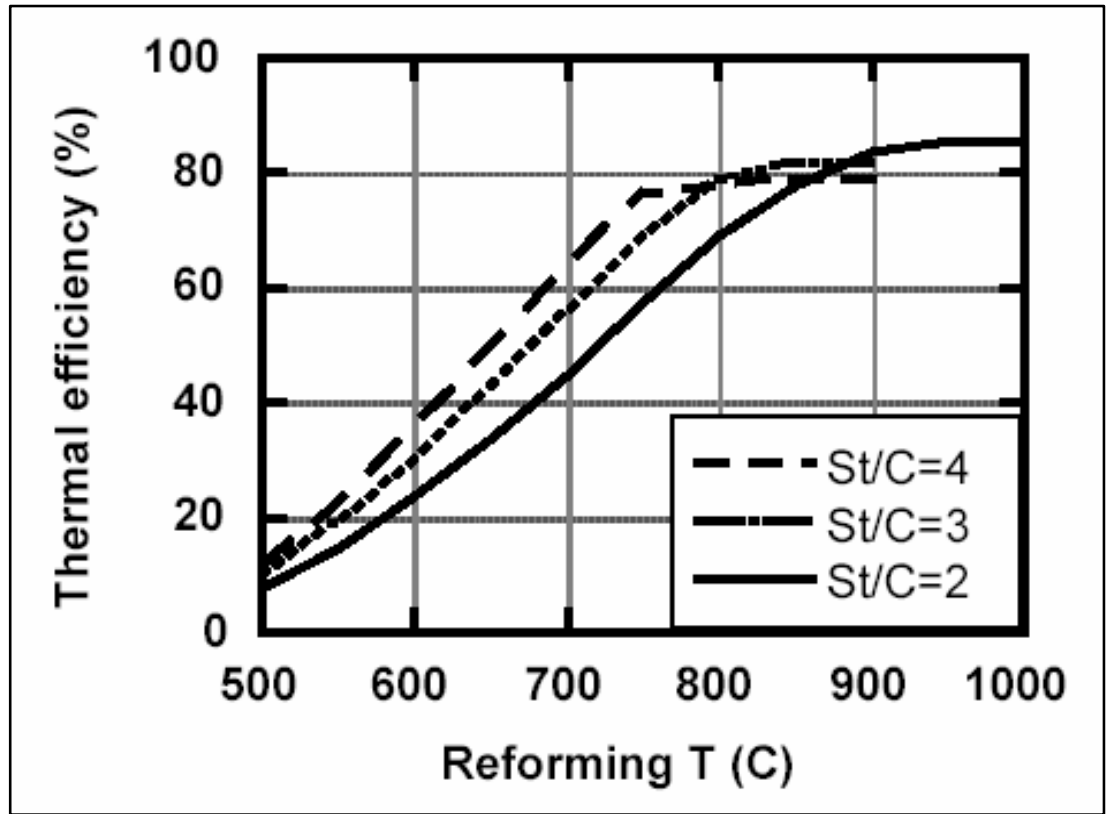

Figure 4.1. Energy Efficiency of the Steam Methane Reforming Process for Various Steam/Carbon Ratios [Lutz 2003b]

The SMR process can potentially be coupled to a high-temperature helium-cooled reactor, such as an MHR. The MHR could function as the high-temperature heat source at about $850^{\circ} \mathrm{C}$ to replace the natural gas burning furnace. The high operating temperature can enable process efficiencies approaching $80 \%$. This alternative has been estimated to be potentially cost competitive in the near future with the conventional SMR process [Yildiz et al., 2003].

\section{SMR Major Challenges}

Although natural gas was seen as a cost effective feed for making hydrogen compared to other fossil fuels [NAE/NRC, 2004], due to its wide availability and ease of handling, there can be potential drawbacks in its large-scale use in a hydrogen economy. It is less polluting than other fossil fuels, but still contributes to the accumulation of $\mathrm{CO}_{2}$ in the atmosphere, leading to further global warming concerns. Its use is subject to penalties or taxation depending on policies for remediation of global warming, adding to cost uncertainties for the product hydrogen. In addition, natural gas is largely imported to the U.S. today, and its increased use would raise imports and lead to higher prices. Thus, this technology path would not ensure a long-term clean energy infrastructure independent of foreign resources. Nevertheless, its use in the near term, as a transitional fuel for distributed or centralized hydrogen production, has merit and will be evaluated in evolving hydrogen markets.

SMR is already an available technology, commercialized in various capacities. Nevertheless, its use in the near term supported by a nuclear reactor depends on how soon an advanced hightemperature reactor can be built to make the process highly efficient and cost-effective. 
July 31,2005

\section{(b) Sulfur-Iodine (SI) Cycle}

The sulfur-iodine, SI, cycle was proposed by General Atomics in the mid-1970s. It consists of the following three chemical reactions, which yield the dissociation of water [Brown et al., 2003]:

$$
\begin{array}{ll}
\mathrm{I}_{2}+\mathrm{SO}_{2}+2 \mathrm{H}_{2} \mathrm{O} \rightarrow 2 \mathrm{HI}+\mathrm{H}_{2} \mathrm{SO}_{4} & \left(120^{\circ} \mathrm{C}\right) \\
\mathrm{H}_{2} \mathrm{SO}_{4} \rightarrow \mathrm{SO}_{2}+\mathrm{H}_{2} \mathrm{O}+1 / 2 \mathrm{O}_{2} & \left(830-900^{\circ} \mathrm{C}\right) \\
2 \mathrm{HI} \rightarrow \mathrm{I}_{2}+\mathrm{H}_{2} & \left(300-450^{\circ} \mathrm{C}\right)
\end{array}
$$

The net process takes in water and high-temperature heat, and releases hydrogen and oxygen. All reactions involve fluid interactions. All reagents are to be recycled; there are no effluents. The individual chemical reactions in this process have been demonstrated in the laboratory. Japan Atomic Energy Research Institute and CEA are also actively working on the research, development, and demonstration of the SI cycle [Shimizu, et al., 2000; Shiozawa, et al., 2000; Goldstein, et al., 2005]. They have both independently designed flow sheets for the SI cycle and are working on component development for the process.

\section{SI Major Challenges}

The most important technical issues and uncertainties that influence the performance and economics of this process are reported as:

- Materials durability at high temperature high acidity environment;

- HI inventory recovery in the system;

- Separations between reactants and products in solutions.

If better heat recuperation can be achieved or heat losses can further be eliminated by using highly effective compact heat exchangers, the energy efficiency of the process can be enhanced, contributing to better economics.

Decomposition of sulfuric acid and hydrogen iodide involve aggressive chemical environments. Hence, the materials for the SI cycle hydrogen plant should be chosen to accommodate corrosion and durability problems. CEA has reported a study on the corrosion behavior of the candidate materials for different sections of the SI process. Figure 4.2 shows the expected corrosion rate from the structural candidate materials (tantalum, zirconium, and Hastelloy B3). GA has proposed fluorocarbon lining as an option, but this has yet to be tested under realistic operating conditions of the SI process. The CEA's corrosion experiments indicate the resistance of the candidate materials at several sections of the SI process, but an optimized material composition is not yet identified. Although very expensive, tantalum-based materials in contact with the reactive species yields the least amount of material loss due to corrosion, compared to zirconium or Hastelloy. The materials for this process will determine the effectiveness of heat transfer in the system and the durability of the components, and thus will influence the efficiency and the capital cost of for an SI plant significantly. 


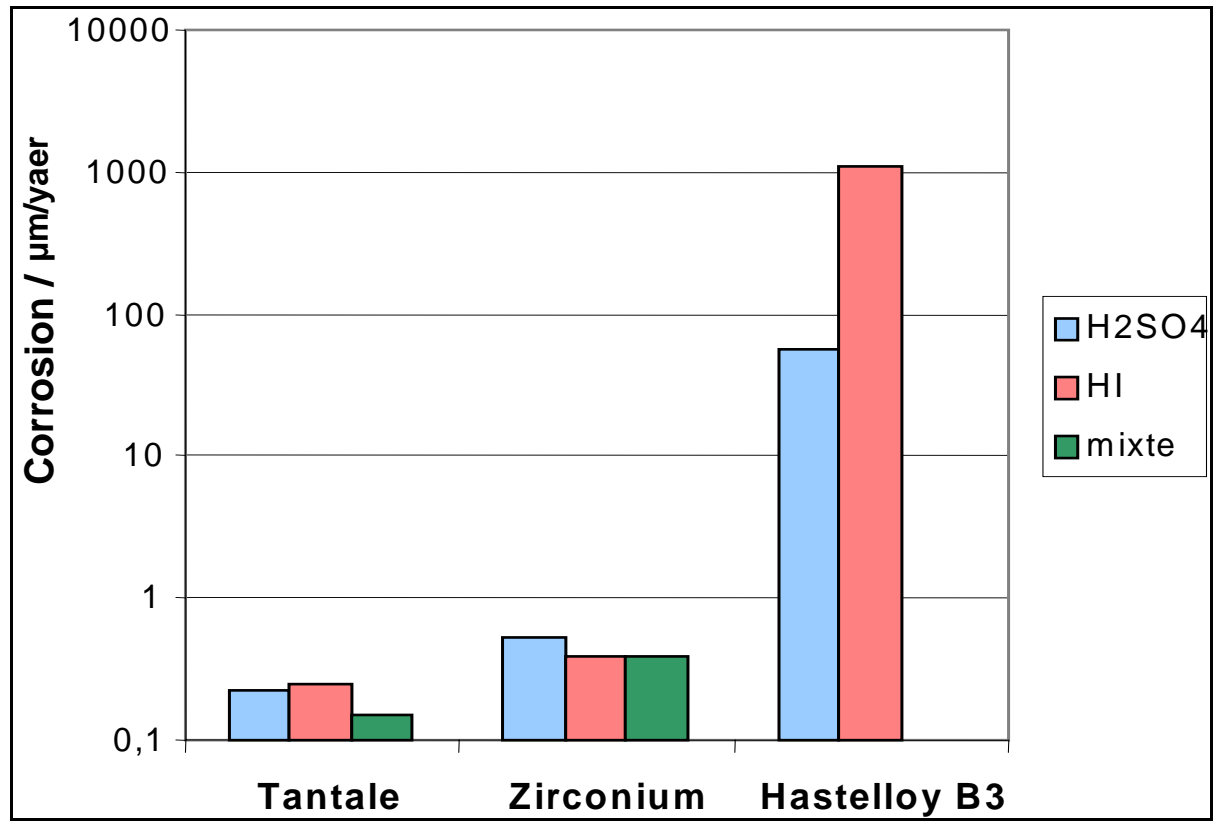

Figure 4.2. Corrosion Rate of Candidate Materials for

Components of the SI Process [CEA, 2005]

(Illustration courtesy of the French Atomic Energy Commission

(Commissariat à l'énergie atomique).)

Owing to the uncertainties in the process materials, the capital cost of this system is also a major uncertainty. Figure 4.3 presents the cost per kilogram of base material that can be used in the process. Candidate materials considered in Figure 4.3 are pure tantalum, zirconium, Hastelloy, fluorocarbon, and Hastelloy lined with tantalum or with fluorocarbon. As seen from this figure, the material choice can significantly influence the capital cost of the process. GA reports that fluorocarbon coating with nickel alloys as a candidate for the $\mathrm{H}_{2} \mathrm{SO}_{4}$ decomposition section can cost about $\$ 15 / \mathrm{kg}$, similar to pure zirconium, or Hastelloy coated with tantalum or with fluorocarbon. The effect of the cost of major components for SI is reflected in Table 4.2 for the cost-breakdown of the SI process plant. 




Figure 4.3. Price of Candidate Materials for SI Process Components [data from MetalPrices, 2005]

* Tantalum (T) lining into Hastelloy $(\mathrm{H})$ tanks, with mass ratio of $9 \mathrm{H}$ to $1 \mathrm{~T}$.

** Fluorocarbon (FC) lining into Hastelloy $(\mathrm{H})$ tanks, with mass ratio of $9 \mathrm{H}$ to $1 \mathrm{FC}$.

Use of membranes at various steps of the cycle is also one of the important factors for improving system performance. These membranes would be used for separating $\mathrm{SO}_{2}$ from $\mathrm{O}_{2}$, liquid $\mathrm{H}_{2} \mathrm{O}$ from $\mathrm{H}_{2} \mathrm{SO}_{4}, \mathrm{HI}$ from $\mathrm{HI}_{x}$, and $\mathrm{H}_{2}$ from $\left(\mathrm{H}_{\mathrm{I}}+\mathrm{H}_{2} \mathrm{O}\right)_{\mathrm{g}}$. Several groups, particularly in Japan, currently work on this area of research. Major focus is given to concentrating the HI solution, and an electrodialysis membrane reactor is identified as the most important membrane technique for this objective [Nomura, 2004]. In this regard, CEA also reports that the capability to recover $\mathrm{HI}$ effectively is a key issue. The excess amount of iodine and water in the Bunsen reaction can burden heavily the heat balances in the rest of the SI process, influencing the thermal efficiency of the process negatively. If membranes with high permeability and selectivity can be produced economically, then they can be considered as facilitators for the SI process.

Finally, sufficient thermodynamic and kinetic data do not exist for the HI section in the process. This makes the design of a reactive distillation stage and the realistic evaluation of the system performance a challenge.

The influence of the scaling of individual component size on cost and performance still comprises uncertainties. It is likely that the scale up of the SI process plant will be more economical by increasing the volume of the process components, rather than adding modular units. In doing so, the influence of the large volumes of reactants on the process efficiency should be evaluated. 


\section{SI Efficiency/Performance}

An upper bound of $51 \%$ (HHV) of efficiency was found by CEA assuming ideal reversible chemical reactions and constraints related to the heat exchange between helium and the chemical process. It was found that the separations between $\mathrm{H}_{2} \mathrm{O}$ and $\mathrm{H}_{2} \mathrm{SO}_{4}$ and between $\mathrm{HI}$ acid and I are the most energy-consuming steps. Thus, considering the potential inefficiencies due to these challenges, a best estimate of efficiency at $850^{\circ} \mathrm{C}$ of peak temperature reported by CEA is within $33-36 \%$ (HHV). CEA believes, however, that process improvements through, say, the use of membranes for separations may allow efficiencies approaching 50\% [CEA 2005].

A schematic of the SI flow sheet based on the design by GA is shown in Figure 4.4. Figure 4.5 represents the energy efficiency of this process with the design from GA, which indicates about $46 \%$ (HHV) thermal efficiency at $850^{\circ} \mathrm{C}$ of process peak temperature. Savannah River National Laboratory (SRNL) has worked on improving the flow sheet design for this process with better internal recuperation [Summers, et al., 2004]. The SNRL evaluation indicated an overall thermal efficiency range of $42-56 \%$ (HHV) depending on the operating temperature and the degree of optimization in process design. Figure 4.5 shows the plots for the predicted efficiency of the SI process by GA, CEA, SRNL and Ozturk, et al., under various operating conditions.

Communication with GA [Brown, 2005] based on their recent analysis indicates that the SI efficiency is not sensitive to temperature increase above $850^{\circ} \mathrm{C}$, contrary to the extrapolations shown in Figure 4.5. Clearly, there are yet uncertainties for the achievable thermal-to-hydrogen energy efficiency using the SI process. Nevertheless, there is margin for improvements for a target efficiency identified by SRNL, accompanied by the uncertainty of costs that would arise from improving the efficiency.



Figure 4.4. Schematic of SI Flow Sheet [Brown, et al., 2003]

(Illustration courtesy of General Atomics) 


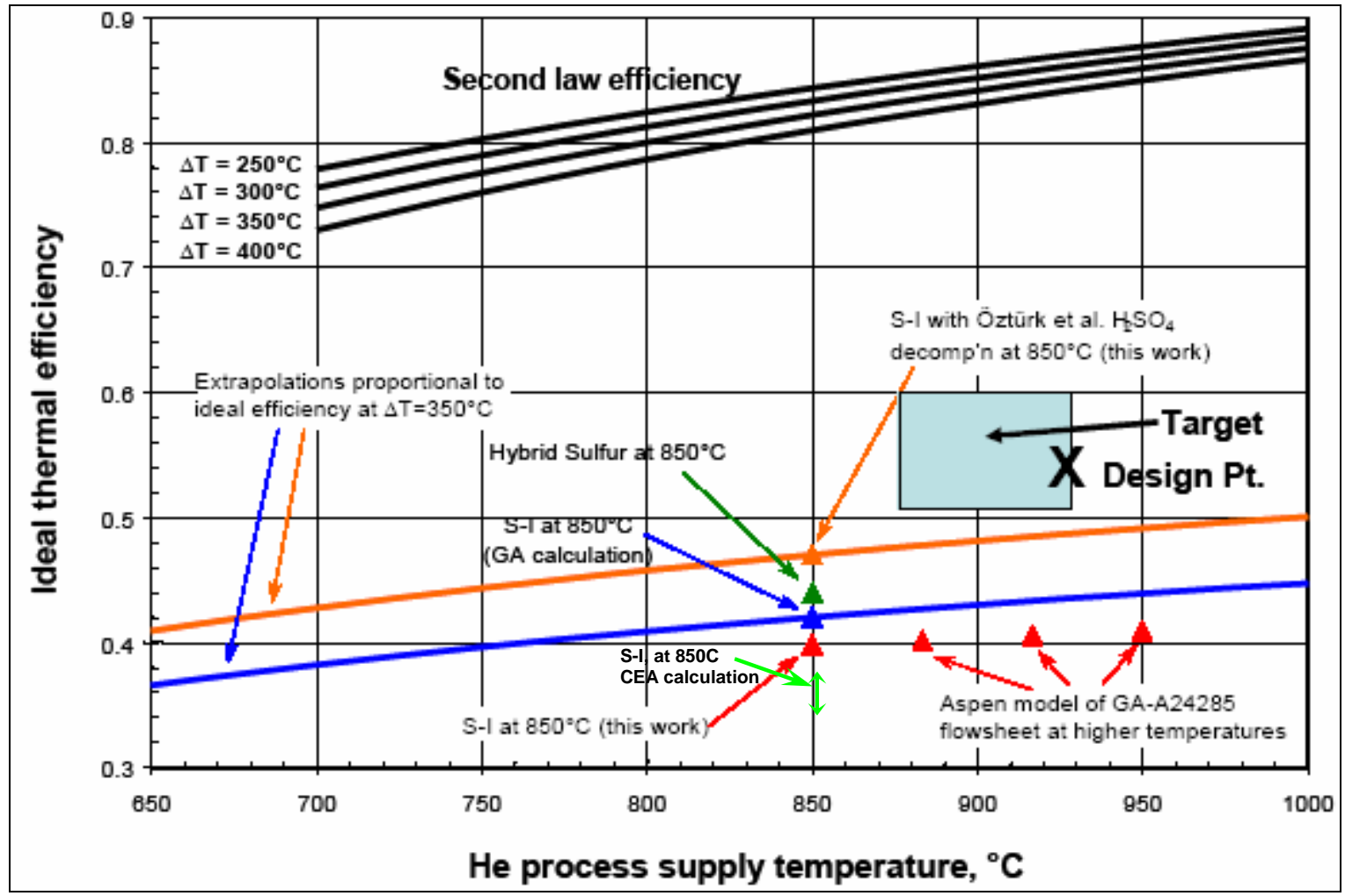

Figure 4.5. SI Process Efficiency vs. Peak Operating Temperature [Modified from Summers, et al., 2004]

(Illustration courtesy of Savannah River National Laboratory)

\section{SI Cost Breakdown}

There are yet many uncertainties about the cost of a hydrogen production plant based on the SI process, due to the uncertainties in materials choice, the process flow sheet, and component design. Thus, a current cost estimate cannot yet be presented for this or similar technologies. Nevertheless, an potential cost breakdown for the SI process plant is shown in Table 4.2. The input values are based on estimates from literature [Brown et al., 2003; Summers et al., 2004], and incorporates a higher end value to account for the uncertainty in the choice of materials and the range of process efficiency: 
Table 4.2. Cost Breakdown for a SI Process Plant

\begin{tabular}{|l|c|}
\hline $\begin{array}{l}\text { Major } \\
\text { Components }\end{array}$ & $\begin{array}{l}\text { Cost of the } \\
\text { component at a given } \\
\text { capacity (\$/kW } \mathbf{H}_{\mathbf{2}} \text { ) }\end{array}$ \\
\hline $\begin{array}{l}\mathrm{H}_{2} \mathrm{SO}_{4} \\
\text { Decomposition }\end{array}$ & $109.8-500$ \\
\hline $\begin{array}{l}\text { Bunsen } \\
\text { Reaction }\end{array}$ & $58.9-105.8$ \\
\hline $\begin{array}{l}\text { HI Reactive } \\
\text { Distillation }\end{array}$ & $225.4-405.0$ \\
\hline $\begin{array}{l}\text { Iodine } \\
\text { inventory }\end{array}$ & $95.5-171.7$ \\
\hline Auxiliary & $82.4-148.0$ \\
\hline Total cost & $572-1330$ \\
\hline
\end{tabular}

${ }^{*}$ Based on the higher heating value of hydrogen, $141.9 \mathrm{MJ} / \mathrm{kg}$. Thus, $141,900 \mathrm{~kW}_{\mathrm{H} 2}$ of output is equivalent to a hydrogen production rate of $1 \mathrm{~kg} / \mathrm{s}$.

(c) $\mathrm{Ca}-\mathrm{Fe}-\mathrm{Br}(\mathrm{UT}-3)$ cycle

The UT-3 cycle was first developed by the University of Tokyo. It involves solid-gas interactions, which may facilitate the reagent-product separations, as opposed to the all-fluid interactions in the SI cycle. It is formed of the following reactions [Yoshida et al, 1990; Doctor et al., 2003]:

$$
\begin{array}{ll}
\mathrm{CaBr}_{2}+\mathrm{H}_{2} \mathrm{O} \rightarrow \mathrm{CaO}+2 \mathrm{HBr} & \left(730^{\circ} \mathrm{C}\right) \\
\mathrm{CaO}+\mathrm{Br}_{2} \rightarrow \mathrm{CaBr}_{2}+1 / 2 \mathrm{O}_{2} & \left(550^{\circ} \mathrm{C}\right) \\
\mathrm{Fe}_{3} \mathrm{O}_{4}+8 \mathrm{HBr} \rightarrow 3 \mathrm{FeBr}_{2}+4 \mathrm{H}_{2} \mathrm{O}+\mathrm{Br}_{2} & \left(220^{\circ} \mathrm{C}\right) \\
3 \mathrm{FeBr}_{2}+4 \mathrm{H}_{2} \mathrm{O} \rightarrow \mathrm{Fe}_{3} \mathrm{O}_{4}+6 \mathrm{HBr}+\mathrm{H}_{2} & \left(650^{\circ} \mathrm{C}\right)
\end{array}
$$

\section{Ca-Fe-Br Major Challenges}

The complications of the cycle include high mass flows and membrane development requirements, and limited prospects for further efficiency improvements.

\section{Ca-Fe-Br Efficiency/Performance}

The thermodynamics of these reactions have been found favorable [JAERI, Doctor]. However, the hydrogen production efficiency of the process is limited to about $40 \%$ owing to the melting point of $\mathrm{CaBr}_{2}$ at $760^{\circ} \mathrm{C}$. This is confirmed by Toyo Engineering Corporation, who calculated an efficiency of 39.4\% [Sukurari, et al., 1996]. If a high-recovery membrane can be developed and a steam turbine generator can be used to produce export power with extraction steam for the compressors, the cycle efficiency can be raised to $44.9 \%$ [Takodoro, et al., 1997]. 
The DOE NHI is supporting the development at Argonne National Laboratory of the $\mathrm{Ca}-\mathrm{Br}$ cycle, which eliminates the reactions involving Fe compounds, and replaces them with a reaction of $\mathrm{HBr}_{(\mathrm{g})}$ in plasma to generate $\mathrm{H}_{2(\mathrm{~g})}$ :

$$
\begin{array}{lr}
\mathrm{CaBr}_{2(\mathrm{~s})}+\mathrm{H}_{2} \mathrm{O}_{(\mathrm{g})}=\mathrm{CaO}_{(\mathrm{s})}+2 \mathrm{HBr}_{(\mathrm{g})} & \left(727^{\circ} \mathrm{C}\right) \\
\mathrm{Br}_{2(\mathrm{~g})}+\mathrm{CaO}_{(\mathrm{s})}=\mathrm{CaBr}_{2(\mathrm{~s})}+1 / 2 \mathrm{O}_{2} & \left(600^{\circ} \mathrm{C}\right) \\
2 \mathrm{HBr}_{(\mathrm{g})}+\text { plasma }=\mathrm{Br}_{2(\mathrm{~g})}+\mathrm{H}_{2} & \left(25^{\circ} \mathrm{C}\right)
\end{array}
$$

Process flow sheets are being developed for this modified process and experimental work on the plasma decomposition reaction will begin in FY 2006. Owing to the early stage of this research, a cost analysis is not yet possible. Further research is needed to have a better understanding of the cycle's efficiency and economic implications.

\subsubsection{Electrochemical Processes}

Electrolysis of water or steam at different temperatures decomposes $\mathrm{H}_{2} \mathrm{O}$ directly into $\mathrm{H}_{2}$ and $\mathrm{O}_{2}$. Electrolysis is an available technology that has been demonstrated commercially in many smallscale applications for hydrogen production. It requires high electrical energy consumption that currently renders the process more expensive than steam methane reforming. Both water and steam electrolysis can play a role at various stages of a hydrogen energy infrastructure.

\section{(a) Low-Temperature Water Electrolysis (LTE)}

Water electrolysis is the electrolytic decomposition with the cell reaction:

$$
\mathrm{H}_{2} \mathrm{O}_{(\mathrm{l})} \rightarrow \mathrm{H}_{2(\mathrm{~g})}+\mathrm{O}_{2(\mathrm{~g})}
$$

Pure hydrogen can be produced by the electrolysis process. Current water electrolysis technologies fall into two categories: 1) solid polymer cells using proton exchange membranes (PEMs) and 2) liquid electrolyte cells, most commonly using a potassium hydroxide (KOH) solution. PEM electrolyzers are simply PEM fuel cells operating in reverse polarization mode. Protons diffuse in the PEM electrolyte while oxygen ions diffuse in the liquid electrolyte of these systems.

\section{LTE Major Challenges}

Currently the cost of hydrogen from PEM and $\mathrm{KOH}$ systems are roughly comparable. Reaction efficiency tends to be higher for the $\mathrm{KOH}$ system because of better conductivity of the liquid electrolyte. But this advantage is offset by the higher purification and compression energy requirements compared to PEM systems, especially at small scales. Thus, the successful development of relatively higher temperature, higher conductivity, and lower cost electrolyte membranes for PEM cells remain a challenge for reducing the cost. Another major contributor to the cost of both PEM and $\mathrm{KOH}$ electrolyzers is the extensive use of rare and expensive noble 
metal catalyst materials for their electrodes. This need limits the large-scale use of this technology. Development of alternative catalyst structures and formulation with less expensive materials is necessary and can significantly influence the economics of hydrogen production through electrolysis. New advances in high-pressure PEM systems could substantially lower the cost by reducing the need for hydrogen gas compression.

\section{LTE Efficiency/Performance}

Because of the need for electricity, water electrolysis efficiency and economics also depend on the electricity production efficiency and price. The electrochemical efficiency of current electrolysis units can vary between 65 to $90 \%$ [IAEA 1999]. It is currently possible to couple an electrolysis unit to a nuclear power plant in order to produce electrolytic hydrogen. Owing to the relatively low thermal efficiency of the LWRs, however, the final thermal-to-hydrogen energy efficiency of this path, $\eta_{H}$, is relatively low. In conventional water electrolysis, $\eta_{H}$ is represented as $\eta_{H}=\eta_{t h} \times \eta_{e s}$ where $\eta_{e s}$ is the electrochemical efficiency and $\eta_{H}$ is the thermal efficiency for electricity production. Therefore, $\eta_{H}$ for electrolysis supported by LWRs, ALWRs, or CANDUs is limited to $21-30 \%$. Significantly higher efficiencies can be achieved if an advanced power conversion system, such as the He or $\mathrm{S}-\mathrm{CO}_{2}$ turbine systems, with thermal efficiencies of about $45 \%$, provide the electricity for LTE; raising $\eta_{H}$ to about $40 \%$.

\section{LTE Cost Breakdown}

The cost of hydrogen production from water electrolysis has been estimated to range from $\$ 5.1$ to $\$ 6.2 / \mathrm{kg}$, depending on the conditions for delivery (such as the pressure of hydrogen produced) [Simbeck and Chang, 2002]. This study presumed a 75\% efficient electrolyzer and \$0.06$0.09 / \mathrm{kWh}$ of electricity. Higher efficiency electrolyzers may not necessarily result in lower hydrogen costs, depending on the capital costs of those systems. Indeed, the largest contributor to the costs determined by Simbeck and Chang was the electrolyzer itself.

DOE's goal for water electrolysis is a capital cost of $\$ 300 / \mathrm{kW}$ for a $250 \mathrm{~kg} / \mathrm{d}$ plant (with $73 \%$ system efficiency) [NAE/NRC, 2004, pp. 8-11]. Under this program goal, a large centralized plant would produce hydrogen at $\$ 2.00 / \mathrm{kg}$ [NAE/NRC, 2004, pp. 8-11]. The DOE research program is focusing on ways to improve efficiency and reduce the cost of electrolyzers based on the technical challenges described in this section.

\section{(b) High-Temperature Steam Electrolysis (HTSE)}

The reaction scheme in the high-temperature steam electrolysis (HTSE) process is the reverse of that in a solid-oxide fuel cell (SOFC), a technology being developed vigorously for specialized power applications. In solid-oxide electrolysis cells (SOECs), water vapor molecules are dissociated at the porous cathode, producing an enriched $\mathrm{H}_{2} \mathrm{O} / \mathrm{H}_{2}$ mixture, while oxygen ions are transported through the nonporous, ion-conducting solid electrolyte to the porous anode where they recombine. Thus, the product gases (hydrogen and oxygen) are automatically separated by 
the solid electrolyte membrane. Only the gases $\mathrm{H}_{2} \mathrm{O}, \mathrm{O}_{2}$, and $\mathrm{H}_{2}$ have to be circulated in the electrolysis plant and no other chemicals are involved that could give rise to safety or environmental problems.

SOEC cells and stacks for high-temperature steam electrolysis are being tested at the Idaho National Laboratory (INL) [Stoots, et al., 2005]. The specific materials for the electrodes and electrolyte and the geometry of the unit cell can change depending on the operating temperature in order to provide optimized performance.

\section{HTSE Efficiency/Performance}

The electrical energy demand decreases with increasing temperature for electrolysis. The decrease in electrical energy demand drives the thermal-to-hydrogen energy conversion efficiency to higher values. The HTSE process can be particularly advantageous when coupled to high-efficiency power cycles and can consequently promise high overall thermal-to-hydrogen efficiency. The higher temperature also favors electrode activity and helps lower the cathodic and anodic over-potentials. Therefore, it is possible to increase the electric current density at higher temperatures and consequently lower the polarization losses, which yields an increase in the process efficiency. Thus, the HTSE is advantageous from both thermodynamic and kinetic standpoints over lower-temperature electrolysis.

The steam electrolysis concept can be coupled to a range of nuclear technologies, such as gascooled reactors, lead-bismuth cooled reactors, and molten salt cooled reactors, all of which can deliver relatively high temperatures and relatively high net power cycle efficiencies. Different configurations reported for producing hydrogen using HTSE with SOECs supported with hightemperature reactors indicate a range of efficiencies for the process. These will be discussed further in the next chapter on system configurations. Here, we note that the efficiency for HTSE reported by Stoots, et al., 2005 and Yildiz, et al., 2004 ranges from 46-56\% HHV (40-48\% LHV) with SOECs operating at $800^{\circ} \mathrm{C}$ to $900^{\circ} \mathrm{C}$ at atmospheric pressure.

\section{HTSE Major Technological Challenges}

The main technological challenges for the SOECs are similar to those in the development and commercialization of SOFCs. Through the efforts of the Department of Energy Nuclear Hydrogen Initiative work led by Idaho National Laboratory, SOECs have been developed that are already producing hydrogen in the laboratory. The remaining hurdle for SOECs that prevent them from being readily adopted for the commercial production of hydrogen is the high cost of the hydrogen produced. Most of this cost comes from the SOECs themselves, rather than from the ancillary plant equipment needed to handle feed streams and output. Significant SOEC cost reductions related to raw material costs, manufacturing costs, stack lifetimes, and cell efficiency will be needed for high-temperature steam electrolysis to become a competitive source of hydrogen. 
One of the most important challenges is to ensure the durability of the SOECs at high operating temperature ranges and against thermal cycling. High temperatures require glass-ceramic seals and exotic interconnect materials (lanthanum chromite or high-temperature stainless steel) increasing the stack's cost. In addition, to prevent component failure (thermal shock), slow startup time (up to several hours) is required before the SOEC systems can operate at their optimal performance. Since the SOFCs, which are more widely studied, bear the similar challenge, most recent developments for SOFCs have been related to bringing the operating temperatures down while maintaining good electrochemical performance through materials development. Similar efforts will also be needed for SOEC development. Temperatures as low as $500^{\circ} \mathrm{C}$ have been reported for SOFC operation, and comparable operating conditions should be investigated for the SOEC mode of operation. Progress has been reported in chemically compatible cell designs for SOFC operations at lower temperatures, and this can guide the choice for SOEC materials.

The manufacturing of the solid-oxide electrolysis cells and stacks is not yet a standard technology, and thus is costly. The planar designs are considered easier to manufacture and have the potential to provide higher power densities, therefore lowering the cost. Accomplishing series and large scale cell manufacturing can help to reduce the cost of the SOECs for hydrogen production significantly.

Additional cost reduction challenges can include: new high-power high-efficiency designs, reduced costs of components and improved and cheaper manufacturing processes (e.g., tapecasting versus electrodepositing techniques). Further development is underway worldwide to reduce the costs for SOFCs.

\section{HTSE Cost Breakdown}

Tubular SOFC stacks presently cost about $\$ 1000-1500 / \mathrm{kW}$, and planar designs about $\$ 600$ 800/kW [Colson-Inam, 2004; Parrish, 2003]. The Solid-State Energy Conversion Alliance's ultimate goal for $5-\mathrm{kW}$ planar solid-oxide modules (mass produced at 100,000 unites per year) is approximately $\$ 400 / \mathrm{kW}$, with 40,000 hours of life by 2010 . About $40 \%$ of the total module cost is attributed to the stack cost, and the rest comprises gas handling and auxiliary equipment [NAE/NRC, 2004].

\subsubsection{Hybrid Thermochemical Cycles}

Hybrid cycles combine thermochemical and electrolytic reactions for water splitting. The hybrid process offers the possibility to run low-temperature reactions using electricity as a substitute for the high-temperature reactions. The processes considered here are the low-temperature $\mathrm{Cu}-\mathrm{Cl}$ process, and the high-temperature Westinghouse Sulfur Process (WSP) (also called the hybrid sulfur process). 
July 31, 2005

\section{(a) $\mathrm{Cu}-\mathrm{Cl}$ Cycle}

Argonne National Laboratory is studying the copper-chlorine hybrid cycle as a relatively low temperature water splitting process. This cycle is expected to operate at $530^{\circ} \mathrm{C}$ to produce hydrogen (and oxygen) - a temperature compatible with power plant technologies [Lewis et al., 2003] such as the Sodium-Cooled Fast Reactor (SFR) or the Super-Critical Water Reactor (SCWR).

Corrosion issues are likely to be more tractable at $530^{\circ} \mathrm{C}$ than at the higher temperatures such as those for the SI and $\mathrm{Ca}-\mathrm{Br}$ cycles. The energy efficiency of the process is projected to be about $40 \%$. The cycle consists of the following reactions, where the copper generation step is through electrolysis of $\mathrm{CuCl}$ :

$$
\begin{array}{ll}
2 \mathrm{Cu}_{(\mathrm{s})}+2 \mathrm{HCl}_{(\mathrm{g})} \rightarrow 2 \mathrm{CuCl}_{(\mathrm{l})}+\mathrm{H}_{2(\mathrm{~g})} & \left(435-475^{\circ} \mathrm{C}\right) \\
4 \mathrm{CuCl}_{(\mathrm{s})} \rightarrow 2 \mathrm{CuCl}_{2}+2 \mathrm{Cu}, \quad \text { electrolytic } & \left(25-75^{\circ} \mathrm{C}\right) \\
2 \mathrm{CuCl}_{2(\mathrm{~s})}+\mathrm{H}_{2} \mathrm{O}_{(\mathrm{g})} \rightarrow \mathrm{CuO}^{*} \mathrm{CuCl}_{2(\mathrm{~s})}+2 \mathrm{HCl}_{(\mathrm{g})} & \left(350-400^{\circ} \mathrm{C}\right) \\
\mathrm{CuO}^{*} \mathrm{CuCl}_{2(\mathrm{~s})} \rightarrow 2 \mathrm{CuCl}_{(\mathrm{l})}+1 / 2 \mathrm{O}_{2(\mathrm{~g})} & \left(530{ }^{\circ} \mathrm{C}\right)
\end{array}
$$

The reactions are thermodynamically favored based on the values of the free energies. This process is, as of now, at laboratory scale and detailed flow sheets and plant configuration studies are under development. Therefore, a cost analysis is not yet possible. Nevertheless, the hybrid nature and relatively-low peak temperature requirement of the process can lead to favorable plant configurations, as will be discussed in the next chapter.

\section{(b) Hybrid Sulfur Cycle}

The hybrid sulfur cycle or the Westinghouse Sulfur Process, WSP, was first developed by Westinghouse in 1975 [Lahoda, 2003]. This cycle is given by the reaction equations:

$$
\begin{aligned}
& \mathrm{H}_{2} \mathrm{SO}_{4(\mathrm{~g})} \rightarrow \mathrm{SO}_{2(\mathrm{~g})}+\mathrm{H}_{2} \mathrm{O}_{(\mathrm{g})}+1 / 2 \mathrm{O}_{2(\mathrm{~g})} \\
& 2 \mathrm{H}_{2} \mathrm{O}_{(\mathrm{l})}+\mathrm{SO}_{2(\mathrm{~g})} \rightarrow \mathrm{H}_{2} \mathrm{SO}_{4(\mathrm{aq})}+\mathrm{H}_{2(\mathrm{~g})}-\text { electrolytic }
\end{aligned}
$$

The major difference between the WSP and the SI processes is the elimination of the HI decomposition step and its replacement with the electrolysis of $\mathrm{SO}_{2}$ at low temperatures in WSP. Consequently, the HI-related materials and inventory difficulties are eliminated from the process.

The hydrogen generation stage involves electrolysis, but not heat transfer at high temperature from the nuclear reactor. Therefore, this stage of the process can be located away from the nuclear plant at a distance without a heat-loss penalty, which may be a safety advantage. At the same time, the stage of the process that requires the high temperature heat from the nuclear reactor is not involved with hydrogen generation, and hence can be kept closer to the reactor. This configuration of the hydrogen plant can help reduce the heat losses that may incur if the heat transfer were to take place over long distances to the hydrogen plant. 
July 31, 2005

\section{Hybrid Sulfur Cycle Efficiency/Performance}

The base case energy efficiency of the WSP cycle is shown in Figure 4.5. SRNL indicates an efficiency of $44 \%$ (HHV) with a peak process temperature of $850^{\circ} \mathrm{C}$ for this process when the electrical energy efficiency is $50 \%$.

\section{Hybrid Sulfur Cycle Major Technology Challenges}

For significantly improving the efficiency, operability, and the economics of the WSP there are certain technical advances needed:

- Different approaches to the electrolysis operation that reduce water use, use less expensive electrode and body materials, and take advantage of polymer electrolyte proton exchange membrane fuel cell developments;

- Process changes and component development that allow more efficient separations and smaller equipment sizes;

- Equipment design using structural materials with better durability to accommodate operation at high temperature and high acid concentrations, such under $\mathrm{H}_{2} \mathrm{SO}_{4}$ and $\mathrm{SO}_{3} / \mathrm{SO}_{2}$ environments.

The sulfuric acid decomposition section brings the same issues as in the relevant section of the SI process. Thus, the material affects on performance and cost for the $\mathrm{H}_{2} \mathrm{SO}_{4}$ decomposition section are the same as that covered for the SI process. Here, we analyze the effect of the electrolyzer and its margins for improvement and its influence on performance and cost of the hybrid sulfur process.

Extensive work in the 1970s identified and tested various catalysts for electrodes to promote the electrolytic reaction of the process. Results indicated that the reaction could proceed at about 0.6 volts with a current density of $200 \mathrm{~mA} / \mathrm{cm}^{2}$, at slightly elevated temperatures [Lahoda, 2005]. Westinghouse noted that significant energy losses were incurred because of the $\mathrm{SO}_{2}$ electrolyzer of the original design. Figure 4.6 presents the major differences between the ideal and actual electrolyzer potential. The irreversibilities in the electrolyzer are attributed to the high cathodic overpotentials and electrolyte resistance due to a lack of optimization of the catalyst material, composition, and cell design.

Figure 4.7 presents the margin of improvement in the efficiency of the latest WSP concept [Jeong, et al., 2005] as a function of the $\mathrm{H}_{2} \mathrm{SO}_{4}$ concentration and the reduction in electrolyzer potential over that of the original design from 1970s. This analysis also confirms the possibility of significantly increasing the WSP efficiency by improvements in the $\mathrm{SO}_{2}$ electrolyzer design. Therefore, the $\mathrm{SO}_{2}$ electrolyzer performance and cost will be a major factor in determining the cost of hydrogen produced by the hybrid sulfur process.

Table 4.3 shows a comparison of the efficiency (of the base case design concept) for the ideal and actual energy use of the electrolyzer, given that the thermal energy required for the rest of 
Potential Nuclear Hydrogen System Applications

Argonne National Laboratory

July 31,2005

the process is equal to $237.5 \mathrm{MJ} / \mathrm{kg}-\mathrm{H} 2$ [SRNL]. Clearly, the currently available $\mathrm{SO}_{2}$ electrolyzer is a major reason for the reduced efficiency by about $8 \%$-LHV $(10 \%-H H V)$ within the analysis from SRNL.

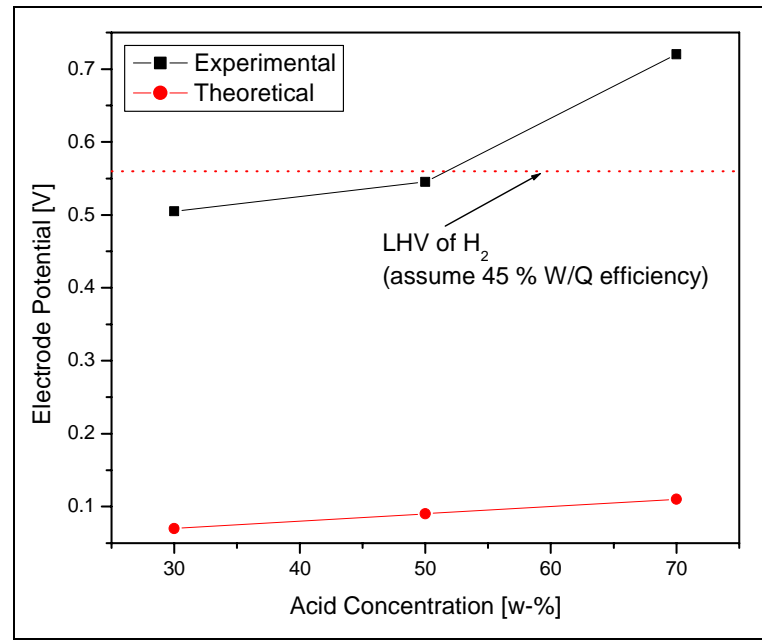

Figure 4.6. Theoretical and Experimentally Measured Cell Potential for the $\mathrm{SO}_{2}$ Electrolyzer

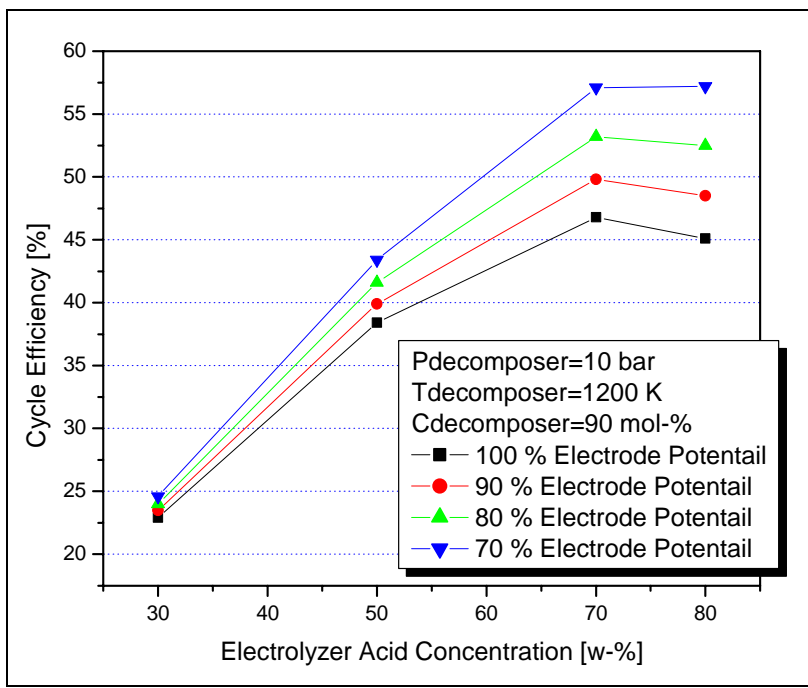

Figure 4.7. WSP Cycle Efficiency for Various $\mathrm{SO}_{2}$ Electrolyzer Potentials (\% of the Experimentally Measured Values in Figure 4.7)

(Reprinted with permission from ref. Jeong et. al. Copyright 2005, Center for Advanced Nuclear Energy Systems at MIT)

Table 4.3. Influence of the $\mathrm{SO}_{2}$ Electrolysis Efficiency on the Overall WSP Efficiency

\begin{tabular}{|c|r|c|c|}
\hline & \multicolumn{1}{|c|}{$\mathrm{Q}$} & $\%$ of $\mathrm{Q}_{\text {in }}$ & $\begin{array}{c}\eta_{\mathrm{H} 2} \\
\text { LHV (HHV) }\end{array}$ \\
\hline WSP(850C) $-\eta_{\mathrm{el}}=43 \%$ & $275.6 \mathrm{MJ} / \mathrm{kg}$ & & $43.6(50.9) \%$ \\
\hline electrical (ideal) & $38.1 \mathrm{MJ} / \mathrm{kg}$ & $12.82 \%$ & \\
\hline thermal+other & $237.5 \mathrm{MJ} / \mathrm{kg}$ & $86.17 \%$ & \\
\hline WSP(850C) $-\eta_{\mathrm{el}}=46 \%$ & $273.2 \mathrm{MJ} / \mathrm{kg}$ & & $43.9(51.2) \%$ \\
\hline electrical & $35.7 \mathrm{MJ} / \mathrm{kg}$ & $13.05 \%$ & \\
\hline thermal+other & $237.5 \mathrm{MJ} / \mathrm{kg}$ & $86.95 \%$ & \\
\hline & & & \\
\hline WSP(850C) $-\eta_{\mathrm{el}}=43 \%$ & $339.5 \mathrm{MJ} / \mathrm{kg}$ & & $35.3(41.2) \%$ \\
\hline electrical (actual) & $102.0 \mathrm{MJ} / \mathrm{kg}$ & $30.04 \%$ & \\
\hline thermal+other & $237.5 \mathrm{MJ} / \mathrm{kg}$ & $69.96 \%$ & \\
\hline WSP(850C) - $\eta_{\mathrm{el}}=46 \%$ & $332.8 \mathrm{MJ} / \mathrm{kg}$ & & $36.1(42.1) \%$ \\
\hline electrical (actual) & $95.3 \mathrm{MJ} / \mathrm{kg}$ & $28.64 \%$ & \\
\hline thermal+other & $237.5 \mathrm{MJ} / \mathrm{kg}$ & $71.35 \%$ & \\
\hline
\end{tabular}


The electrode composition in these tests included significant loading of precious metals that would lead to high capital costs. In addition, in the 1970s ion exchange membranes did not exist. Therefore the 1970s development work was performed using flow through rubber separators similar in design and concept to the asbestos separators used at the time in the chlor-alkali industry. One of the issues faced by the earlier investigators was the need to have a net flow from the water side to the sulfuric acid side of the electrolysis cell to prevent sulfur from plating out on the cathode. This excess water has to be removed from the exit $\mathrm{H}_{2} \mathrm{SO}_{4}$ through evaporation, resulting in a large energy penalty.

There are already possible candidates for improved $\mathrm{SO}_{2}$ electrolysis, based on new lowtemperature fuel cell designs. Since the 1970s, ion transport membranes have been developed that effectively transport $\mathrm{H}^{+}$cations, especially for the PEM fuel cells. These membranes have completely replaced the old asbestos separators in the chlor-alkali industry. The testing and use of ion transport membranes should result in higher process efficiency and lower capital and operating costs at a relatively small development cost as part of the WSP.

Advanced electrodes with better dispersion and lower loading of the precious metal catalyst are being developed for PEM fuel cells, with the objective of reducing the costs and extending the operating life of the components. The cost and efficiency of the electrolysis step in the WSP can benefit from this progress.

\section{Hybrid Sulfur Cost Breakdown}

A reference for the cost projection of the $\mathrm{SO}_{2}$ electrolyzer can be taken from that of PEM fuel cells. The current cost of PEM units is about $\$ 4000 / \mathrm{kWe}$, while the expected reduced cost by 2010 is $\sim \$ 400 / \mathrm{kWe}$ (equivalently $\$ 330 / \mathrm{kW}-\mathrm{H}_{2}$ ). Other advances can improve the cathodic activity, reduce the overpotentials, and increase the electrolysis efficiency. For instance, in November 2004, Ticonia (a subsidiary of Celanese Corp.) announced the first 17-bipolar PEM fuel cell prototype made solely of engineering thermoplastics [Lahoda, 2005]. They estimated that the new fuel cell would cut the cost per $\mathrm{kW}$-e for the stack to about $\$ 1,050$ from the $\$ 4,000$ costs needed with aluminum, gold-coated stainless steel, graphite or thermoset graphite blends. These polymers withstand the aggressive media found in fuel cells and remain dimensionally stable, even at temperatures as high as $200^{\circ} \mathrm{C}$. A summary of the expected cost breakdown is shown in Table 4.4. 
Potential Nuclear Hydrogen System Applications

Argonne National Laboratory

July 31,2005

Table 4.4. Cost Breakdown for a WSP Plant

\begin{tabular}{|l|c|}
\hline $\begin{array}{l}\text { Major } \\
\text { Components }\end{array}$ & $\begin{array}{l}\text { Cost of the } \\
\text { component at a } \\
\text { given capacity } \\
\left(\mathbf{\$} / \mathbf{k} \mathbf{W}_{\mathbf{H} 2}\right)\end{array}$ \\
\hline $\begin{array}{l}\mathrm{H}_{2} \mathrm{SO}_{4} \\
\text { Decomposition }\end{array}$ & $109.8-500$ \\
\hline $\begin{array}{l}\mathrm{SO}_{2} \\
\text { electrolyzer }\end{array}$ & $722-330$ \\
\hline Auxiliary & $82.4-148.0$ \\
\hline Total cost & $525-1370$ \\
\hline
\end{tabular}




\section{Properties and Market Implications of Nuclear Hydrogen Production Plant Configurations}

Each hydrogen market will have characteristics such as the demand, time dependence of demand, geographic location, and desired hydrogen purity. For each hydrogen market, a set of nuclear hydrogen plant configurations can be defined to meet individual market needs while optimizing nuclear hydrogen economics. Thus, it is important to examine the technology choices that can be competitive in different hydrogen markets. Here, we categorize the nuclear hydrogen production technologies according to their configuration properties. These properties include:

1. Hydrogen-only production versus cogeneration with electricity;

2. Direct versus indirect power cycle heating;

3. Series versus parallel arrangement of heat loads for the power cycle and hydrogen process.

These categories are shown in Figure 5.1. More detailed analysis of the listed properties are presented for the sulfur-iodine and copper-chlorine processes supported by a He-cooled hightemperature reactor by Vilim, 2005, and this paper is presented as Appendix B of this report. The interface between the primary reactor system and the hydrogen production process has important cost, operations, and safety issues associated with it. These properties can indicate benefits of the specific technology, such as cogeneration, flexibility of output rates, and feasibility in operation. The parallel and indirect options are subject to increased system energy losses and increased equipment count and cost, but offer the potential for greater flexibility with respect to system isolation and control of temperature and the hydrogen-electricity production mix. In contrast, the series and direct options can provide significant benefits in system efficiency and equipment cost, but the feasible control of co-generation products (electricity, hydrogen, and process heat) requires more intricate design. A combination of these features can determine the compatibility and competitiveness of the specified technology in a given hydrogen market.

Other factors that can influence the technology choice are the flexibility in the siting of the plant, safety of the plant, and the size of the plant (e.g., small-scale distributed generation versus largescale centralized generation of hydrogen). The siting and size of the plant for several configuration options will be discussed in this section. Safety implications of the plant configurations require more analysis to draw conclusions and are not covered in this report.

The nuclear-hydrogen plant configuration options that fall into the three categories listed above are presented here for various hydrogen production processes discussed in the previous chapter. The objective of this section is to present an assessment of operational and economic features of nuclear hydrogen plant technologies and their compatibility in several hydrogen markets within different time frames. An example of this high-level assessment for near-term markets is given in Figure 5.2. 
Potential Nuclear Hydrogen System Applications

Argonne National Laboratory

July 31, 2005

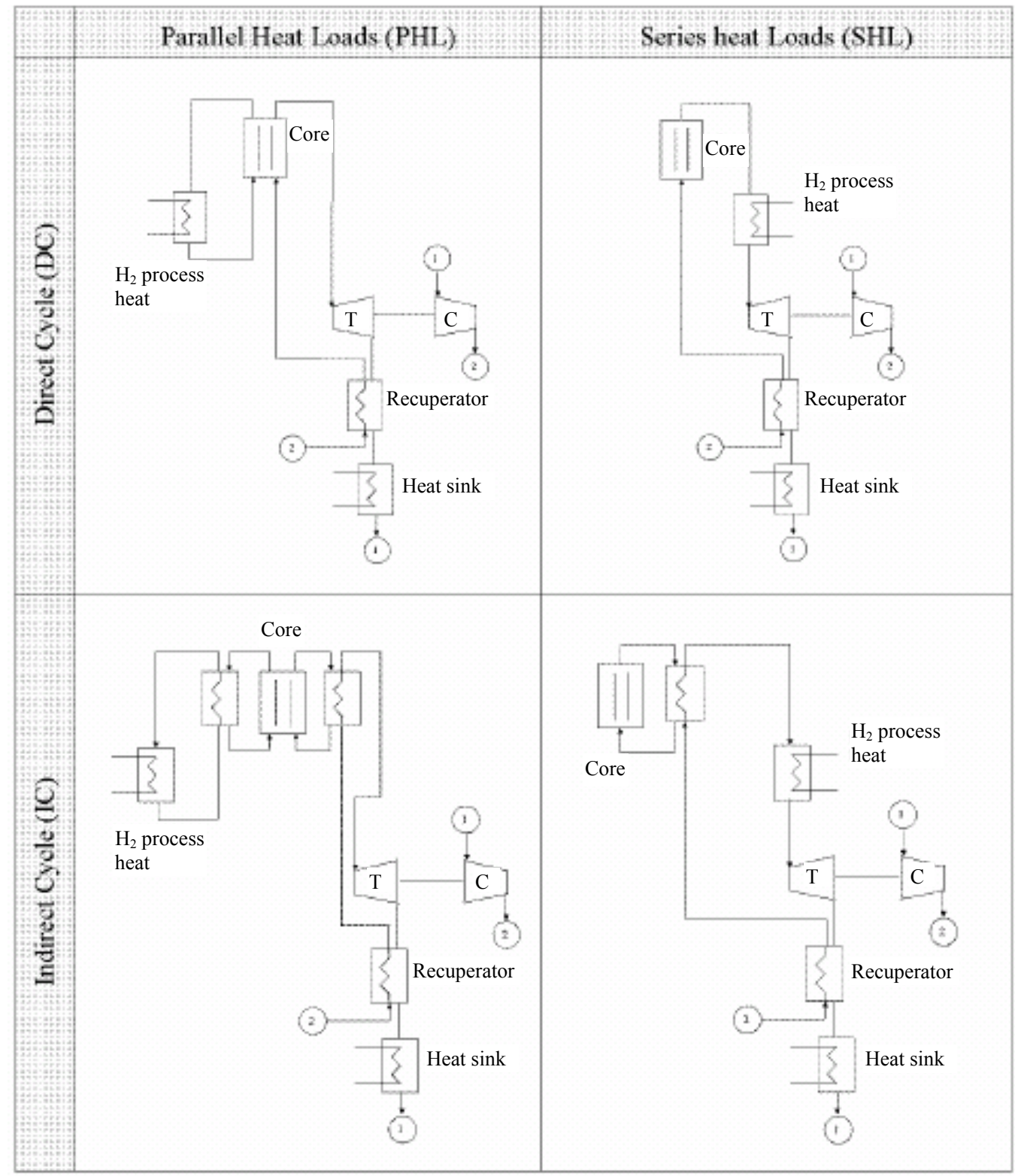

Figure 5.1. Matrix of interface configurations for a nuclear hydrogen production plant. The representative configurations are for the $\mathrm{Cu}-\mathrm{Cl}$ cycle supported by an advanced high-temperature gas cooled reactor [Vilim, 2005; Appendix B]. (Illustration courtesy of the author) 

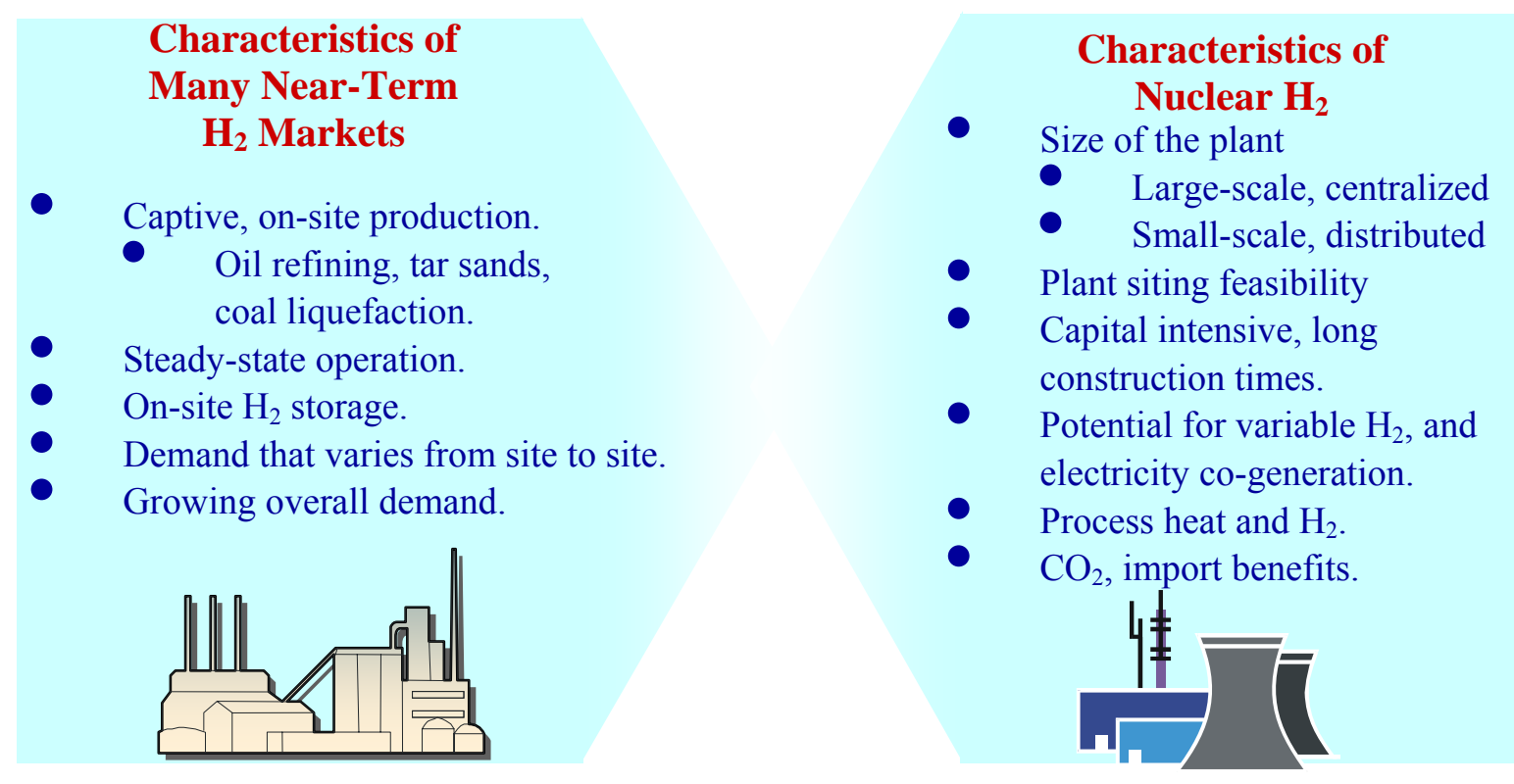

Figure 5.2. Nuclear Hydrogen Production Characteristics and Their Compatibility with Near-Term Hydrogen Market Needs

\subsection{Configurations for Thermochemical Processes}

The pure thermochemical water-splitting processes considered for hydrogen production (as described in Chapter 4) require high temperatures. Process designs attempt to make the best use the heat from product streams, for instance for separations. The final hydrogen and oxygen output streams tend to be at relatively low temperatures and, thus, cannot be utilized for preheating the feed water or steam.

It is possible to control the operation of a nuclear/hydrogen facility such that the rates of hydrogen and electricity production can be varied in order to follow electricity and/or hydrogen demands without changing the nuclear reactor thermal power. This can be accomplished by several additional components such as power conversion cycles or fuel cells and batteries as means of energy storage.

If a cogeneration plant is considered for both electricity production and hydrogen production with pure thermochemical processes, the parallel heat-load configuration would be necessary, the exit stream from the reactor being split into two paths-one supplying heat for the thermochemical process and one for the power conversion cycle. This configuration can burden the flexibility and economics of shifting the hydrogen and electricity output rates, if the plant is intended to follow power loads.

Peak Electricity Nuclear Systems that depend on generating and storing hydrogen and providing electricity during peak demands can serve as an alternative configuration for co-generation of 
hydrogen and electricity and for load following. The details of this system concept are presented in Appendix A.

Scale and markets to address: Thermochemical processes are more likely to be economical when they are scaled up to large volumes and output rates. They can address the near- and long-term large hydrogen markets, such as the oil refining or transportation industries.

Time-frame of application: High-temperature thermochemical hydrogen production processes currently under development continue to have engineering challenges to overcome, such as the design of high-temperature material systems. Commercialization of a very high temperature nuclear reactors to support these processes will take decades. Therefore, it is more likely that these technologies may start contributing in the longer-term evolving hydrogen markets.

\subsection{Configurations for Low-Temperature Electrolysis}

Low-temperature electrolysis technologies can be supported with the currently operating LWRs or CANDUs, as well as in the future by advanced nuclear technologies. Among these can be the advanced LWRs (ALWRs) and the GenIV program reactor designs, such as the advanced gas cooled reactors and the liquid-metal cooled reactors. Thermal-to-hydrogen energy efficiency for water electrolysis supported by LWRs, CANDUs, or ALWRs is limited to $21-30 \%$ owing to the relatively low efficiency of the Rankine cycle for electricity production. The process efficiency supported with advanced gas cooled reactors with higher electricity production efficiency $(\sim 45 \%)$ can increase this value to $29-40 \%$. It is clear that high electrical production efficiency is a key factor in the viability of low-temperature electrolysis.

The interface between the electrolyzer unit and the nuclear plant requires only the transfer of electricity since current water electrolyzer technology does not require heat input. Thus, the heat load from the nuclear reactor is needed only for electricity production. This feature can allow the electrolyzer to be placed at a large distance from the reactor if required for safety reasons. This also allows for distributed or regional hydrogen production that could be customized for the application and would minimize hydrogen transportation costs. For advanced water electrolyzers at relatively higher temperatures, the heat load necessary for the electrolyzer can be retrieved from the balance of the plant (BOP), but would require on-site hydrogen production

Cogeneration of both hydrogen and electricity is a feature of this technology, with excess electricity available for the grid. It is possible to control the operation such that the rates of hydrogen and electricity production can be varied in order to follow electricity and hydrogen demands without changing the nuclear reactor thermal power. The fast startup times of lowtemperature electrolyzers means that this load following can be accomplished without the need for energy storage methods.

Scale and markets to address: Both centralized large-scale and distributed small-scale hydrogen production is possible using water electrolysis technology supported by nuclear energy. For 
instance, converting the Canadian tar sands to liquid fuels is a likely near-to-mid-term application for water electrolysis supported by CANDU reactors.

Time-frame of application: Electrolysis is a readily available technology and can be considered as a candidate technology at any period of evolving hydrogen markets. Advanced, highefficiency nuclear technology would make this technology more attractive, as will further electrolyzer developments such as high-pressure PEM devices. A limitation to large-scale deployment of low-temperature electrolysis (for, say, transportation) is its current reliance on noble-metal catalysts. Basic science advances in catalysis may be able to overcome this limitation. Meanwhile, an advantage of high-temperature steam electrolysis through solid-oxide fuel cell technology is its lack of reliance on such exotic materials.

\subsection{Configurations for High-Temperature Steam Electrolysis}

High-temperature steam electrolysis can be supported by intermediate- to high-temperature nuclear reactors. The interface between the HTSE process and the nuclear reactor can be based on either a parallel heat load between the BOP and the HTSE plant or a series heat load configuration. The two alternatives and their operational implications, based on the plant layout designs by INL researchers (Stoots, et. al, 2005) and Yildiz, et al., 2005, respectively, are summarized here. Both of the studies calculated essentially the same efficiency values when the same operating conditions are used.

1. Parallel heat-load, direct or indirect cycle: HTSE supported by a He-cooled HTR and a He power cycle (abbreviated here as GT-MHR-HTSE) [Stoots, et al., 2005]

An improved plant configuration flow sheet analysis of HTSE with a He-cooled HTR and a He power cycle with better thermal recuperation was presented in this study. The study showed the margins for improving the overall efficiency with heat recuperation from the product hydrogen and oxygen gases, and detailed implications of separation efficiency and electrolyzer efficiency on the performance of the process. This analysis indicated that up to $47 \%$ LHV (55\% HHV) of thermal-to-hydrogen efficiency is achievable for this HTSE system for solid-oxide electrolysis cells operating at $827^{\circ} \mathrm{C}$.

2. Series heat-load, direct cycle: HTSE supported by the $\mathrm{CO}_{2}$-cooled AGR and a supercritical $\mathrm{CO}_{2}\left(\mathrm{~S}-\mathrm{CO}_{2}\right)$ power cycle (abbreviated here as AGR-S-CO $-\mathrm{HTSE}$ ) [Yildiz, et al., 2005]

A design evaluation of the integrated system AGR-S-CO $\mathrm{CO}_{2}-\mathrm{HTSE}$ was presented by Yildiz, et al., 2004. The configuration assumed reactor and power cycle operating conditions based on the $\mathrm{S}-\mathrm{CO}_{2}$ cycle design operating conditions provided by Dostal, 2002. A study of this enhanced configuration showed the margins for improving the overall efficiency and the operational feasibility of the AGR-S- $\mathrm{CO}_{2}-\mathrm{HTSE}$ based on improvements in materials, heat recuperation from product gases, heat exchanger performance, and HTSE operating pressure. Figure 5.3 shows the configuration for this 
plant layout with recuperation of heat from product gases, placement of the intermediate heat exchanger (IHX) after the turbine exit as a series-heat load from the reactor, and electrical heating of the steam after internal recuperation. The IHX in this configuration serves as a boiler at a given pressure, and the exit from the cold-leg is saturated steam, while the hot-leg has $\mathrm{S}-\mathrm{CO}_{2}$ gas flow. The range of efficiency improvement estimated for this design is presented in Figure 5.4 as a function of reactor exit temperature, electrolysis pressure at an electrolysis cell efficiency of $90 \%$, and a hydrogen distribution pressure of $7 \mathrm{MPa}$ at the plant gate.

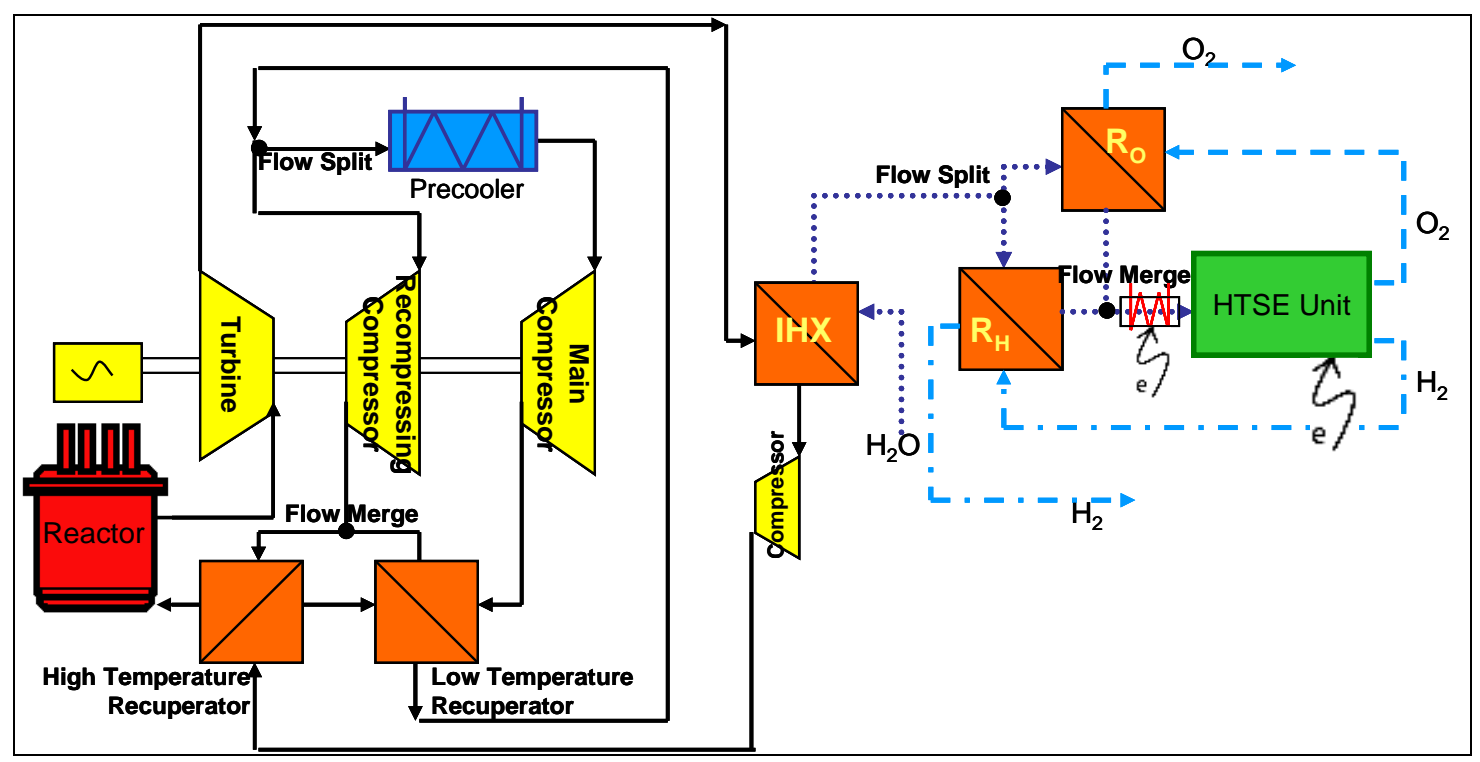

Figure 5.3. An Integrated HTSE-SCO $\mathrm{H}_{2}$-AGR Plant, with Recuperation of Heat into Steam from Hydrogen and Oxygen Flow Streams and with Heat Provided from the S-CO 2 turbine exit for Boiling the Feed Water [Yildiz, et al., 2004]

(Reprinted with permission from ref. Yildiz et. al, 2004. Copyright 2004, Center for Advanced Nuclear Energy Systems at MIT) 


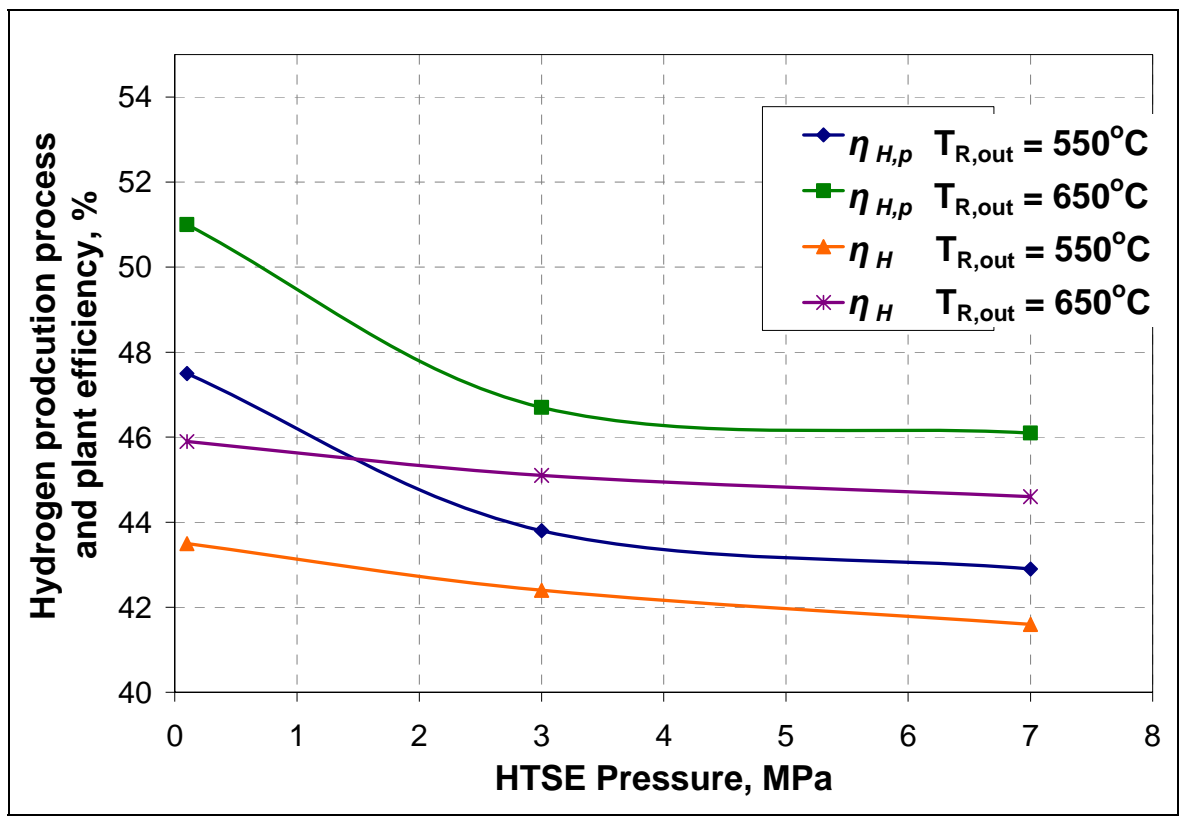

Figure 5.4. Comparison of the Process $\left(\eta_{H, P}\right)$ and Overall Energy Efficiency $\left(\eta_{H}\right)$ (in LHV) for the Recuperative HTSE-SCO${ }_{2}$-AGR Plant Configuration Represented in Figure 5.3 for Different Reactor Exit Temperatures and Electrolysis Pressures [Yildiz, et al., 2004]

(Reprinted with permission from ref. Yildiz et. al, 2004. Copyright 2004, Center for Advanced Nuclear Energy Systems at MIT)

Based on the analysis, the HTSE-SCO 2 -AGR configuration can be founded on four technological developments, each of which will significantly influence the cost of the product:

1. The HTSE $\mathrm{H}_{2}$ production units are to comprise solid-oxide electrolysis cells (SOECs) and their support structures. The challenges of developing these systems and important contributors to their performance and cost were presented in Chapter 4.

2. A high- efficiency $\mathrm{S}-\mathrm{CO}_{2}$ recompression Brayton cycle power conversion system with a maximum temperature range of $550-700^{\circ} \mathrm{C}$ and a pressure of $22 \mathrm{MPa}$ has been designed thermodynamically by Dostal, et al., and is a strong candidate for supporting the HTSE process for $\mathrm{H}_{2}$ production. The operating parameters (such as temperature, pressure, heat exchanger effectiveness, and rotating machinery efficiency) in the design of the HTSE$\mathrm{SCO}_{2}$-AGR configuration in this study were kept consistent with those of the $\mathrm{S}-\mathrm{CO}_{2}$ system.

3. AGR is not part of the GenIV initiative. AGR units have been commercially operating in UK since 1976, with a coolant pressure of $4 \mathrm{MPa}$ and a coolant outlet temperature of $650^{\circ} \mathrm{C}$. A design update for the AGR to operate at $20 \mathrm{MPa}$ would be needed to address the integrity of the pressure vessel and containment at these elevated pressures. In addition, $\mathrm{CO}_{2}$ may react with structural materials and graphite. There is extensive 
July 31,2005

experience in AGRs for eliminating structural material corrosion. This experience could lead to appropriate materials selection and development in a new AGR design.

4. To keep the plant compact, advanced heat exchangers are needed. The printed circuit type heat exchangers (PCHE) by HEATRIC ${ }^{\mathrm{TM}}$, for example, are among the most compact heat exchangers with the advantages of low mass-to-duty ratio and high effectiveness. Such heat exchangers can offer a large saving compared to the traditional shell-and-tube heat exchangers. There is sufficient reliable experience with their use at the same range of temperatures and pressures as the current AGRs. More development is needed for stronger materials suitable for the higher pressure and temperature operation that may be needed for use in the HTSE-SCO $2-A G R$ design concept.

\section{Co-generation and Operational Feasibility of the Series Heat-Load Configuration}

Series heat-load configurations (where the IHX is placed at the exit of the turbine), as in the Figure 5.3 example, has advantages over parallel heat-load configurations. The first is the flexibility that can be brought to adjusting the relative electricity and hydrogen production rates without changing the nuclear reactor thermal power. This offers attractive operational flexibility. Hydrogen can be stored during high hydrogen production hours; the external demand for hydrogen can be followed by the help of onsite storage. Electricity demand is more difficult to follow in this way, because of the lack of good electricity storage technologies. The configuration in Figure 5.3 can accomplish regulating the electricity production rate closer to the electricity demand by adjusting the feed water flow rate sent to the IHX. This regulates the temperature at the exit of the hot-leg of the IHX and the power cycle efficiency that influences the electrical power of the cycle. The second main advantage of this configuration is the additional separation of the hydrogen production process from the nuclear reactor by means of coupling the HTSE unit to the S- $\mathrm{CO}_{2}$ cycle rather than to the reactor directly. In this way, the flow stream of the hydrogen process plant is further isolated from a flow stream that is directly coupled to the reactor. This can yield better operational safety.

Time-frame of application: HTSE cells that can operate at intermediate temperatures (650$\left.800^{\circ} \mathrm{C}\right)$ and higher temperatures $\left(>800^{\circ} \mathrm{C}\right)$ have the potential to become available in the near to mid term. This is based on the ongoing promising research for developing well performing SOFC materials for the intermediate temperature range. High-temperature SOFC's are already available, but intermediate temperature cells would provide cost benefits. If an MHR is used for this configuration, commercialization would take longer, especially for very high temperature operation. The AGR is a currently available technology. Nevertheless, the $\mathrm{S}-\mathrm{CO}_{2}$ turbine and updated AGR designs are not readily available technologies, and would only be realized in the mid to long term. Thus, this integrated technology would be applicable to the evolving mid- to long-term hydrogen markets.

Scale and markets to address: Due to the modularity of the HTSE units, the technology can be implemented as small-scale modular or a large-scale centralized facility. It can as well start as a co-generation plant, with small-scale hydrogen capacity and excess electricity production. The 
hydrogen capacity can be increased by additional modules, while decreasing the excess electricity production rate, to address the demand of a growing localized market. Overall, this integrated technology can be evaluated in the evolving mid- to long-term hydrogen markets.

\subsection{Configurations for the Westinghouse Hybrid Sulfur Process}

The WSP plant configuration $\mathrm{H}_{2}$ and $\mathrm{O}_{2}$ streams, because of separation steps within the process, are at relatively low temperatures. Thus, it is not feasible to use those streams fully for recuperation purposes. A WSP process requires a parallel heat-load configuration with the power cycle supported by a high-temperature (preferably above $900^{\circ} \mathrm{C}$ peak temperature) reactor. Improvements have been proposed to the process flow sheet by Jeong, et al., 2005, and Gorensek et al., 2005.

In the study by Jeong, et al., 2005, ways to optimize the energy efficiency of the hybrid cycle were explored by varying the electrolyzer acid concentration, decomposer acid concentration, pressure and temperature of the decomposer, and the internal heat recuperation. The energy analysis included the currently available experimental data for the electrolysis potential. The improved flow sheet configuration from this study is shown in Figure 5.5. The study of this enhanced configuration showed the margins for improving the overall efficiency of the WSP through better internal heat recuperation and product separation schemes. A cycle efficiency of $43.9 \%$ (LHV) $(51.2 \% \mathrm{HHV}$ ) appears to be achievable at $1100 \mathrm{~K}$ (at $5 \mathrm{bar}, 1100 \mathrm{~K}$ and $60 \mathrm{~mol}-\%$ of $\mathrm{H}_{2} \mathrm{SO}_{4}$ for the decomposer, $70 \mathrm{w}-\%$ of $\mathrm{H}_{2} \mathrm{SO}_{4}$ for the electrolyzer). For a process peak temperature of $1200 \mathrm{~K}, 47.0 \%$ (LHV) $(54.8 \% \mathrm{HHV})$ appears to be the achievable cycle efficiency (at 10 bar, $1200 \mathrm{~K}$ and $60 \mathrm{~mol}-\%$ of $\mathrm{H}_{2} \mathrm{SO}_{4}$ for the decomposer, $70 \mathrm{w}-\% \mathrm{of} \mathrm{H}_{2} \mathrm{SO}_{4}$ for the electrolyzer).

Operation under elevated pressures (70 bar or higher) results in loss of cycle efficiency, but can decrease the equipment size and capital cost. However, the loss in efficiency as pressure increases is not as large at higher temperatures $(1200 \mathrm{~K})$ compared to that of lower temperatures $(1000-1100 \mathrm{~K})$. Therefore, high pressure operation would be favored only if higher temperatures can be achieved. The study did not evaluate the quantitative implications of the parametric variations in operating conditions on the economics of the process. Although high-pressure and high-temperature operation is favorable in terms of efficiency, there can be an economic burden brought by such conditions. Thus, although the range of operating conditions under which the process is likely to be more efficient has been determined, the competition between improved efficiency and economics of the process has not been analyzed.

The objective of the study by Gorensek, et al., 2005, was to demonstrate a WSP flow sheet that has a thermal efficiency in excess of $50 \%$ (HHV). The net thermal efficiency of the initial version of this cycle was predicted to be $46.5 \%$ (HHV), assuming the use of heat from a $950^{\circ} \mathrm{C}$ gas-cooled nuclear reactor. Based on Gorensek, et al., with further process flow sheet optimization and at increased reactor outlet temperatures, higher thermal efficiencies exceeding $50 \%$ can be expected. Preliminary estimates for the capital cost and the hydrogen production cost for an Nth-of-a-kind nuclear $\mathrm{H}_{2}$ production plant using the hybrid sulfur cycle were also 
calculated. The nuclear heat source design and cost prepared for a NERI study [Brown, et al., 2003] using General Atomics Modular Helium Reactors and the SI thermochemical cycle was used as a cost basis. The cost of hydrogen production was determined to be $\$ 1.64 / \mathrm{kg}$ at the plant gate for the baseline case. This cost significantly depended on the electrolyzer cost, and it varied between $\$ 1.44 / \mathrm{kg}$ and $\$ 1.94 / \mathrm{kg}$ for electrolyzer costs of $\$ 1025 / \mathrm{m}^{2}$ and $\$ 3500 / \mathrm{m}^{2}$, respectively. These hydrogen costs are nearly the same as those estimated for an SI nuclear hydrogen production plant.

As discussed in Chapter 4, introducing a second electrolysis stage to reduce $\mathrm{SO}_{3}$ would significantly reduce the required temperature for the hybrid sulfur process. Although this would require the extra expense of electricity and the solid-oxide electrolysis system, those penalties may be offset by the significantly reduced temperature demand and the reduction in costly materials that would otherwise be needed for the high temperatures of the WSP process.

Because it is a hybrid process, a WSP-based facility can market electricity production in excess of the need for the $\mathrm{SO}_{2}$ electrolyzer without any additional system requirement. It is possible to control the operation such that the rates of hydrogen and electricity production can be varied in order to follow electricity and hydrogen demands without changing the nuclear reactor thermal power.

Scale and markets to address: The WSP process, because it includes a high-temperature thermochemical decomposition reaction, is more likely to be economical when it is scaled up to large volumes and output rates. It can address the near- and long-term large hydrogen markets, such as the oil refining or transportation industries.

Time-frame of application: Owing to the high-temperature thermochemical hydrogen production stage, this process bears large cost uncertainties related, in part, to the advanced materials needed for this environment. In addition, the commercialization of a very high temperature nuclear reactor to support the WSP process is decades away. Therefore, it is more likely that these technologies may start contributing in the longer term hydrogen markets. 


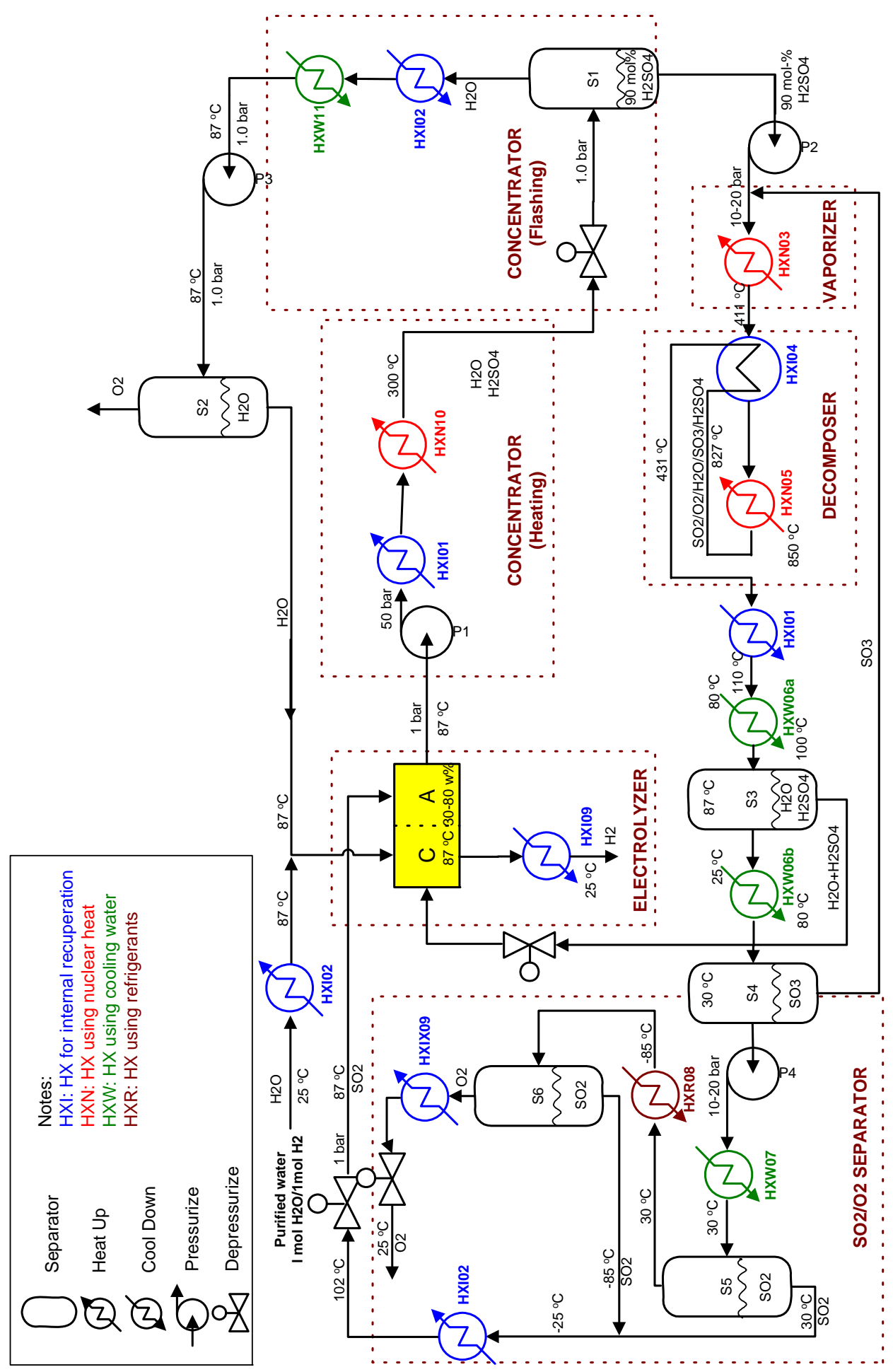

Figure 5.5. Improved WSP Flow Sheet [Jeong et al, 2005]

(Reprinted with permission from ref. Jeong et. al. Copyright 2005, Center for Advanced Nuclear Energy Systems at MIT) 
July 31, 2005

\subsection{Configurations for the $\mathrm{Cu}-\mathrm{Cl}$ Cycle}

Bench-scale experiments have demonstrated the individual reaction steps of this cycle. Recent experimental work yielded reaction kinetics data for the hydrogen and oxygen generation steps. These data were used by Vilim, 2004, to estimate the reactor vessels and the inventory of the chemical commodities. The capital costs associated with these two reactions bears directly on the cost competitiveness of this cycle. Thus, design of a facility for this process requires more detailed laboratory-scale and engineering-scale experiments to better characterize the mass and energy transfer in a more realistic environment.

As for the other processes, the cost of the hydrogen product depends on several plant factors, including types and quantity of materials used, the nature of system losses, costs associated with equipment count and complexity, and design features needed for acceptable operational control. Vilim, 2005, examined how design and configuration choices affect these factors, and, consequently, the product cost. This study concluded with a preliminary analysis of a design that should have one of the lowest product costs based on an assessment with respect to these plant factors. The final design in this study used a combination of a direct cycle He-cooled reactor and a He turbine in a series heat-load arrangement with the low temperature $\mathrm{Cu}-\mathrm{Cl}$ process, which retrieves the heat from the exit stream of the turbine. This configuration is similar to that presented for the improved HTSE layout by Yildiz, et al., 2005, and its schematic is shown in Figure 5.6.

The change in cycle efficiency, electrical efficiency, and the combined efficiency for the plant configuration is shown in Figure 5.7 as the electric power to the grid is reduced to $50 \%$ of its full power value while keeping the reactor power constant. Under that condition, the thermochemical efficiency of the $\mathrm{Cu}-\mathrm{Cl}$ process is shown to vary between 45 to $48 \%$ and the combined plant efficiency is shown to vary between 40 to $50 \%$. Further improvement of the performance is expected by the use of an enhanced regulation control scheme for adjusting the electricity and hydrogen production output rates. 
Potential Nuclear Hydrogen System Applications

Argonne National Laboratory

July 31,2005

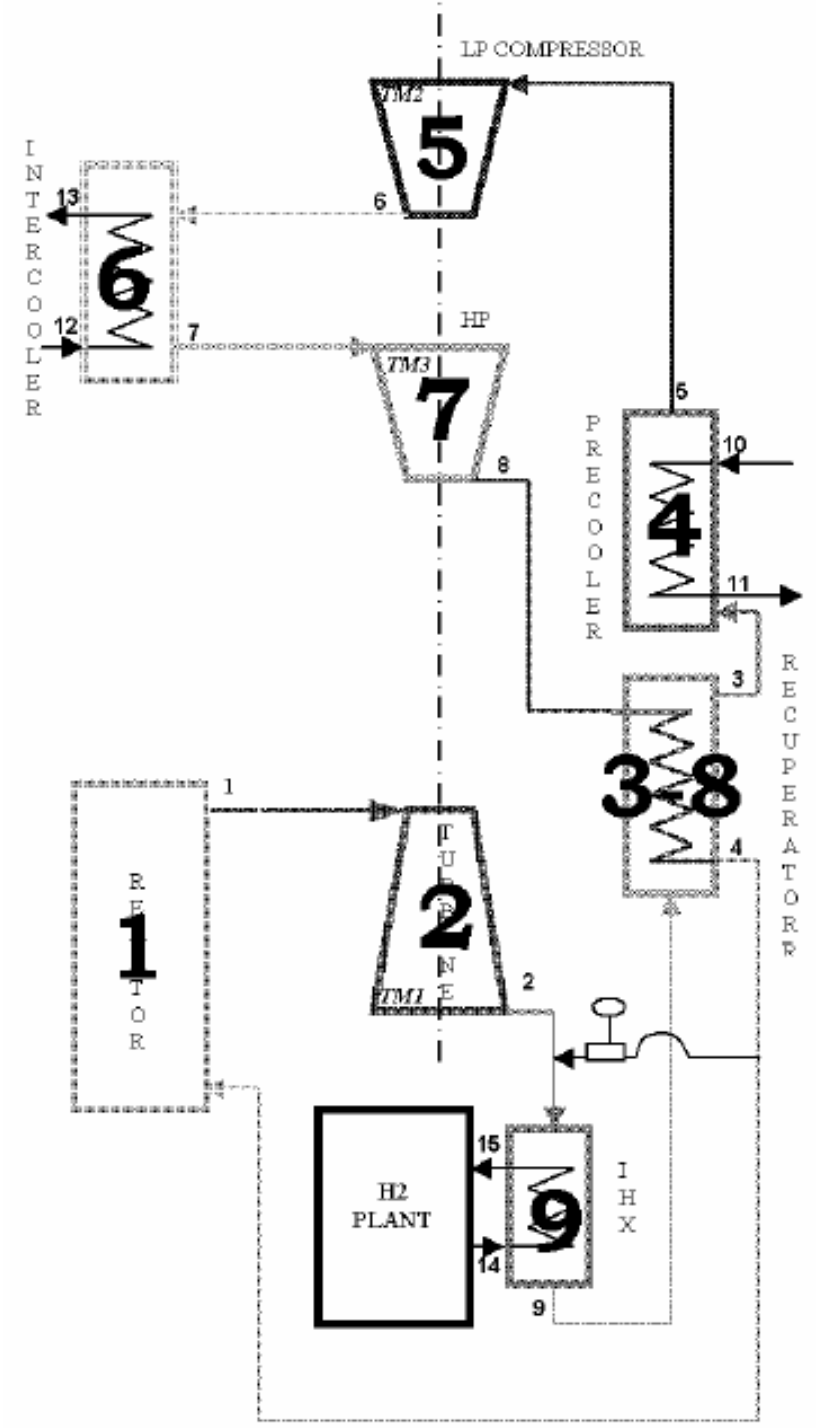

Figure 5.6. Schematic of a Direct-Cycle Series Heat-Load Arrangement Cu-Cl Cycle Plant [Vilim, 2005] (Illustration courtesy of the author) 


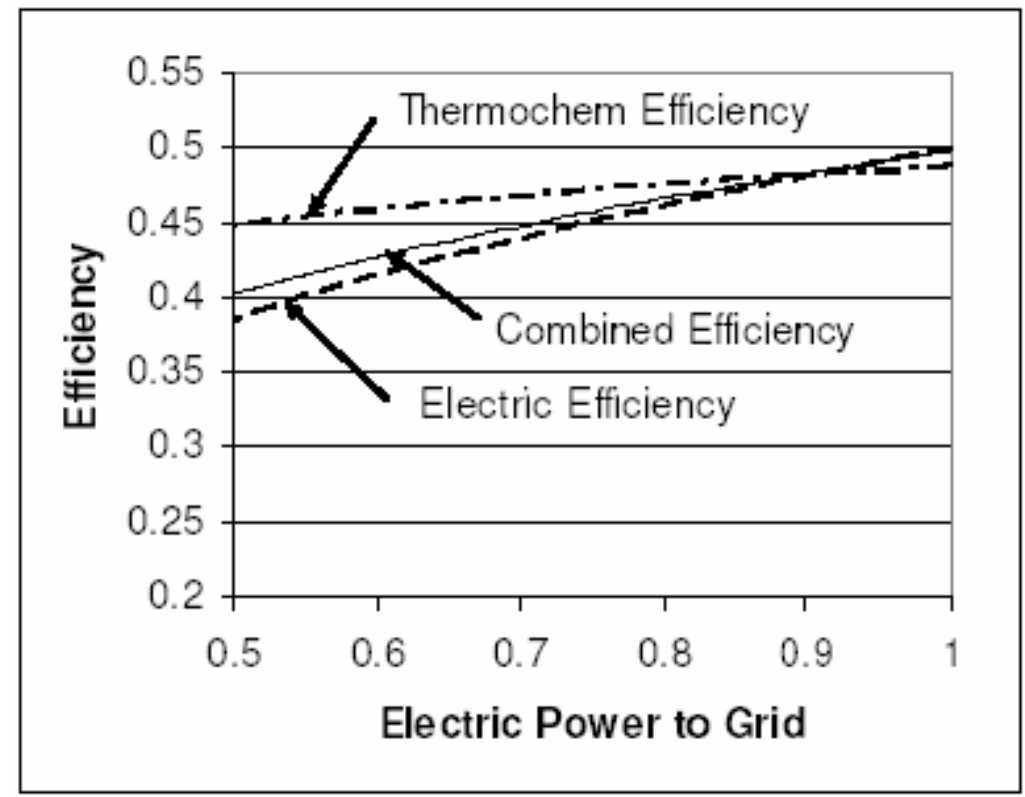

Figure 5.7. Full Hydrogen-Process Power / Partial Electric Power: Efficiencies for the Cu-Cl Process in the Configuration of Figure 5.6 [Vilim, 2005] (Illustration courtesy of the author)

The hybrid $\mathrm{Cu}-\mathrm{Cl}$ cycle with electricity production in excess of the need for the electrolyzer can address co-generation needs without any additional system requirements. It is possible to control the operation such that the rates of hydrogen and electricity production can be varied in order to follow electricity or hydrogen demands without changing the nuclear reactor thermal power.

Scale, time-frame, and markets to address: The scale-up of the $\mathrm{Cu}-\mathrm{Cl}$ process is more likely to be economical with an increase in the volume of the components, since the major components of the hydrogen production technology are based on thermochemical processes. The lower temperature requirement of this process is an advantage in enabling its development for a mid- to long-term application in hydrogen markets.

\subsection{Summary of the Implications for Nuclear Hydrogen Plant Configurations}

Table 5.1 summarizes the features, such as configuration options, co-generation possibility, range of efficiency, and the potential markets that those technologies may be considered for. Not all the possible reactor technologies are listed, but only representative ones for the temperature ranges and the coolant types. 
Table 5.1. Features of Nuclear Hydrogen Production Technologies

\begin{tabular}{|c|c|c|c|c|c|c|c|c|c|}
\hline \multirow[b]{2}{*}{$\begin{array}{l}\text { Hydrogen } \\
\text { production } \\
\text { process }\end{array}$} & \multicolumn{2}{|c|}{$\begin{array}{l}\text { Coupling to the } \\
\text { nuclear reactor as heat } \\
\text { source }\end{array}$} & \multicolumn{2}{|c|}{$\begin{array}{l}\text { Power conversion system: } \\
\text { - working fluid } \\
\text { - reactor interface }\end{array}$} & \multicolumn{2}{|c|}{ Energy mix provided } & \multirow[b]{2}{*}{\begin{tabular}{|l|} 
GHG \\
emissions \\
penalty
\end{tabular}} & \multirow[b]{2}{*}{$\begin{array}{l}\text { Market time } \\
\text { frame } \\
\text { observations }\end{array}$} & \multirow[b]{2}{*}{$\begin{array}{l}\text { Range of } \\
\text { hydrogen } \\
\text { efficiency, } \%\end{array}$} \\
\hline & Series & Parallel & Direct & Indirect & $\begin{array}{l}\text { Cogeneration } \\
\text { of hydrogen } \\
\text { and electricity }\end{array}$ & \begin{tabular}{|l|} 
Load \\
following \\
possibility
\end{tabular} & & & \\
\hline \multirow{7}{*}{$\begin{array}{l}\text { Low temperature } \\
\text { electrolysis, LTE }\end{array}$} & & LWR/ALWR & Steam & & + & + & - & \multirow{2}{*}{ All } & \multirow{2}{*}{$0.23-0.30$} \\
\hline & & CANDU/ACR & Steam & & + & + & - & & \\
\hline & & AGR & $\mathrm{scO} 2$ & $\begin{array}{l}\mathrm{SCO} 2 \\
\mathrm{He}\end{array}$ & $\begin{array}{l}+ \\
+\end{array}$ & $\begin{array}{l}+ \\
+\end{array}$ & $\begin{array}{l}- \\
-\end{array}$ & Mid- to long-term & $0.32-0.40$ \\
\hline & & SFR & & $\mathrm{SCO} 2$ & + & + & - & Mid- to long-term & $0.32-0.40$ \\
\hline & & & & & & & - & & \\
\hline & & MHR & $\mathrm{He}$ & $\begin{array}{l}\mathrm{He} \\
\mathrm{SCO} 2\end{array}$ & $\begin{array}{l}+ \\
+\end{array}$ & $\begin{array}{l}+ \\
+\end{array}$ & $\begin{array}{l}- \\
-\end{array}$ & Mid- to long-term & $0.33-0.43$ \\
\hline & & VHTR & $\mathrm{He}$ & $\begin{array}{l}\mathrm{He} \\
\mathrm{SCO} 2\end{array}$ & $\begin{array}{l}+ \\
+\end{array}$ & $\begin{array}{l}+ \\
+\end{array}$ & $\begin{array}{l}- \\
-\end{array}$ & Long-term & $0.33-0.43$ \\
\hline \multirow{2}{*}{$\begin{array}{l}\text { Steam-methane } \\
\text { reforming, SMR }\end{array}$} & MHR & & & & - & - & + & Mid- to long-term & 0.7 \\
\hline & VHTR & & & & - & - & + & Long-term & 0.8 \\
\hline \multirow{4}{*}{$\begin{array}{l}\text { High temperature } \\
\text { steam } \\
\text { electrolysis, } \\
\text { HTSE }\end{array}$} & AGR & AGR & SCO2 & $\begin{array}{l}\mathrm{SCO} 2 \\
\mathrm{He}\end{array}$ & $\begin{array}{l}+ \\
+\end{array}$ & $\begin{array}{l}++ \\
+\end{array}$ & - & $\begin{array}{l}\text { Mid- to long-term } \\
\text { Mid- to long-term }\end{array}$ & \multirow{4}{*}{$45-56$} \\
\hline & SFR & SFR & & $\begin{array}{l}\mathrm{SCO} 2 \\
\mathrm{He}\end{array}$ & $\begin{array}{l}+ \\
+\end{array}$ & $\begin{array}{l}+ \\
+\end{array}$ & $\begin{array}{l}- \\
-\end{array}$ & $\begin{array}{l}\text { Mid- to long-term } \\
\text { Mid- to long-term }\end{array}$ & \\
\hline & MHR & MHR & $\mathrm{He}$ & $\begin{array}{l}\mathrm{He} \\
\mathrm{SCO} 2\end{array}$ & $\begin{array}{l}+ \\
+\end{array}$ & $\begin{array}{l}+ \\
+\end{array}$ & - & $\begin{array}{l}\text { Mid- to long-term } \\
\text { Mid- to long-term }\end{array}$ & \\
\hline & VHTR & VHTR & $\mathrm{He}$ & $\begin{array}{l}\mathrm{He} \\
\mathrm{SCO} 2\end{array}$ & $\begin{array}{l}+ \\
+\end{array}$ & $\begin{array}{l}+ \\
+\end{array}$ & $\begin{array}{l}- \\
-\end{array}$ & Long-term & \\
\hline $\begin{array}{l}\text { Sulfur-lodine } \\
\text { cycle, SI }\end{array}$ & \begin{tabular}{|l|} 
MHR \\
VHTR
\end{tabular} & & & & - & * - & - & $\begin{array}{c}\begin{array}{c}\text { Mid- to long-term } \\
\text { Long-term }\end{array} \\
\end{array}$ & $33-56$ \\
\hline \multirow{2}{*}{$\begin{array}{l}\text { Hybrid sulfur } \\
\text { (Westinghouse } \\
\text { sulfur) process, } \\
\text { base case design } \\
\text { WSP-1 }\end{array}$} & MHR & MHR & $\mathrm{He}$ & $\begin{array}{l}\mathrm{He} \\
\mathrm{SCO} 2\end{array}$ & $\begin{array}{l}+ \\
+\end{array}$ & $\begin{array}{l}+ \\
+\end{array}$ & - & Mid- to long-term & \multirow{2}{*}{$45-54$} \\
\hline & VHTR & VHTR & $\mathrm{He}$ & $\begin{array}{l}\mathrm{He} \\
\mathrm{SCO} 2\end{array}$ & $\begin{array}{l}+ \\
+\end{array}$ & $\begin{array}{l}+ \\
+\end{array}$ & - & Long-term & \\
\hline \multirow{4}{*}{$\begin{array}{l}\text { WSP, } \\
\text { with electrolytic } \\
\text { decompostion of } \\
\text { SO3 at } \\
\text { intermediate } \\
\text { temperatures }\end{array}$} & AGR & AGR & $\mathrm{scO} 2$ & $\begin{array}{l}\mathrm{SCO} 2 \\
\mathrm{He}\end{array}$ & $\begin{array}{l}+ \\
+\end{array}$ & $\begin{array}{l}+ \\
+\end{array}$ & - & $\begin{array}{l}\text { Mid- to long-term } \\
\text { Mid- to long-term }\end{array}$ & \multirow{4}{*}{ Uncertain } \\
\hline & SFR & SFR & & $\begin{array}{l}\mathrm{SCO} 2 \\
\mathrm{He}\end{array}$ & $\begin{array}{l}+ \\
+\end{array}$ & $\begin{array}{l}+ \\
+\end{array}$ & $\begin{array}{l}- \\
-\end{array}$ & $\begin{array}{l}\text { Mid- to long-term } \\
\text { Mid- to long-term }\end{array}$ & \\
\hline & MHR & MHR & $\mathrm{He}$ & $\begin{array}{l}\mathrm{He} \\
\mathrm{SCO} 2\end{array}$ & $\begin{array}{l}+ \\
+\end{array}$ & $\begin{array}{l}+ \\
+\end{array}$ & - & $\begin{array}{l}\text { Mid- to long-term } \\
\text { Mid- to long-term }\end{array}$ & \\
\hline & VHTR & VHTR & $\mathrm{He}$ & $\begin{array}{l}\mathrm{He} \\
\mathrm{SCO} 2\end{array}$ & $\begin{array}{l}+ \\
+\end{array}$ & $\begin{array}{l}+ \\
+\end{array}$ & - & Long-term & \\
\hline \multirow{4}{*}{$\begin{array}{l}\text { Copper-Chlorine } \\
\text { cyle, } \mathrm{Cu}-\mathrm{Cl}\end{array}$} & AGR & AGR & $\mathrm{SCO} 2$ & $\begin{array}{l}\mathrm{SCO} 2 \\
\mathrm{He}\end{array}$ & $\begin{array}{l}+ \\
+\end{array}$ & $\begin{array}{l}+ \\
+\end{array}$ & - & $\begin{array}{l}\text { Mid- to long-term } \\
\text { Mid- to long-term }\end{array}$ & \multirow{4}{*}{$45-48$} \\
\hline & SFR & SFR & & $\begin{array}{l}\mathrm{SCO} 2 \\
\mathrm{He}\end{array}$ & $\begin{array}{l}+ \\
+\end{array}$ & $\begin{array}{l}+ \\
+\end{array}$ & - & $\begin{array}{l}\text { Mid- to long-term } \\
\text { Mid- to long-term }\end{array}$ & \\
\hline & MHR & MHR & $\mathrm{He}$ & $\begin{array}{l}\mathrm{He} \\
\mathrm{SCO} 2\end{array}$ & $\begin{array}{l}+ \\
+\end{array}$ & $\begin{array}{l}+ \\
+\end{array}$ & - & $\begin{array}{l}\text { Mid- to long-term } \\
\text { Mid- to long-term }\end{array}$ & \\
\hline & VHTR & VHTR & $\mathrm{He}$ & $\mid \begin{array}{l}\mathrm{He} \\
\mathrm{SCO} 2\end{array}$ & $\begin{array}{l}+ \\
+\end{array}$ & $\begin{array}{l}+ \\
+\end{array}$ & - & Long-term & \\
\hline
\end{tabular}

* Co-generation or load following of electricity and hydrogen demand is not possible without additional equipment and capital costs. 
July 31, 2005

\section{Observations on Hydrogen Markets and Nuclear Technologies}

Potential near- and long-term commercial hydrogen applications and their features in terms of expected location, size, and time-frame were identified in Chapter 3. In addition, the major technical challenges and main contributors to the cost of hydrogen production processes were assessed. Configuration options for nuclear hydrogen technologies were studied in terms of their operational features and the likely hydrogen markets that they can play a role in.

These assessments are summarized in Table 6.1. It is clear that nuclear hydrogen technologies, once developed, can contribute to the needs of current large-scale hydrogen consumers. As nuclear hydrogen becomes more readily available, the technologies can drive a transition to new and growing hydrogen markets. Nevertheless, there is much uncertainty over the future of the evolving hydrogen markets, such as demand size and growth. Similarly, the cost and performance of nuclear hydrogen technologies involve uncertainties related to the production process challenges, such as construction materials, product separations, and flow sheet designs. These uncertainties affect the estimates on the efficiency, durability, and cost of each technology. Therefore, these uncertainties affect predictions of the ultimate ability of nuclear hydrogen to compete with other production methods.

\subsection{Hydrogen Markets and Characteristics}

Major near- to mid-term hydrogen markets are expected to include oil refining, ammonia production, tar sand processing, and possibly coal liquefaction. Smaller industries, such as chemical/industry/food processing, will continue to require hydrogen, but will likely use smaller quantities at any given site. In the long term hydrogen could be used directly for transportation. Other markets are possible, such as oil shale processing, but will require further study to assess their potential.

Oil refining is a promising market, as demand is concentrated in a few regions and demand levels at individual locations match well with the capacities of a nuclear hydrogen production facility. There are about 26 locations where typical single-reactor nuclear hydrogen facilities (each at 60-70,000 tonnes/year) could supply the steady hydrogen demand. Since these refineries would be built with a limit on overall capacity, modularity in the nuclear hydrogen facility is not a key requirement. There are smaller, customized refineries and merchant hydrogen producers, however, that would require more flexibility in the nuclear hydrogen facility design. 
Configuration and Technology Implications of

Potential Nuclear Hydrogen System Applications

Argonne National Laboratory

July 31, 2005

Table 6.1. Summary of Hydrogen Markets and the Implications for Nuclear Technologies

\begin{tabular}{|c|c|c|c|c|c|c|}
\hline Hydrogen Market & $\begin{array}{c}2003 \text { U.S. } \\
\text { Market Size } \\
\text { (1000 tonnes H2) }\end{array}$ & Outlook & Market Characteristics & $\begin{array}{l}\text { Hydrogen Production } \\
\text { Implications }\end{array}$ & $\begin{array}{l}\text { Nuclear Technology } \\
\text { Implications }\end{array}$ & $\begin{array}{c}\text { Nuclear } \\
\text { Hydrogen } \\
\text { Technology } \\
\text { Options }\end{array}$ \\
\hline Oil Refining & 4,084 & Strong growth. & $\begin{array}{l}\text { Captive: } 25,500 \mathrm{t} / \mathrm{y} \text { median; } \\
\text { Merchant: } 1,090 \mathrm{t} / \mathrm{y} \text { median; } \\
\text { Large variation in capacity. }\end{array}$ & $\begin{array}{l}\text { Market suitable to dedicated } \\
\text { hydrogen production at local sites. }\end{array}$ & $\begin{array}{l}\text { Standardized nuclear reactor with } \\
\text { fixed-capacity hydrogen plant } \\
\text { customized for site; excess electricity } \\
\text { for site or grid sales. }\end{array}$ & $\begin{array}{l}\text { Thermochemical or } \\
\text { electrolysis with co- } \\
\text { generation. }\end{array}$ \\
\hline Ammonia Industry & 2,616 & $\begin{array}{l}\text { Market stalled by high } \\
\text { natural gas and } \\
\text { hydrogen costs. }\end{array}$ & $\begin{array}{l}\text { Captive: } 109,000 \text { t/y median; } \\
\text { Large variation in capacity. }\end{array}$ & $\begin{array}{l}\text { Market suitable to dedicated } \\
\text { hydrogen production at local sites. }\end{array}$ & $\begin{array}{l}\text { Standardized nuclear reactor with } \\
\text { fixed-capacity hydrogen plant } \\
\text { customized for site; excess electricity } \\
\text { for site or grid sales. }\end{array}$ & $\begin{array}{l}\text { Thermochemical or } \\
\text { electrolysis with co- } \\
\text { generation. }\end{array}$ \\
\hline Methanol Industry & 393 & $\begin{array}{l}\text { Market stalled by high } \\
\text { natural gas and } \\
\text { hydrogen costs and } \\
\text { MTBE phase-out. }\end{array}$ & $\begin{array}{l}\text { Captive: } 61,000 \text { t/y median; } \\
\text { Large variation in capacity. }\end{array}$ & $\begin{array}{l}\text { Market suitable to dedicated } \\
\text { hydrogen production at local sites, but } \\
\text { possibly shrinking market. }\end{array}$ & $\begin{array}{l}\text { Co-generation plant to switch to } \\
\text { electricity if methanol demand falls. }\end{array}$ & Electrolysis. \\
\hline $\begin{array}{l}\text { Other Industries } \\
\text { - Edible fats and oils } \\
\text { - Metals } \\
\text { - Electronics } \\
\text { - Other }\end{array}$ & $\begin{array}{l}22 \\
48 \\
14 \\
11\end{array}$ & Modest growth. & Small single-site demands. & $\begin{array}{l}\text { Market suitable to scaleable regional } \\
\text { production centers. }\end{array}$ & $\begin{array}{l}\text { Dedicated or co-generation plant that } \\
\text { can be scaled for market growth. }\end{array}$ & Electrolysis. \\
\hline Tar Sands & $\begin{array}{c}515 \text { in Alberta in } \\
2004)\end{array}$ & $\begin{array}{l}\text { Strong growth } \\
\text { (Canada). }\end{array}$ & Captive: $46,300 \mathrm{t} / \mathrm{yr}$ median. & $\begin{array}{l}\text { Market suitable to dedicated } \\
\text { hydrogen production at local sites. }\end{array}$ & $\begin{array}{l}\text { Standardized nuclear reactor with } \\
\text { fixed-capacity hydrogen plant } \\
\text { customized for site; heat for process } \\
\text { steam. }\end{array}$ & $\begin{array}{l}\text { Thermochemical or } \\
\text { electrolysis with } \\
\text { process heat } \\
\text { generation. }\end{array}$ \\
\hline $\begin{array}{l}\text { Coal Liquefaction and } \\
\text { Shale Oil }\end{array}$ & $\begin{array}{l}\text { Medium-to-long } \\
\text { term }\end{array}$ & Potentially significant. & $\begin{array}{l}\text { Facility size would need to be } \\
370,000 \mathrm{t} / \mathrm{y} \text { for } 100,000 \text { bpd } \\
\text { synthetic crude output. }\end{array}$ & $\begin{array}{l}\text { Market suitable to dedicated } \\
\text { hydrogen production at local sites. }\end{array}$ & $\begin{array}{l}\text { Standardized nuclear reactor with } \\
\text { fixed-capacity hydrogen plant } \\
\text { customized for site; excess electricity } \\
\text { for site or grid sales. }\end{array}$ & $\begin{array}{l}\text { Thermochemical or } \\
\text { electrolysis with co- } \\
\text { generation. }\end{array}$ \\
\hline Peak Electricity & $\begin{array}{l}\text { Medium-to-long } \\
\text { term }\end{array}$ & Potentially significant. & $\begin{array}{l}\text { Potentially equal to } 20 \% \text { of } \\
\text { electricity market. }\end{array}$ & $\begin{array}{l}\text { Market suitable to dedicated } \\
\text { hydrogen production at local sites. }\end{array}$ & $\begin{array}{l}\text { Standardized nuclear reactor with } \\
\text { fixed-capacity hydrogen/oxygen plant } \\
\text { customized for site. }\end{array}$ & $\begin{array}{l}\text { Thermochemical or } \\
\text { electrolysis. }\end{array}$ \\
\hline Transportation & Long term & Potentially significant. & $\begin{array}{l}\text { Centralized or distributed } \\
\text { hydrogen production are } \\
\text { possible. }\end{array}$ & $\begin{array}{l}\text { Depending on market scenario, may } \\
\text { be suitable to scaleable regional } \\
\text { production centers. }\end{array}$ & $\begin{array}{l}\text { Dedicated or co-generation plant that } \\
\text { can be scaled for market growth. }\end{array}$ & Electrolysis. \\
\hline
\end{tabular}


Similarly, the ammonia industry with its large producers concentrated in a few locations lends itself to larger localized production technologies. The median hydrogen consumption of U.S. ammonia plants is 109,000 t/yr. There is wide variation about this average, though, as is the case for oil refining and the methanol industry. In these cases there would be an advantage to using a standardized nuclear power plant with a customized, but fixed, hydrogen production capacity for each site. Co-generation of hydrogen and electricity can allow that to happen. Excess heat not needed for hydrogen production can be used for electricity generation as a separate marketable product. The flexibility to shift from electricity to hydrogen production would allow for variable or growing hydrogen demands. Such a need would favor hydrogen facilities that could be readily scaled to different capacities or that are modular in design.

High-temperature electrolysis and the hybrid thermochemical cycles require electricity production, so they naturally lend themselves to co-generation plants. Pure thermochemical cycles do not, in themselves, require co-generation, but the nuclear units could be designed that way. In either case, as discussed in Chapter 5, there are choices to be made in the configuration of the power conversion systems in the nuclear plants. The parallel and indirect heating options are subject to increased system energy losses and increased equipment count and cost, but offer the potential for greater flexibility with respect to system isolation and control of temperature and the hydrogen-electricity mix. In contrast, the series and direct options can provide significant improvements in system efficiency and equipment cost, but the feasible control of co-generation product (electricity, hydrogen, and process heat) requires more intricate design.

All the candidate technologies, including high-temperature steam electrolysis and the hightemperature thermochemical water-splitting cycles, have opportunities for improvement in efficiency. Nevertheless, efficiency improvements may come at the price of higher complexity and capital cost. Some indications to these margins are presented in this report for lowtemperature water electrolysis (LTE), high-temperature steam electrolysis (HTSE), the hightemperature sulfur-iodine cycle (SI), the hybrid sulfur cycle (or the Westinghouse Sulfur Process) (WSP), and the $\mathrm{Cu}-\mathrm{Cl}$ hybrid cycle.

Other factors that can influence the technology choice are the flexibility in the siting of the plant, safety of the plant, and the size of the plant (e.g., small-scale distributed generation versus largescale centralized generation of hydrogen). The siting and size of the plant configurations for several options are discussed in this report. The safety implications of the plant configurations require more analysis to provide conclusions about their viability, and, thus, are not covered at this stage of the study. 


\subsection{Observations on Nuclear Hydrogen Production Options}

Several observations can be made for the various nuclear hydrogen production options considered in this study:

\section{High-Temperature Thermochemical and Hybrid Processes}

High-temperature thermochemical or hybrid processes, such as the sulfur-iodine and hybrid sulfur cycles, currently bear large uncertainties in durable and efficient process design. In addition, the commercialization of a very high temperature nuclear reactor to support these processes can take a long time. Scaling up the output of these processes simply by larger volumes (rather than by modular increments) can be a benefit in terms of the overall economics of the technology. Making modular, small-scale SI plants may not be beneficial in terms of the product cost. By itself, an SI plant does not necessarily cogenerate hydrogen and electricity, but if needed the overall plant design can include an electricity production system. The interface of the nuclear reactor with the SI process and with the power conversion system of a co-generative plant would use parallel heat loads. An appropriate design of the control system can allow changing the output rates of hydrogen and electricity when needed for load-following, without disturbing the reactor power level. In contrast the WSP hybrid cycle with electricity production in excess of the need for the $\mathrm{SO}_{2}$ electrolyzer can address co-generation needs without any additional system requirements.

\section{Low-Temperature Water Electrolysis}

Low-temperature water electrolysis can be supported by any type of nuclear plant since the process requires no heat input. Both distributed small-scale and centralized large-scale hydrogen production using LTE is possible. Since electrolysis is a commercially available technology, this process can be evaluated in both near-term and long-term markets. For instance, LTE is being considered for coupling to CANDU reactors for providing hydrogen in converting the Canadian tar sands to liquid fuels. LTE is technically viable in the near term, but its economics are questionable. LTE would benefit from the development of hightemperature reactor designs that increase the efficiency of electricity production.

\section{High-Temperature Steam Electrolysis}

High-temperature steam electrolysis can be supported by intermediate- to high-temperature nuclear reactors. The interface of the HTSE process and the nuclear reactor can be based on either a parallel or a series heat-load configuration. The advantage of parallel heat loads is a more straight-forward way of controlling the hydrogen and electricity production rates. The major advantages of the series heat load configuration are the elimination of another high temperature heat exchanger at the exit of the reactor and the use of a lower pressure boiler for the feedwater. Upon the design of a new control system, the series heat-load configuration can be a more advantageous configuration for the HTSE process, allowing 
adjustment of the product output rates without altering the reactor power and a higher efficiency. Based on the ongoing promising research in solid oxide fuel cell development, solid-oxide electrolyzers operating at intermediate to high temperatures $\left(650-800^{\circ} \mathrm{C}\right)$ could become available for the near to mid-term hydrogen markets. The commercialization of this technology depends on when the appropriate advanced nuclear reactors can be built in the US., which may take place in the mid-to-long term. Due to the modularity of the HTSE units, the technology can be implemented as a small-scale modular or a large-scale centralized facility. It can inherently operate as a co-generation plant, balancing hydrogen and excess electricity production. The hydrogen capacity can be increased by additional modules, while decreasing the excess electricity production rate, to address the demand of a growing localized market.

\section{The Lower-Temperature Copper-Chloride Hybrid Cycle}

The $530^{\circ} \mathrm{C} \mathrm{Cu}-\mathrm{Cl}$ cycle can be supported by intermediate- to high-temperature reactors. Vilim, 2005, proposed the potentially lowest cost configuration for this process through a Modular Helium Reactor and a direct cycle He gas turbine in a series heat-load configuration with a $\mathrm{Cu}-\mathrm{Cl}$ process that retrieves heat from the exit stream of the $\mathrm{He}$ turbine. This configuration allows for co-generation and load-following flexibility. The scale-up of the process is more likely to be economical with an increase in the volume of the components, since the major components of the hydrogen production technology are based on thermochemical processes. The lower temperature requirement of this process is an advantage in enabling its development for a mid- to long-term application in hydrogen markets.

\subsection{Next Steps and Goals for the Nuclear Hydrogen System Studies}

In FY 2006, the nuclear hydrogen system study at ANL will investigate the likelihood of success for nuclear hydrogen technologies in evolving markets. In this effort the overall economics of nuclear hydrogen will be further studied. Three questions will be addressed:

1. Are there improvements in key technical/cost parameters and components that future research should focus on because of their strong influence on market viability?

2. What are the potential tradeoffs in performance improvements and increased capital costs due to increased system complexity?

3. How will nuclear hydrogen evolve under a number of different futures (low/high hydrogen market demand, low/high natural gas prices, etc.)?

The answers for the questions (1) and (2) will be coordinated with the process designers for the nuclear hydrogen systems. The results of this work can provide feedback for the cost and efficiency of each technology configuration required to be viable in a given market. Consequently, the process designers should judge whether or how those threshold requirements for the market viability of the process can be achieved both from technical and economic aspects. 
The market analysis will be integrated into the larger DOE-EE study on hydrogen infrastructure and markets. The ultimate objective of the DOE-EE project is to use agent-based modeling tools to indicate the role of different technologies in a successful transition to a hydrogen production and delivery infrastructure. Also, for validation and verification purposes, under the DOE-EE project a conventional hydrogen infrastructure analysis framework already developed at ANL (ENPEP-BALANCE) will be used to develop a baseline scenario for hydrogen market penetration of competing technologies.

This FY 2006 DOE-NE activity will leverage the DOE-EE project activities, which in FY06 will concentrate on using ENPEP-BALANCE to develop baseline hydrogen market forecasts. The DOE-EE project has no inherent focus on nuclear technologies. Under the DOE-NE work package, Argonne will develop the nuclear production components to be included in those baseline simulations. Argonne will develop those components/modules, develop consistent sets of input data on nuclear hydrogen production technologies (partly based on the FY 2005 nuclear system studies), and run additional nuclear hydrogen production market simulations. In this analysis, ANL will coordinate its activities with SNL for input from their cost-framework study for the nuclear hydrogen technologies, and with ORNL for their study of new markets. The ANL model simulations will be designed to examine potential thresholds for key parameters (i.e., capital cost, efficiency, and size) of nuclear hydrogen technologies and identify near- and longterm market potential for different technology configurations. In FY 2007 and FY 2008, the DOE-NE activities will be expanded to leverage the agent-based simulation tool developed with DOE-EE funding. The agent-based tool will address uncertainties and risks involved in investment decisions on both production/delivery as well as on the hydrogen consumer side (e.g., vehicle manufacturers).

This work will ultimately highlight the advantages and disadvantages of alternative integrated plant designs in existing and emerging hydrogen markets. The extended project will address how nuclear hydrogen will be able to compete against rival technologies in an open market, and what key drivers will influence not only the economics, but also the market uptake of the technology. It will provide the basis for informed decisions regarding resources and policies to promote the further development of specific nuclear hydrogen production technologies in a way that will improve the likelihood that nuclear hydrogen will be competitive in a growing hydrogen economy. 
Potential Nuclear Hydrogen System Applications

Argonne National Laboratory

July 31,2005

\section{References}

AirProducts, Company Website, www.airproducts.com, 2004.

Alberta Chamber of Resources, "Oil Sands Technology Roadmap, Unlocking the Potential," Edmonton, Alberta, January 2004.

Alberta Department of Energy, “Alberta’s Oil Sands,” December 2004.

Alberta Energy and Utility Board (EUB), "North American Oil Reserves,” 2004.

Besenbruch, G. E., Brown, L. C., Funk, J. F., Showalter, S. K., "High Efficiency Generation of Hydrogen Fuels Using Nuclear Power," Organization for Economic Cooperation and Development, The First Information Exchange Meeting on Nuclear Production of Hydrogen, Paris-France, October 2000.

Brown, L. C., Besenbruch, G. E., Lentsch, R. D., Schultz, K. R., Funk, J. F., Pickard, P. S., Marshall, A. C., Showalter S. K., "High Efficiency Generation of Hydrogen Fuels Using Nuclear Power” General Atomics Technical Report GA-A24285, June 2003.

Bunger, J. W., Crawford, P. M., and Johnson, H. R., "Is Oil Shale America's Answer to the Peak Oil Challenge?” Oil and Gas Journal, August 9, 2004.

Business Communication Company, Press Release on Projected U.S. Hydrogen Demand, February 3, 2005.

Canada Energy Center (CEC), “How are Oil Sands and Heavy Oil Produced?” Calgary, Canada, July 2005.

Canadian Association of Petroleum Producers (CAPP), "Canadian Crude Oil Production and Supply Forecast 2005-2015,” July 2005.

CEA, Presentation on the Activities of CEA on Hydrogen Production Technologies, Presented at ANL, February 2005.

Colson-Inam, S., “Solid Oxide Fuel Cells: Ready to Market?” Fuel Cell Today, 07 January 2004.

Doctor, R. D., Matonis, D. T., Wade, D. C., "Hydrogen Generation Using a Calcium-Bromine Thermochemical Water-Splitting Cycle," Proceedings of Nuclear Production of Hydrogen Second Information Exchange Meeting, Argonne, IL, October 2003.

Dostal, V., Driscoll, M. J., Hejzlar, P., Todreas, N. E., $\mathrm{CO}_{2}$ Brayton Cycle Design and Optimization, MIT Report: MIT-ANP-TR-09, November 2002. 
Potential Nuclear Hydrogen System Applications

Argonne National Laboratory

July 31,2005

Energy Information Administration (EIA), Annual Energy Outlook 2004 (AEO2004), U.S. Department of Energy, Energy Information Administration (EIA), DOE/EIA-0383(2004), January, Washington, D.C., 2004, http://www.eia.doe.gov/oiaf/aeo/index.html.

Energy Information Administration (EIA), Existing Electric Generating Units in the United States, 2003, U.S. Department of Energy, Energy Information Administration (EIA), Washington, D.C., 2003, http://www.eia.doe.gov/cneaf/electricity/page/capacity/newunits2003.xls.

Energy Information Administration (EIA), “U.S. Coal Reserves: 1997 Update,” DOE/EIA0529(97), Washington, DC., February 1999.

Forsberg, C. W., "Hydrogen Production Using the Advanced High-Temperature Reactor," Proceedings of the 14th Annual U.S. Hydrogen Meeting, Washington, D.C., March 2003.

GenIV Roadmap, http://gif.inel.gov/roadmap/system-evaluation-tools.shtml.

Goldstein S., Borgard, J. M., Vitart, X., "Upper Bound and Best Estimate of the Efficiency of the Iodine Sulfur Cycle,” Int. J. of Hydrogen Energy, 2005 (30) 619-626.

Gorensek, M. B., Summers, W. A., Buckner, M. R., and Qureshi, Z. H., "Conceptual Design for a Hybrid Sulfur Thermochemical Hydrogen Production Process," Transactions of the American Nuclear Society, 92, p.101, 2005.

Hori, M., "Synergistic Production of Hydrogen By Fossil Fuels and Nuclear Energy," Presented at Global 2003, New Orleans, Louisiana, November 2003.

Innovation Group (IG), Chemical Profiles - Methanol, available on company website, Dec., 2002.

Innovation Group (IG), Chemical Profiles - Hydrogen, available on company website, Feb., 2003.

International Atomic Energy Agency (IAEA), "Hydrogen as an Energy Carrier and its Production by Nuclear Power,” IAEA Report -TECDOC-1085, 1999.

Jeong, Y. H., Kazimi, M. S., Hohnholt, K. J., Yildiz, B., "Optimization of the Hybrid Sulfur Cycle for Hydrogen Generation,” MIT-NES-TR-004, MIT, Department of Nuclear Engineering, May 2005.

LaBar, M. P., "The Gas-Turbine Modular Helium Reactor: A Promising Option for Near-Term Deployment," Proceedings of International Congress on Advanced Nuclear Power Plants, Hollywood, Florida, June 2002. 
Potential Nuclear Hydrogen System Applications

Argonne National Laboratory

July 31,2005

Lahoda, E. J., "Research Opportunities for the Westinghouse Sulfur Process (Hybrid Sulfur Process-HyS)," Proceedings of the MIT Symposium on The Next Generation Nuclear Plant Goals and Challenges, February 2005.

Lahoda, E. J., "The Westinghouse Sulfur Process for Hydrogen Production," Proceedings of the Symposium on Nuclear Energy and the Hydrogen Economy, MIT, Cambridge, MA, USA, September 23-24, 2003.

Larsen, R., Wang, M., Wu, Y., Vyas, A., Santini, D., and Mintz, M., "Might Canadian Oil Sands Promote Hydrogen Production for Transportation? Greenhouse Gas Emission Implications of Oil Sands Recovery and Upgrading," Paper submitted for publication in World Resources Review, Argonne National Laboratory, December 2004.

Lewis, M. A., Serban, M., "Hydrogen Production at $<550^{\circ} \mathrm{C}$ using a Thermochemical Cycle," Proceedings of Nuclear Production of Hydrogen - Second Information Exchange Meeting, Argonne, IL, October 2003.

Lutz, A. E., Bradshaw, R. W., Keller, J. O., Witmer, D. E., "Thermodynamic Analysis of Hydrogen Production by Steam Reforming," Int. J. of Hydrogen Energy, 2003;28:159-167, (2003a).

Lutz, A. E., Bradshaw, R. W., Keller, J. O., Witmer, D., E., "Thermodynamic Analysis of Hydrogen Production by Steam Reforming," Int. J. of Hydrogen Energy, 2003;28:159-167, (2003b).

Lynch, M., "Unconventional Oil: Filling in the Gap or Flooding the Market?" Presentation at the DOE NEMS Conference, Washington, D.C., April 2005.

Manor, R., "Canada Oil Sands Favor Midwest,” Chicago Tribune, March 13, 2005.

MetalPrices, http://www.metalprices.com/subscription/metals/stainless_product/product.asp, 2005.

NAE/NRC, "The Hydrogen Economy: Opportunities, Costs, Barriers, and R\&D Needs," National Research Council and National Academy of Engineering of the National Academies, 2004,

Natural Resources Canada, "Canadian Natural Gas - Review of 2003 and Outlook to 2020," December 2004.

Nomura, M., Kasahara, S., Okuda, H., Nakao, S., "Evaluation of the IS Process Featuring Membrane Techniques by Total Thermal Efficiency," Int. J. of Hydrogen Energy, Article In Press, Available Online 20 December 2004. 
Potential Nuclear Hydrogen System Applications

Argonne National Laboratory

July 31,2005

Parrish, A., "Fuel Cell Report to the Congress: Fuel Cell Future not Certain," Fuel Cell Today, 13 March 2003.

Petri, M. C., Conzelmann, G., Yacout, A. M., Forsberg, C., and Pickard, P., "Nuclear Hydrogen System Configuration Options and Method Assessment," NHI Work Packages CH12T122, OR14T121, AL14T112, Sept. 15, 2004.

SenterNovem, 2002, World Methanol Plants (through December 2001), available at company website.

Shell, 2004, "Shell Hydrogen Unveils Concept to Develop Hydrogen Market," Press Release from Shell Hydrogen, July 7, 2004.

Shell, 2004b, "Moving Research to Reality: The Next Stretch - Mini Networks," Presentation of Jeremy Bentham, Yokohama, Japan, July 1, 2004.

Shimizu, S., Nakajima, H., Kubo, Shinji, K., "A Study of the Thermochemical IS Process," Organization for Economic Cooperation and Development, The First Information Exchange Meeting on Nuclear Production of Hydrogen, Paris, France, October 2000.

Shiozawa, S., Ogawa, M., Iganaki, Y., "Present Status of JAERI's R\&D on Hydrogen Production Systems in HTGR," Organization for Economic Cooperation and Development, The First Information Exchange Meeting on Nuclear Production of Hydrogen, Paris, France, October 2000 .

Simbeck, D.R., Chang, E., "Hydrogen Supply: Cost Estimate for Hydrogen Pathways - Scoping Analysis," Technical Report NREL/SR-540-32525, 2002.

Stoots, C. M., O’Brien, J. E., McKellar, M. G., Hawkes, G. L., and Herring, S. J., "Engineering Report to DOE on the Process Model for High-Temperature Electrolysis System Performance Evaluation," May 2005.

Sukurai, E., Bilgen, E., Tsutsumi, A., Yoshida, K., "Adiabatic UT-3 Thermochemical Process for Hydrogen Production,” Int. J. Hydrogen Energy, 21 (10) : 865-870, 1996.

Summers, W. A., et al., "Centralized Hydrogen Production from Nuclear Power: Infrastructure Analysis and Test-Case Design Study, Phase A Infrastructure Analysis," NERI Project 02-0160, WSRC-TR-2004-00318, July 2004.

Tadokoro, Y., Kajiyama, T., Yamaguchi, N., Sakai, H., Kameyama, H., Yoshida, K., "Technical Evaluation of UT-3 Thermochemical Hydrogen Production Process for an Industrial Scale Plant,” Int. J. Hydrogen Energy, 22 (1) : 49-56, 1997.

Teo, E. D., Brandon, N. P., Vos, E, Kramer, G. J., “A Critical Pathway Energy Efficiency Analysis of the Thermochemical UT-3 Cycle," Int. J. Hydrogen Energy 30 : 559 - 564, 2005 
Vilim, R. B., and Lewis, M. A., "The Gas Reactor and Low Temperature Thermochemical Cycles for Hydrogen Production," Proceedings of ICAPP '05, Seoul, Korea, May 15-19, 2005.

Vilim, R.B., "Commodity Inventories and Equipment Sizes for a Low Temperature Nuclear Chemical Plant for Production of Hydrogen," Proceedings of the AIChE Spring Meeting, 2004.

Wade, D. C., Doctor, R. D., Sienicki, J. J., Matonis, D. T., and Faibish, R. S., "STAR-H2: A Long-Refueling Interval Battery Reactor for Hydrogen and Water Supply to Cities of Developing Countries," presented at the $5^{\text {th }}$ International Conference on Nuclear Option in Countries with Small and Medium Electricity Grids, Dubrovnik, Croatia, May 16-20, 2004.

Williams, R. H., and Larson, E. D., "A Comparison of Direct and Indirect Liquefaction Technologies for Making Fluid Fuels from Coal," Energy for Sustainable Development, 7 (4) : 103-29, Dec. 2003.

Westinghouse Savannah River Company (WSRC), "Centralized Hydrogen Production from Nuclear Power: Infrastructure Analysis and Test Case Design Study,” July 2004.

World Energy Council (WEC), "Survey of Energy Resources,” 2004.

World Nuclear Association, Weekly Digest, August, 20, London, UK, 2004.

Yildiz, B., Hohnholt, K. J., Kazimi, M. S., "H${ }_{2}$ Production Using High Temperature Steam Electrolysis Supported by Advanced Gas Reactors with Supercritical $\mathrm{CO}_{2}$ Cycles," MIT-NESTR-002, MIT, Department of Nuclear Engineering, December 2004.

Yildiz, B., Kazimi, M. S., "Nuclear Energy Options for Hydrogen and Hydrogen-Based Liquid Fuel Production," MIT Report: MIT-NES-TR-001, September 2003.

Yosihida, K., Kameyama, H., Aochi, T., Noube, M., Aihara M., Amir, R., Kondo, H., Sato, T., Tadokoro, Y., Yamaguchi, T., Sakai, N., "A Simulation Study of the UT-3 Thermochemical Hydrogen Production Process," Int. J. of Hydrogen Energy, 1990;15:171-178. 
Potential Nuclear Hydrogen System Applications

Appendix A

July 31,2005

\title{
Appendix A
}

\section{Alternative Hydrogen Markets: Implications for Nuclear Hydrogen Production Technologies}

\author{
Charles W. Forsberg \\ Oak Ridge National Laboratory* \\ P.O. Box 2008 \\ Oak Ridge, TN 37831-6165 \\ Tel: (865) 574-6783 \\ Fax: (865) 574-0382 \\ E-mail: forsbergcw@ornl.gov
}

Manuscript Date: July 31, 2005

The submitted manuscript has been authored by a contractor of the U.S. Government under contract DE-AC05-00OR22725. Accordingly, the U.S. Government retains a nonexclusive, royalty-free license to publish or reproduce the published form of this contribution, or allow others to do so, for U.S. Government purposes.

\footnotetext{
*Oak Ridge National Laboratory, managed by UT-Battelle, LLC, for the U.S. Department of Energy
} under contract DE-AC05-00OR22725. 


\title{
Alternative Hydrogen Markets: Implications for Nuclear Hydrogen Production Technologies
}

\author{
Charles Forsberg, ORNL
}

July 31,2005

\begin{abstract}
Summary
There are many possible hydrogen futures. This appendix provides additional thought about (1) alternative hydrogen futures and their associated markets, including future markets that have not received as much attention or are considered less likely and (2) smaller markets that could be significant-such as steel production and fuel for aircraft.

Different methods for hydrogen production have different characteristics. The characteristics of hydrogen generated by using nuclear energy (nuclear hydrogen) include (1) economics that strongly favor largescale centralized production of hydrogen, (2) the co-production of oxygen as a byproduct, and (3) availability of low-cost heat. In contrast, hydrogen production technologies that use fossil fuels generally do not produce oxygen as a byproduct or low-cost heat. Hydrogen production technologies that use renewable energy generally involve smaller scale of production facilities and the production facilities are dispersed.
\end{abstract}

Each existing and future market for hydrogen has different characteristics that will favor particular methods of hydrogen production--even if each technology produces hydrogen at exactly the same production costs. For example, if there is a large centralized demand for hydrogen, nuclear hydrogen can provide the hydrogen to the customer without the need for an expensive infrastructure of pipelines for hydrogen delivery. In contrast, dispersed hydrogen production by renewable energy sources would require a pipeline collection system for hydrogen delivery. If the demand for hydrogen is dispersed, smaller-scale hydrogen production technologies would have a potential economic advantage by reducing the size of the pipeline distribution system. As a consequence, it is important to understand potential hydrogen markets when developing a specific hydrogen production technology. Some markets are better matched to specific hydrogen production technologies. This appendix describes various hydrogen markets to assist in the development of nuclear hydrogen production techniques by addressing three issues.

- What are the likely first markets for nuclear hydrogen? Markets should be identified to determine potential partners for development of nuclear hydrogen production technologies. Because the characteristics of nuclear hydrogen production are different than other methods of hydrogen production (large scale co-production of hydrogen and oxygen), there may also be new markets that do not exist for other hydrogen production technologies.

- What are the requirements for nuclear hydrogen? Different customers have different requirements in terms of daily demand (steady state or variable), hydrogen purity, delivery pressures, use of the oxygen byproduct, and other technical parameters. This can impact the choice of the preferred nuclear hydrogen production technology (thermochemical, hybrid, etc.) that should be developed. Requirements are the starting point for any plant design. 
- Are there user technologies that should be developed to maximize the incentives for nuclear hydrogen? For example, nuclear hydrogen may be used to provide hydrogen for upgrading of heavy oils, oil shale, tar sands, or coal into transport fuels (gasoline, diesel, and jet fuel). However, the production of hydrogen using nuclear energy yields byproduct oxygen while traditional hydrogen production technologies do not produce byproduct oxygen. The availability of low-cost oxygen may allow major improvements in the technologies and economics of converting heavier hydrocarbon feedstocks to transport fuels. In this case, the economic viability of nuclear hydrogen in this market may depend upon both improvements in nuclear hydrogen production technologies and changes in refinery technologies to take advantage of the low-cost co-product oxygen.

Two major potential markets were identified for nuclear hydrogen where the characteristics of nuclear hydrogen production may give it a competitive edge over alternative hydrogen production technologies. The largest hydrogen market is for the production of transport fuels. This is a highly centralized market that matches the centralized production characteristic of nuclear hydrogen. There is a near-term and a long-term hydrogen market. The existing near-term market for hydrogen is for conversion of heavy oil, tar sands, and other heavy hydrocarbons into liquid transport fuels (gasoline, diesel, and jet fuel). Large quantities of hydrogen are required by these facilities in the conversion processes.

Most existing refineries and other fuel production facilities do not use significant quantities of oxygen in fuels production. However, if nuclear hydrogen is developed and used, low-cost oxygen becomes available. The coproduction and use of hydrogen and oxygen could (1) significantly improve refinery economics, (2) reduce releases of greenhouse gases from these fuel production facilities, and (3) increase liquid transport fuel yields per unit of heavy oil, tar sands, oil shale, or coal. In this context, if there are any restrictions on greenhouse gas emissions, there are potential advantages for using nuclear hydrogen with the coproduced oxygen to minimize carbon dioxide releases from the refinery.

The longer-term hydrogen transport market may use hydrogen for production of non-greenhouse liquid fuels or hydrogen for direct use as a transport fuel. These longer-term markets require hydrogen but probably not oxygen. They have their own set of constraints.

The other potentially large nuclear hydrogen market is for production of peak electricity. For this market, hydrogen and oxygen are produced and stored. During times of peak electricity demand, the hydrogen and oxygen are converted to electricity using fuel cells or other technologies. There are a variety of other markets (steel production, commercial, etc.); but, these markets are smaller and do not create the strong incentives for the development of nuclear hydrogen production technologies.

Two user technologies were identified that require analysis and possible development to assist development of nuclear hydrogen markets. Both have the characteristic that they can partly or fully use the byproduct oxygen from centralized nuclear hydrogen production —one of the unique characteristics of nuclear hydrogen.

- Liquid transport fuel production using hydrogen and oxygen. There are many ways to convert heavy feedstocks (heavy oil, tar sands, shale oil, and coal) into liquid transport fuels. Most require hydrogen. Some of the technologies use hydrogen and oxygen. Historically, hydrogen has been produced by steam reforming of fossil fuels - a technology that does not produce oxygen. If oxygen was required, separate processes were needed to extract oxygen from air. If nuclear 
hydrogen becomes available, oxygen is the coproduct with the secondary option of the nuclear reactor also providing low-cost heat. Analysis is required to determine the economic advantages of using nuclear hydrogen and taking advantage of the available low-cost coproduced oxygen for conversion of heavy feedstocks to transport fuels. Oxygen can be used to convert carbon residues from thermal crackers and other sources into carbon monoxide. The carbon monoxide is combined with hydrogen to produce syngas that is converted into liquid fuels. Only a fraction of the available oxygen would be used. Any such an analysis should consider two cases: liquid transport fuels production with no constraints on carbon dioxide releases and liquid transport fuels production where there are constraints on carbon dioxide releases. If carbon dioxide releases are constrained, the availability of hydrogen, oxygen, and heat may enable conversion of all carbon in a feedstock to liquid fuels with no carbon dioxide releases from the fuel production facility.

- Very large scale hydrogen and oxygen storage. Compared to other hydrogen production technologies, nuclear hydrogen systems will produce very large quantities of hydrogen and oxygen at centralized sites. There are strong economic incentives to develop large-scale low-cost storage systems for these two gases to couple centralized plant output to demand. There is limited experience in storing hydrogen on a very large scale. There is no experience in very large scale storage of oxygen. The status of these technologies needs to be fully understood and may require added development. 


\section{Introduction}

Each hydrogen production technology has its own specific characteristics. The characteristics of hydrogen production using nuclear energy (nuclear hydrogen) have three defining characteristics:

- Large scale. The technical characteristics of nuclear energy plants make small scale operations uneconomic. The technology is intrinsically a large-scale centralized technology.

- Coproduction of hydrogen and oxygen. Hydrogen can be made by a variety of different processes using nuclear energy. However, in all cases the raw material is water. As a consequence, one mole of oxygen is coproduced for every two moles of hydrogen.

- Heat. The nuclear reactor can also be used to supply heat to industrial facilities.

Different markets for hydrogen have different requirements. The markets partly define the requirements for any new production technology. This paper describes various hydrogen markets to assist in the development of nuclear hydrogen production techniques by addressing three issues.

- What are the likely markets for nuclear hydrogen? Markets should be identified to determine potential partners for development of nuclear hydrogen production technologies. Because the characteristics of nuclear hydrogen production are different than other methods of hydrogen production (large scale co-production of hydrogen and oxygen), there may also be new markets that do not exist for other hydrogen production technologies.

- What are the requirements for nuclear hydrogen production technologies? Different customers have different requirements in terms of daily demand (steady state or variable), hydrogen purity, delivery pressures, use of the oxygen byproduct, and other technical parameters. This can impact the choice of the preferred nuclear hydrogen production technology (thermochemical, hybrid, etc.) that should be developed. Market requirements are the starting point for any plant design.

- Are there user technologies that should be developed to maximize the incentives for deployment of nuclear hydrogen? Nuclear hydrogen has a unique combination of characteristics: large-scale production of hydrogen with coproduction of oxygen. That unique combination may lead to specialized markets that can not be economically met by other hydrogen production technologies. However, these specialized markets may require the development of new technologies or modification of old technologies to maximize the benefits from use of nuclear hydrogen.

To answer these questions, Chapter 2 provides an overview of the potential markets while the following four chapters address the four major hydrogen markets: transportation, industrial, electrical, and commercial. In each of these four chapters various markets are described and characterized. Chapter 7 examines explicit implications for hydrogen from nuclear energy while chapter 8 provides some conclusions. 


\section{Markets}

Existing and potential hydrogen markets were identified and characterized as shown in Table 1 . There are four major classes of markets.

- Transportation (Vehicle)-Section 3. Transportation requirements can be met with different fuels. Each fuel requires different amounts of hydrogen in the production process and releases different quantities of carbon dioxide to the environment. These hydrogen uses are described in Section 3.

- Industrial-Section 4. The two major industrial markets for hydrogen are fertilizer production and steel. All nitrate fertilizers require hydrogen in their production processes. Some but not all steel production processes require hydrogen.

- Electrical-Section 5. Hydrogen is a candidate for electrical production, particularly for production of peak electricity.

- Commercial-Section 6. Hydrogen is being considered for commercial applications in buildings with the co-production of electricity and heat.

Each market and submarket is characterized by several parameters that impact the choices of preferred hydrogen production technologies (Table 1).

- Feedstock. Different feedstocks are used to produce transport fuels. The feedstock often determines the size of any required hydrogen production facility. When feedstocks (tar sands, shale, coal, etc.) are available in concentrated form, economic considerations favor large production facilities that, in turn, favor large centralized hydrogen production facilities. In contrast, feedstocks such as biomass are dispersed and have high shipping costs. Production facilities will be smaller because it is uneconomic to ship these feedstocks to large centralized facilities. This characteristic, in turn, implies smaller hydrogen production facilities. Large centralized facilities better match the characteristics of nuclear hydrogen.

- Carbon dioxide production. Releases of carbon dioxide to the atmosphere may ultimately be limited. Transport fuels may release carbon dioxide to the atmosphere by two routes: (1) consumption of the transport fuel and (2) production of the transport fuel. If liquid fuels are made from crude oil, most of the carbon dioxide is from burning the gasoline. However, if liquid fuels are made from coal with traditional processes, more carbon dioxide may be released in making the liquid fuels than in burning the liquid fuels. Table 1 shows the relative amount of carbon dioxide released from the fuel versus the production process. If nuclear or other non-fossil sources of hydrogen are used, releases of carbon dioxide from transport fuel production process can be eliminated.

- Oxygen use. Some markets require both oxygen and hydrogen. Such markets favor hydrogen production technologies that use water as an input and co-produce oxygen. In particular, a high demand for oxygen may favor nuclear hydrogen production options.

- Heat use. Some process applications require hydrogen and heat. This encourages co-location of the hydrogen production plant with the application.

- Existing market. Hydrogen is used in many markets. For existing applications, technology is not the market constraint. If the cost of hydrogen is reduced, market use will increase. 
Potential Nuclear Hydrogen System Applications

Appendix A

July 31,2005

- User size. If a single large hydrogen consumer uses all the hydrogen from a production facility, development of such a facility is simple. However, if many customers are needed to consume the hydrogen from a production facility, major infrastructure elements (storage, pipelines, etc.) are required to deliver the hydrogen as well as the added difficulty of matching production to demand. Markets with many small users are more difficult to commercialize.

- Steady-state. Some applications are constant users of hydrogen, while others require variable delivery.

- Storage and distribution. Different applications have very different needs for a supporting hydrogen storage and distribution system. 
Table 1: Markets for Hydrogen

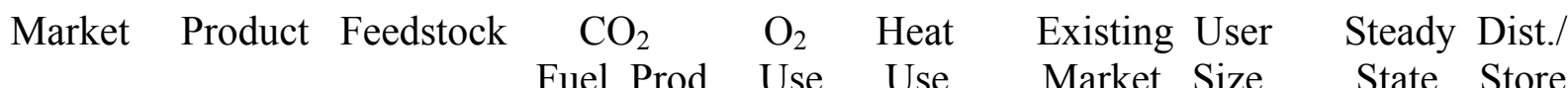

\begin{tabular}{|c|c|c|c|c|c|c|c|c|c|c|}
\hline \multirow[t]{9}{*}{ Vehicle } & \multirow[t]{5}{*}{$\begin{array}{l}\text { Liquid } \\
\text { Fuels }\end{array}$} & $\begin{array}{l}\text { Crude } \\
\text { Oil }\end{array}$ & Yes & 0.2 & No & Maybe & No & Large & Yes & No \\
\hline & & $\begin{array}{l}\text { Heavy } \\
\text { Oil }\end{array}$ & Yes & & $?$ & Maybe & Yes & Large & Yes & No \\
\hline & & $\begin{array}{c}\text { Tar } \\
\text { Sands }\end{array}$ & Yes & & $?$ & Yes & Yes & Large & Yes & No \\
\hline & & Oil Shale & Yes & & $?$ & No & No & Large & Yes & No \\
\hline & & Coal & Yes & $1+$ & Yes & Maybe & No & Large & Yes & No \\
\hline & \multirow{3}{*}{$\begin{array}{c}\mathrm{CO}_{2} \\
\text { Free } \\
\text { Fuels }\end{array}$} & Biomass & \multicolumn{2}{|c|}{ No } & No & Maybe & No & Medium & $?$ & Some \\
\hline & & Air & \multicolumn{2}{|c|}{ No } & No & No & No & Large & Yes & No \\
\hline & & $\begin{array}{c}\mathrm{H}_{2} \\
\text { Carrier }\end{array}$ & \multicolumn{2}{|c|}{ No } & No & No & No & $\begin{array}{c}\text { Medium / } \\
\text { Large }\end{array}$ & Yes & Some \\
\hline & $\mathrm{H}_{2}$ & $\mathrm{H}_{2} \mathrm{O}$ & \multicolumn{2}{|c|}{ No } & No & No & No & Small & No & Yes \\
\hline \multirow[t]{2}{*}{ Industrial } & \multicolumn{2}{|c|}{ Chemical } & \multicolumn{2}{|c|}{ No } & No & Maybe & Yes & Large & Yes & No \\
\hline & \multicolumn{2}{|c|}{ Steel } & \multicolumn{2}{|c|}{ No } & No & Maybe & Yes & Large & Yes & No \\
\hline \multirow[t]{2}{*}{ Electrical } & \multicolumn{2}{|c|}{ Variable } & \multicolumn{2}{|c|}{ No } & No & No & No & Medium & No & No \\
\hline & \multicolumn{2}{|c|}{ PENS (peak) } & \multicolumn{2}{|c|}{ No } & Yes & Maybe & No & Large & Yes & No \\
\hline Commercial & \multicolumn{2}{|c|}{$\begin{array}{l}\text { Building Heat \& } \\
\text { Electricity }\end{array}$} & \multicolumn{2}{|c|}{ No } & No & No & No & Small & No & Yes \\
\hline
\end{tabular}

\section{Transport Markets}

About $40 \%$ of the U.S. energy demand is met by oil that is converted primarily to liquid fuels. Today's transportation system depends upon liquid fuels (gasoline, diesel, and jet) because of their high energy density by weight and volume and their ease of use. The world is rapidly exhausting its resources (Fig. 1) of the light crude oils (Wells 2005) used to make liquid fuels. These crude oils are the easiest to recover, have the lowest costs of recovery, and have the highest market prices. Consequently, for a century, oil companies have preferentially explored for and recovered these crude oils for the production of liquid fuels.

There are many alternative transport fuel futures. Almost all of the options (with the exception of an electric car with an efficient, low-cost, high-power density, light-weight battery) require the large scale use of hydrogen. Different options use the hydrogen in different ways. These options have been defined into three broad categories based on how the hydrogen is used: liquid fuels, $\mathrm{CO}_{2}$-free liquid fuels, and direct hydrogen fuels. In some cases, the hydrogen is used in large centralized facilities whereas in other cases it is used in a decentralized manor. 


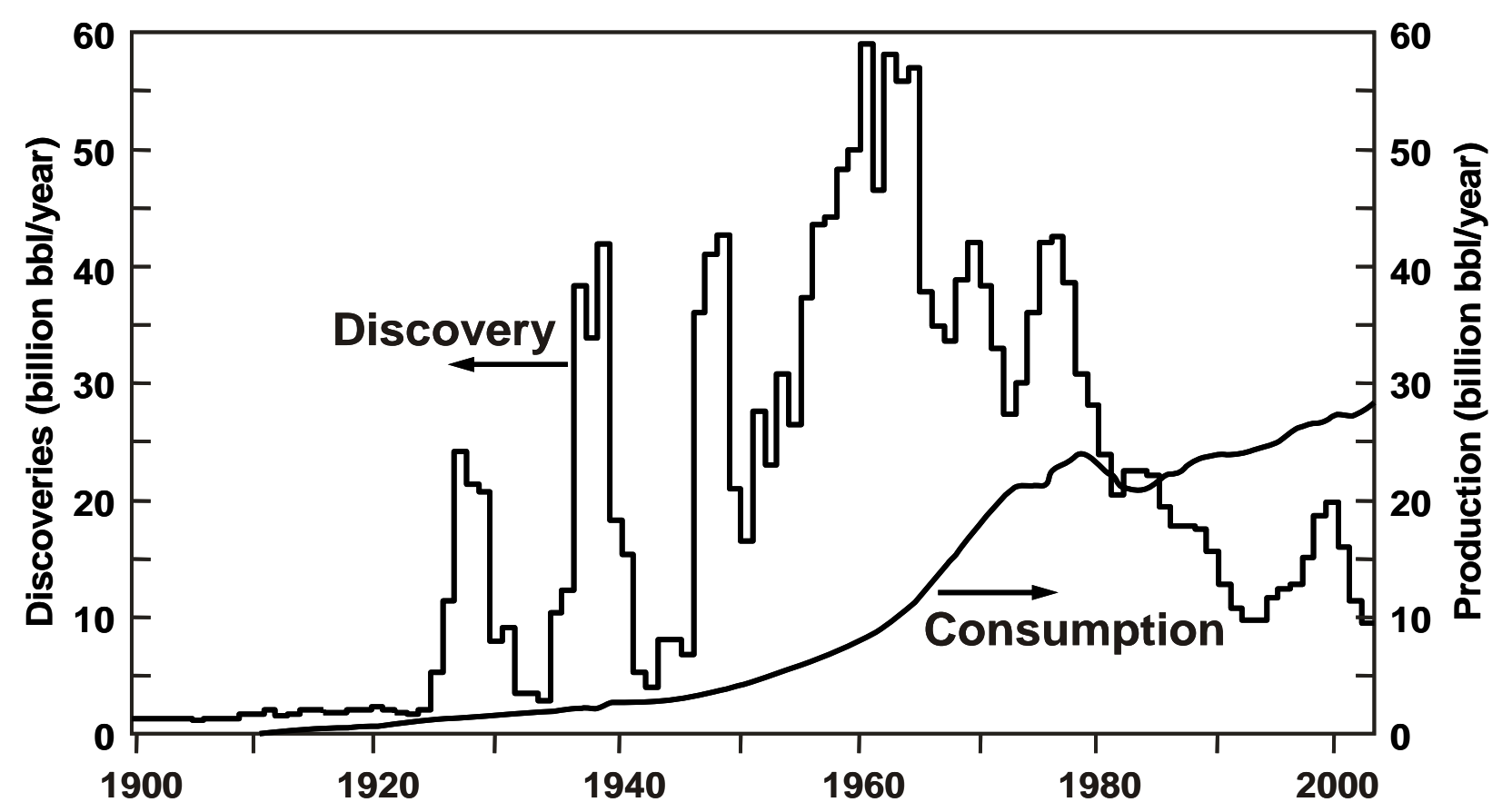

Fig. 1. Rate of discovery and consumption of conventional crude oils vs time (Wells 2005).

\subsection{Traditional Liquid Fuels}

Liquid fuels can be made from hydrogen and any source of carbon (crude oil, heavy crude oil, tar sands, oil shale, coal, etc.). Liquid fuels have been traditionally made from light crude oils, a process that does not require hydrogen. However, liquid fuels in the future will increasingly be produced from other feedstocks with lower hydrogen-to-carbon ratios. Liquid fuels today are also made from heavy oils (many countries), tar sands (Canada), and coal (South Africa). In a refinery, these lower-grade feeds are converted to liquid fuels by adjusting the hydrogen-to-carbon ratio of the feedstock. Liquid fuels are typically hydrocarbons that have ratios of hydrogen to carbon of 1.5 to 2 . A heavy crude oil may have a hydrogen-to-carbon ratio of slightly above 1 . Coal may have a hydrogen-to-carbon ratio as low as 0.6.

The hydrogen-to-carbon ratio in various feeds is adjusted to produce liquid fuels by adding hydrogen or removing carbon. Hydrogen is traditionally made by steam reforming of fossil fuels where a fossil fuel plus water is converted into hydrogen and carbon dioxide. The various methods for removing carbon ultimately release that carbon as carbon dioxide. With traditional fossil technologies, both adding hydrogen and removing carbon from the feedstock release carbon dioxide to the atmosphere.

If current technologies are used, the carbon dioxide emissions per unit of liquid-fuel production will likely increase dramatically in the next several decades as the hydrogen-to-carbon ratio of the feedstocks 
Potential Nuclear Hydrogen System Applications

Appendix A

July 31,2005

decreases. Figure 2 shows the relative quantities of carbon dioxide released to the atmosphere from diesel SUVs versus the carbon dioxide from various parts of the fuel production cycle for various feedstocks using traditional fuel production processes. Ultimately, in a business-as-usual scenario, the carbon dioxide emissions from the facilities producing the liquid fuels may exceed the carbon dioxide emissions from the actual burning of the liquid fuels in transport vehicles. Alternatively, if economic hydrogen is available from non-greenhouse-emitting sources and the energy for the fuel processing does not release greenhouse gases to the atmosphere, the atmospheric carbon dioxide emissions from liquid-fuel production per unit of liquid fuel can be the same or lower than that from light crude oil.

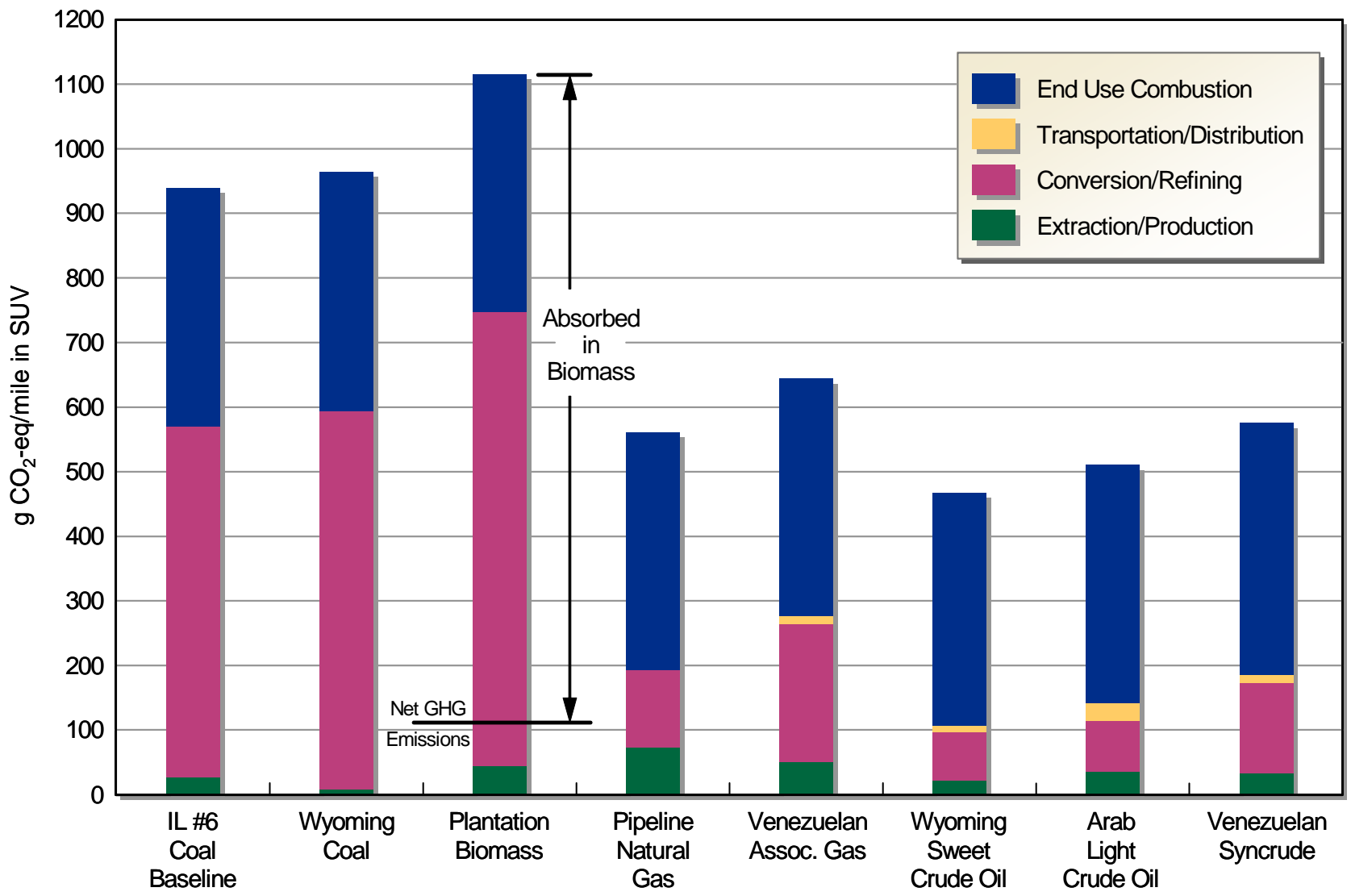

Fig. 2. Carbon dioxide equivalent releases from a diesel SUV and the various steps in the diesel fuel production for different feedstocks. (Marano 2001)).

\subsubsection{Traditional Processing of Feedstocks to Liquid Fuels}

Hydrogen demand and potential impacts on carbon dioxide releases to the atmosphere are described for different feedstocks that may be used to produce traditional liquid fuels. 


\subsubsection{Light Crude Oil}

Gasoline, diesel, and jet fuels are characterized by their performance in engines. No fixed hydrogen-tocarbon ratio is associated with each fuel. Typical refineries that convert light crude oil to liquid fuels are hydrogen neutral, neither consuming nor producing hydrogen. However, if low-cost hydrogen were available or there were penalties for carbon dioxide releases to the environment, the hydrogen-to-carbon ratio of fuels could be increased toward a maximum hydrogen-to-carbon ratio of $\sim 2$. In effect, the quantity (energy content) of liquid fuels produced per unit of crude oil or the equivalent transportation service provided per unit of crude oil is increased by 10 to $20 \%$.

\subsubsection{Heavy Oil and Tar Sands}

Many experts believe that conventional oil production will peak in this decade and then decrease. The shortfalls in production are likely to be initially offset by conversion of heavy oils, tar sands, and other low-grade hydrocarbon deposits to liquid fuels (Williams 2003). The amount of synthetic crude oil that can be produced from these low-grade deposits far exceeds those of all conventional oil deposits combined.

The traditional refinery processes use hydrocracking and/or thermal cracking to upgrade these feedstocks to liquid fuels. Either option implies significant increases in the releases of carbon dioxide to the atmosphere by the refinery per gallon of liquid fuel produced. If thermal cracking is used (remove carbon), the byproduct carbon that is removed is ultimately released to the atmosphere as carbon dioxide. If hydrocracking is used (addition of hydrogen), the hydrogen is traditionally produced by steam reforming of fossil fuels with the byproduct carbon dioxide released to the atmosphere. Refineries use varying amounts of hydrocracking and thermal cracking for liquid-fuel production, depending upon hydrogen production costs and raw material characteristics. If hydrogen is inexpensive, hydrogen will be added. Hydrocracking has the advantage of maximizing the liquid fuel production per unit of feedstock. If hydrogen is expensive, thermal cracking will be used.

Because of the imminent decline in conventional crude oils, the major oil companies of the world are rapidly expanding their facilities that convert these low-grade reserves into oil. Some perspective on the scale of operations can be obtained by examining the Alberta, Canada, tar sands developments (Williams 2003). Production is being raised from its current level of 500,000 barrels/day of synthetic crude oil to 2.5 million barrels/day by 2010 . Since 1996, $\$ 23$ billion has been invested to increase production. An additional $\$ 37$ billion in new plants and expansions has been announced. Most of the new world-class hydrogen plants are being built to support these facilities. If these tar-sand deposits are fully developed and natural gas is used to produce the required heat and hydrogen, the natural gas requirements will be 2 to 3 times the total projected Canadian natural gas reserves. The demand of heavy oil and tar sands facilities represents the primary factor in the current growth in demand for hydrogen. This demand for hydrogen, and the resultant demand for natural gas to make the hydrogen, is beginning to have a serious impact on North American natural gas demand and prices.

\subsubsection{Shale Oil and Coal Liquefaction}

The U.S. has some of the largest deposits of shale oil and coal. Consequently, shale oil and coal liquefaction are potentially large long-term markets for hydrogen to produce liquid fuels and minimize imports of oil. 
In World War II, the Germans built large-scale facilities to convert coal to liquid fuels to replace imports of fuel. In 1955, South Africa started the first Sasol synthetic fuel plants that convert coal to liquid fuels using the German Fisher-Tropsch process. This complex was ultimately expanded to produce 100,000 barrels of oil per day. Following South Africa, in the 1980s New Zealand built a synthetic fuels plant using natural gas feed. This plant uses a two-step process that first produces methanol and then converts the methanol to gasoline.

There are two classes of coal liquefaction processes: direct and indirect. The direct processes (Beychok 1979) hydrogenate coal directly to produce liquids. The best of these processes have an efficiency of about $65 \%$, which implies that about a third of the energy in the coal (and effectively onethird of the coal) is used to overcome these unavoidable process inefficiencies. Depending upon the coal, some fraction of the remaining coal is used to make hydrogen; thus, perhaps half of the carbon in the original coal is a component of the final liquid fuel.

The indirect processes convert carbon, oxygen, and water into synthesis gas - a mixture of hydrogen, $\mathrm{CO}$, and $\mathrm{CO}_{2}$. There are two mainline indirect processes. The traditional process is Fisher-Tropsch that directly converts synthesis gas to liquid fuels. The newer synthetic fuel processes convert the synthesis gas into methanol $\left(\mathrm{CH}_{3} \mathrm{OH}\right)$, which in turn is converted to liquid fuels. There are many variants of these processes. All existing commercial plants have used the indirect processes for a variety of reasons: the output of indirect processes is insensitive to the feedstock, the capital costs per unit of production are lower, the processes are technologically easier, and the products contain higher fractions of high-value liquid fuels. The process efficiency (Maiden 1988) for the New Zealand methanol to liquid-fuels plant is estimated at $54 \%$ (ratio of energy value of liquid fuels to energy input).

These processes can be considered black boxes, carbon, oxygen, and water go into the process and liquid fuels and carbon dioxide exit the process. The carbon is used (1) as a chemical feedstock to provide the carbon in the liquid fuel and (2) as a fuel to provide energy for the process - including hydrogen production. At a fundamental level, the feed can be any carbon-containing material: coal, garbage, natural gas, etc.

The economics of liquid-fuel production require very large plants with massive demands for hydrogen and, in most cases, massive quantities of oxygen. The large German program in the 1970s to produce hydrogen using nuclear energy was to supply hydrogen and energy for coal liquefaction. (Germany has large coal resources but no liquid fuels.) The smaller nuclear hydrogen program in the United States in the 1970s had the same goal.

\subsubsection{Alternatives to Traditional Fuel Processing}

\subsubsection{Carbon sequestration}

Greenhouse gas releases from the production of liquid fuels can be eliminated by sequestration of the carbon dioxide.

\subsubsection{Non-Fossil Hydrogen Production}

Greenhouse gas releases from the production of liquid fuels can be eliminated by providing non-fossil sources of hydrogen. The hydrogen can be used in two modes. 
- Hydrogen replacement. The hydrogen can substitute for hydrogen produced from fossil fuels.

- Liquid fuels production. Many of the processing technologies such as thermal cracking produce carbon that is then converted to carbon dioxide and released to the atmosphere. Alternatively, the carbon can be converted to carbon monoxide. The carbon monoxide and hydrogen form synthesis gas that is the required input to produce liquid fuels by indirect processes. This option has two other characteristics: (1) the requirement for large quantities of oxygen, a co-product of nuclear hydrogen and (2) fully utilizes the carbon in the feedstock for fuel production.

If non-fossil hydrogen production costs approach those of hydrogen from fossil fuels, this option becomes the preferred option because of its much more efficient use of hydrocarbon feedstocks. All of the carbon is ultimately in the liquid fuel product. For these options, the benefits of co-producing oxygen with the hydrogen can be significant.

There is one other important consideration. The geographical distribution of fossil resources is limited. The geographical distribution of geological environments that can be used for carbon dioxide sequestration is limited. If carbon dioxide sequestration proves viable, in many cases the fossil fuels or the carbon dioxide for sequestration will have to be transported long distances. Nuclear hydrogen may provide a viable hydrogen source to use fossil resources where transport costs of the fossil fuel or carbon dioxide is excessive.

\subsection{Carbon Dioxide Neutral Liquid Fuels}

Traditional liquid fuels are made from fossil fuels. However, there are a wide variety of hydrocarbon liquid fuels that do not require fossil fuels and do not result in net emissions of carbon dioxide to the atmosphere.

\subsubsection{Direct Atmospheric Fuel Production}

Liquid fuels can be made from water and carbon dioxide extracted from (1) the atmosphere or (2) the ocean. In this case, external sources of energy must be used. This energy can be in the form of electricity and hydrogen. The electricity is used in process operations including recovery of carbon dioxide from the atmosphere. The hydrogen is used (1) as a feedstock to make the liquid fuels and (2) as an internal energy source to drive the process of producing the fuel. Either of the indirect liquid fuels processes described above can be used to convert the hydrogen and carbon dioxide into liquid fuels. Given unlimited hydrogen, this option provides unlimited liquid fuel. No greenhouse impacts occur because the carbon dioxide is recycled from the atmosphere or seawater. There is no import of crude oil - the fuel is produced domestically. There have been a series of studies on the technology for liquid-fuel production and the cost implications.

- Navy. The primary logistical demand for the Navy is the provision of liquid fuels for aircraft and ships. Aircraft carrier flight operations and fleet operations are limited by the capability of the oil tankers to provide fuel. This constraint can be eliminated by the use of a nuclear-powered tanker (Terry 1995) that manufactures jet fuel with nuclear hydrogen from seawater and carbon dioxide from the air or ocean.

- Fusion energy complexes. Engineering studies indicate that likely fusion energy plants may be very large [several thousand megawatts (electric) equivalent], even relative to the size of fission nuclear 
power plants. The very large energy output of these machines would create major difficulties in electrical transmission. These constraints would be eliminated if there were a large local market for that energy such as the production of liquid fuels (Fillo, Powell, and Steinberg, 1981). A series of studies were done to evaluate alternative liquid fuels production with the carbon from atmospheric carbon dioxide.

Most of these studies have assumed that the hydrogen is produced through electrolysis. Detailed studies (Steinberg and Dang, 1975) have examined alternative methods for recovery of carbon dioxide from the atmosphere and ocean. The generally recommended atmospheric-carbon-dioxide-recovery method is the use of aqueous potassium carbonate $\left(\mathrm{K}_{2} \mathrm{CO}_{3}\right)$ solution for absorption and stripping of carbon dioxide form the atmosphere. About $80 \%$ of the total energy input required to produce the liquid fuel is used in the processes to produce hydrogen from water. The hydrogen is then used to produce the liquid fuel. If a high-temperature reactor is assumed to have $50 \%$ efficiency in the conversion of heat to electricity with hydrogen made by electrolysis, about $30 \%$ of the thermal energy produced by a nuclear reactor is converted into liquid fuels. This technology has several implications:

- Liquid-fuel impacts. This option provides unlimited liquid fuels with no greenhouse impacts as long as the hydrogen and electricity come from non-greenhouse energy sources. If there is a nongreenhouse source of energy, it caps the potential costs of liquid fuels because the raw materials (water and atmosphere) are available in unlimited quantities. It allows all liquid fuels to be produced domestically.

- Hydrogen economy. From an economic perspective, this technology places an upper economic limit on the allowable costs for using hydrogen directly as a transport fuel compared with using liquid fuels. The production costs of liquid fuels using hydrogen and carbon dioxide from the atmosphere are clearly higher than the production costs of hydrogen. However, the costs of distributing and storing liquid fuels are much lower than the cost of distributing and storing hydrogen. Either approach can provide the fuel for the transport system without increasing atmospheric greenhouse concentrations. Economics will likely determine the preferred option.

\subsubsection{Biomass Conversion}

Biomass today is used to produce liquid fuels such as alcohol by fermentation. This is potentially a nongreenhouse domestic liquid-fuel source. There are no greenhouse impacts because the carbon dioxide used to make the biomass comes from the atmosphere. However, in a plant that converts biomass to liquid fuel, part of the carbon in the feedstock is converted to carbon dioxide by the biomass to provide the energy to keep the biomass alive. For example, the conversion of corn to ethanol results in roughly a third of the carbon from the original corn in the ethanol, one-third in the by-product animal feed, and onethird in the carbon dioxide released to the atmosphere. Biomass processing facilities are concentrated sources of carbon dioxide recovered from the atmosphere.

This carbon dioxide can be combined with hydrogen to produce liquid fuels. In effect, there is the potential to use biomass as a non-greenhouse-generating domestic carbon source to make liquid fuels as well as an energy source. This type of option has been investigated by Bruce Energy Center of Ontario Hydro and Integrated Energy Development Corporation. The concept was to produce hydrogen through electrolysis of water using electricity from the Bruce Nuclear Generating Station in Tiverton, Ontario, Canada, and to collect carbon dioxide from an ethanol plant. The carbon dioxide would then be converted into liquid fuels and chemicals using existing technology (Gurbin and Talbot 1994). This type 
of liquids fuel production is distributed because of the cost to collect and transport biomass to a central fuel plant location.

An alternative to producing alcohol from biomass (primarily cellulose-- $\mathrm{C}_{6} \mathrm{H}_{10} \mathrm{O}_{5}$ ) is to convert the biomass into a hydrocarbon fuel. Biomass contains significant quantities of oxygen. It can be thought of as a partially oxidized hydrocarbon. The energy value per unit of carbon in a liquid fuel can be significantly increased by hydrogenation processes (directly or indirectly) that remove that oxygen while producing a liquid fuel.

\subsubsection{Hydrogen Carrier Systems}

Hydrogen is proposed as the ultimate transport fuel for cars, trucks, and buses. There are several systems that deliver hydrogen to the vehicle engine but that do not require (1) hydrogen distribution systems to the vehicle refueling station (gasoline station) and (2) vehicle on-board hydrogen storage. These systems use some type of chemical hydrogen carrier. The production of that hydrogen carrier does require large quantities of hydrogen but the hydrogen is only used at centralized fuel production facilities - a non-oil version of a refinery. These hydrogen use options would thus have the same characteristics and requirements for hydrogen production as a large refinery.

\subsubsection{Carbon-Dioxide Vehicle Recycle Systems}

Liquid fuel systems that deliver hydrogen to the vehicle engines, capture the carbon dioxide on-board the vehicle, and recycle carbon dioxide for production of new liquid fuels, are being investigated in Japan (Kato et al., 2003). The vehicle is fueled with a hydrocarbon fuel and a calcium oxide (CaO) bed. The system contains the following components.

- Vehicle steam reformer. The $\mathrm{CaO}$ bed is used as a steam reformer where the liquid fuel is converted to hydrogen and carbon dioxide and the carbon dioxide reacts with the $\mathrm{CaO}$ to form solid calcium carbonate $\left(\mathrm{CaCO}_{3}\right)$. The reaction of the $\mathrm{CaO}$ and the $\mathrm{CO}_{2}(1)$ is highly exothermic and provides the energy necessary to drive the highly endothermic stream reforming reaction to completion to maximize hydrogen production and (2) removes all the $\mathrm{CO}_{2}$ and thus drives the equilibrium reactions to produce hydrogen rather than a mixture of $\mathrm{H}_{2}, \mathrm{CO}$, and $\mathrm{CO}_{2}$.

- Vehicle engine. Fuel cells or an internal combustion engine powers the vehicle with hydrogen.

- Fuel factory. The $\mathrm{CaCO}_{3}$ bed is returned to a fuel factory where hydrogen chemically reduces the $\mathrm{CaCO}_{3}$ to $\mathrm{CaO}$ for recycle to vehicles and the recovered carbon dioxide is combined with hydrogen to produce new liquid fuel.

In this system, carbon is a recyclable hydrogen and energy storage mechanism between the fuel factory and the vehicle. Hydrogen enters the fuel factory and reappears inside the vehicle. Current estimates indicate that the volume and mass of this hydrogen fuel delivery system on-board the vehicle are less than other existing methods to deliver hydrogen to a vehicle engine. The low volume and mass of the fuel system aboard the vehicle is because energy is stored in two high energy-density forms: (1) the solid $\mathrm{CaO}$ reformer beds and (2) the liquid fuel. Most fuel factories would be near cities to minimize transport cost of solid $\mathrm{CaO}$ reformer beds. This system configuration implies distributed fuel factories requiring hydrogen - probably via pipeline. 


\subsubsection{Metal Ammines (ammonia) hydrogen transport}

Ammonia $\left(\mathrm{NH}_{3}\right)$ is a potential hydrogen carrier. Ammonia, the primary fertilizer in the world, is made by combining hydrogen with nitrogen from the atmosphere. Ammonia production is the largest single use of hydrogen today. It is transported by pipeline and truck as a liquid under pressure and could be used to fuel a vehicle. On-board the vehicle, the ammonia can be dissociated into hydrogen and nitrogen. However, there has been relatively little interest in this form of hydrogen storage because of (1) the requirements to store ammonia as a liquid under pressure and (2) the toxicity of ammonia.

Recent work (Christensen 2005) has experimentally shown that ammonia can be stored reversibly in metal ammine complexes such $\mathrm{Mg}\left(\mathrm{NH}_{3}\right)_{6} \mathrm{Cl}_{2}$ and $\mathrm{Ca}\left(\mathrm{NH}_{3}\right)_{8} \mathrm{C}_{12}$. Hydrogen is $9.1 \mathrm{wt} \%$ of the magnesium compound and $9.7 \mathrm{wt} \%$ of the calcium compound---both compounds exceed the Department of Energy 2015 hydrogen storage goals of $9.0 \mathrm{wt} \%$ hydrogen in a hydrogen storage system. For the magnesium system, 4 of the 6 ammonia molecules are released during heating the compound from 350 to $500^{\circ} \mathrm{C}$ with the last two ammonia molecules released below $620^{\circ} \mathrm{C}$

\subsubsection{Hydrocarbon hydrogen carrier}

Hydrogen can be reversibly stored as part of certain liquid chemical compounds. The classical example is the dehydrogenation of liquid methylcyclohexane with a catalyst aboard a vehicle to produce methyltoulene and three hydrogens. The methyltoulene is returned to the refinery where hydrogen is added to produce methylcyclohexane. In this system, the hydrogen is only about $6 \%$ of the weight of the methylcyclohexane; however, all the organics are liquids that simplify transport relative to sold reagents.

\subsection{Hydrogen Auto and Truck Transport System}

Hydrogen is proposed as the ultimate transport fuel for cars, trucks, and buses. Recent reports (U.S. National Research Council 2004) describe the various scenarios where the hydrogen is distributed to filling stations and stored by a variety of methods (high pressure gas, reversible sorption on various solids, liquid hydrogen, etc.) on-board the vehicle. This can be considered the ultimate end state of hydrogen development if the various technical barriers are eliminated. In all of these futures, the hydrogen demand is highly distributed, varies with time, and requires a massive distribution system. The requirements for the production system may be significantly different than markets with centralized demand for hydrogen.

\subsection{Aircraft}

Aircraft fuel requirements are very different than those associated with other forms of transportation because of volume, weight, and performance requirements. As a consequence, the use of hydrogen in these systems may follow a pathway different from that of other transport systems. The technical constraints indicate that the options are liquid hydrocarbon fuels or liquid hydrogen. Liquid hydrogen has been considered for three types of aircraft applications: commercial jets, hypersonic jets, and electric airplanes.

Commercial jets. Commercial aircraft can be fueled with liquid hydrogen. The European Union (Airbus Deutschland GmbH 2003) funded a consortium of 35 partners from the aviation sector, led by Airbus Deutschland, to conduct a systems analysis of hydrogen-fueled aircraft - the CRYOPLANE project. This consortium examined a wide range of aircraft from business jets to large long-range aircraft such as the 
new jumbo Airbus A380. The key issue was to model the liquid-hydrogen fuel system. Per unit energy, liquid hydrogen has four times the volume of jet fuel; therefore, the fuel tanks must be four times larger. Analysis showed that because of the larger external surface area of the aircraft needed to accommodate the fuel tanks, the energy consumption would increase by 9 to $14 \%$. This is in contrast to use of hydrogen in cars and trucks where the energy consumption is expected to significantly less for hydrogen compared to traditional liquid fuels. Overall operating costs would increase by 4 to $5 \%$ based on fuel alone. It was also concluded that the engines would be equally efficient, the aircraft would have safety equivalent to that of current aircraft, and the environmental impacts would be substantially less (i.e., no carbon dioxide emissions). Further development is needed; however, such an aircraft system could be implemented within 15 to 20 years of a decision to use hydrogen as a fuel.

Hypersonic jets. Hypersonic aircraft require liquid-hydrogen fuel. The air velocity through a ram jet requires a fuel with a very fast flame temperature and diffusion rate to ensure combustion within the engine. Hydrogen is the only option. Liquid hydrogen is also used to provide active cooling to leading aircraft surfaces to avoid melting. This market depends upon the development of these jets.

Electric aircraft. Aircraft can use electric motors and hydrogen fuel cells to power propellers. These systems have potentially very high efficiencies compared with alternative propulsion systems. If fuel cell and motor weight and cost can be sufficiently reduced, liquid hydrogen becomes a preferred fuel. The viability of such aircraft depends upon technological progress in fuel cells and related systems.

Because aircraft have very different fuel requirements than cars or trucks, the potential penetration of hydrogen into this market is likely to be on a very different schedule than other transport markets. It is a market that may be more driven by technological advances in aerospace propulsion systems than development of new hydrogen production markets.

\section{Industrial Markets}

\subsection{Ammonia and Other Chemical Applications}

Ammonia production (fertilizer) consumes about half the hydrogen produced today and is the primary chemical industry use of hydrogen. The market is growing slowly and is international. Ammonia is made where there is inexpensive natural gas that provides inexpensive hydrogen and shipped to the customer. Because of the increasing use of precision agriculture that has lowered the nitrogen fertilizer inputs per unit of food or biomass produced, large growth in demand for ammonia (and thus hydrogen) is not expected in this industry.

\subsection{Direct Reduction of Iron Ore}

In the production processes for converting iron ores into iron and steel, carbon, primarily in the form of coke, has been traditionally used to reduce the iron oxides to iron metal. However, in the last several decades, there has been increasing production of iron using the direct reduction iron (DRI) process. In 1998 , about $4 \%$ of the primary iron in the world was produced by the DRI process with rapid growth in iron production. In the DRI process, syngas (a mixture of hydrogen and carbon monoxide) made from natural gas is used to reduce iron ores to iron. The major chemical reactions are as follows: 


$$
\begin{gathered}
\mathrm{Fe}_{3} \mathrm{O}_{4}+\mathrm{CO} \rightarrow 3 \mathrm{FeO}+\mathrm{CO}_{2} \\
\mathrm{Fe}_{3} \mathrm{O}_{4}+\mathrm{H}_{2} \rightarrow 3 \mathrm{FeO}+\mathrm{H}_{2} \mathrm{O} \\
\mathrm{FeO}+\mathrm{CO} \rightarrow \mathrm{Fe}+\mathrm{CO}_{2} \\
\mathrm{FeO}+\mathrm{H}_{2} \rightarrow \mathrm{Fe}+\mathrm{H}_{2} \mathrm{O}
\end{gathered}
$$

The DRI process has lower capital costs than alternative methods used to produce iron but requires a lowcost source of hydrogen. The primary market for DRI is to provide a purified iron feed for electric arc furnaces (EAFs) that produce various steel products. EAFs have lower capital costs than traditional steel mills and are environmentally cleaner operations than blast furnaces. Over a third of the world's steel production uses this process. It is predicted that by 2010 up to $45 \%$ of the world's steel may be made with EAFs. Historically, scrap metal has been the traditional feed for EAFs. However, there are two constraints: the availability of scrap metal and the various difficult-to-remove impurities (copper, nickel, chrome, molybdenum, etc.) that are present in the lower-grade scrap metal. Blending clean DRI-process iron with scrap metal dilutes the impurities below the level that affect product quality.

Iron production is a significant existing market for hydrogen. If low-cost hydrogen were available, the DRI process would replace other methods of iron production. The economics of DRI relative to other processes depend upon three factors.

- Technological developments. The continuing improvements in EAF technology in terms of reduced production costs and increased capabilities to produce higher-quality steel have expanded the market share of this technology. That creates the demand for more iron by the DRI process as traditional sources of scrap metal are exhausted.

- Environmental protection. Traditional steel processes use coal and generate large quantities of pollutants. Clean air requirements strongly affect the economics of these competing processes.

- Hydrogen costs. The process is used where there is low-cost natural gas for hydrogen production near iron deposits.

A variant of this option was studied in Japan between 1973 and 1980. The "Nuclear Steelmaking Project" conducted major engineering tests and designed a 500-MW(t) reactor. This project was the start of the Japanese high-temperature reactor program.

\section{Electricity}

\subsection{Energy Storage for Intermediate and Peak Electrical Production}

The demand for electricity varies daily, weekly, and seasonally. As a result, the market price of electricity varies by an order of magnitude as a function of time. To meet this demand, the utilities buy lower-capital-cost peaking power units, typically gas turbines that burn natural gas. In addition, utilities have developed storage devices so that they can buy electricity during times of low demand and low cost and sell the electricity during times of high demand and high prices. 
For example, the Tennessee Valley Authority (TVA) operates the Raccoon Mountain pumped-hydro storage facility. This facility pumps water up the mountain when low-cost power is available. During times of high power demand and high-priced electricity, the water direction is reversed to produce electricity. This facility has a rated capacity of $1530 \mathrm{MW}(\mathrm{e})$. Another example is the Duke Power Koewee-Jocasse Project where water is pumped from Lake Koewee to Lake Jocasse during times of low power demand and the water is released through turbines to generate electricity during times of peak power demand.

The variability of the price of electricity creates the potential for a large hydrogen market aimed at producing electrical power at those times of day when the price of electricity is at its maximum. A peak electricity nuclear system (PENS) using nuclear hydrogen (Forsberg 2005) has been proposed that consists of three components (Fig. 3):

- Hydrogen production. A nuclear power plant with an associated hydrogen and oxygen (optional) production plant to produce hydrogen and oxygen at a constant rate to minimize the production costs.

- Hydrogen storage. One or more underground facilities for the low-cost storage of hydrogen and oxygen (optional). Underground caverns, depleted oil and gas fields, and aquifers are the traditional approaches to the low-cost storage of natural gas to meet seasonally variable natural gas demand. About 8 trillion cubic feet of natural gas can be stored in existing underground facilities in the United States (half of this quantity as a buffer gas to maintain high pipeline pressures). In countries such as Great Britain, salt caverns have been used for many decades for the low-cost storage of hydrogen. Underground storage is the only known low-cost technology for storing compressed gases; however, the economics demand very large facilities.

- Peak electric production. Large banks of fuel cells convert hydrogen to electricity during periods of high demand for electrical power and associated high prices for electricity. For every megawatt of steady-state hydrogen production from the nuclear reactor, there would be several megawatts of fuel cells. While the reactor produces hydrogen at a constant rate, the fuel-cell electrical production is highly variable-from zero to many times the rate of energy production from the reactor when the price of electricity is high. The fuel cells may be placed at the reactor site. As an alternative, to reduce electrical grid requirements, hydrogen pipelines may be built around major cities, with large fuel cell facilities located at junctions where the pipeline crosses long-distance transmission lines. 
Appendix A

July 31,2005

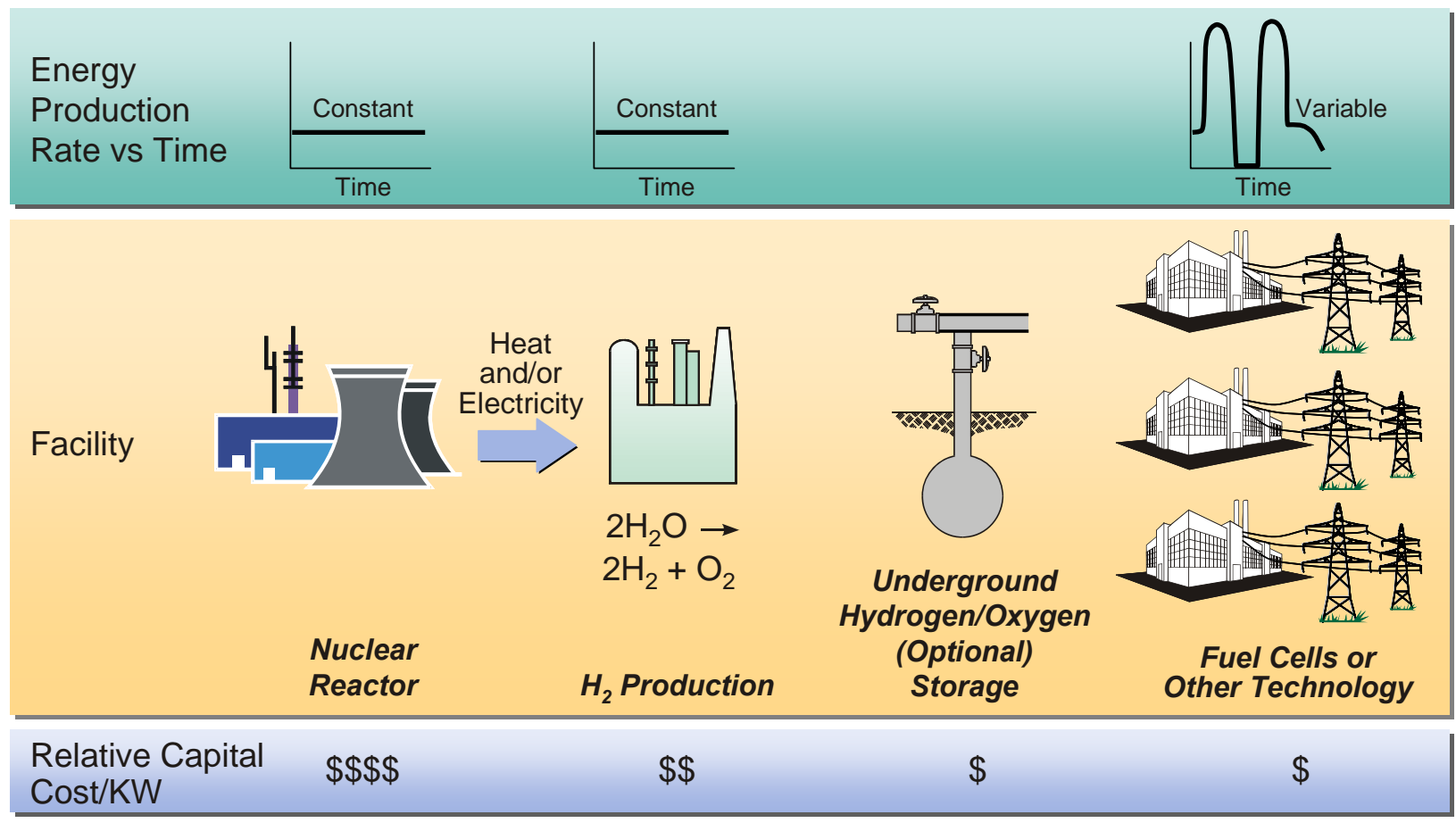

Fig. 3. Peak Electricity Nuclear System using nuclear hydrogen

The economic feasibility of PENS is based on projected costs and efficiencies of fuel cells. The goal of fuel cell developers is to reduce the capital cost for hydrogen fuel cells to $<\$ 100 / \mathrm{kW}$ (e) with efficiencies of about $70 \%$, compared with costs of $\$ 500 / \mathrm{kWe}$ for gas-turbine plants burning natural gas with efficiencies of about 50\%. This use of fuel cells allows PENS to have a very large capacity to produce peak electrical power compared with the steady-state output of the reactor. The capital costs of fuel cells per kilowatt electric may be further reduced by the use of oxygen rather than air. Hydrogen is produced at a constant rate to minimize hydrogen production costs. However, the ultimate product, electricity, is sold at times of peak demand for premium prices.

PENS is a stand-alone facility, like the TVA Raccoon Mountain project. It is not dependent on the outside market for hydrogen. Should another demand for hydrogen exist, however, the hydrogen can be sold at the plant gate. In the United States, the potential market exceeds $100 \mathrm{GW}(\mathrm{e})$ equivalent on a steady-state basis if the peak and much of the intermediate load are replaced by PENS. There are several variants of this concept using various hydrogen production and electricity production technologies - all dependent upon the low-cost storage of hydrogen and oxygen on a large scale.

PENS, if successful, may be an enabling technology for a nuclear- $\mathrm{H}_{2}$ renewables economy. Work is underway to develop solar devices and other renewable technologies that have low costs per kilowatt. The fundamental problem for renewables is to match electricity production to electricity demand. Were there no energy storage problem, wind or solar would become economic wherever their production cost is the below the price of electricity, not the cost of electricity plus energy storage. Without storage requirements, the potential exists for a significant fraction of electricity and the total energy market to 
Appendix A

July 31,2005

ultimately be provided by renewable energy sources. Recent system studies (Mazza 2004) indicate that current solar technologies are better suited for production of electricity for the electrical grid than hydrogen production. PENS may provide that storage function and thus become the enabling technology for larger-scale use of renewables - the centralized production of hydrogen matches the centralized storage of hydrogen and oxygen. If ultimately direct methods to produce hydrogen using solar energy are developed, then the storage and hydrogen-to-electricity components of the PENS technology become the basis for matching electrical production with demand using solar energy.

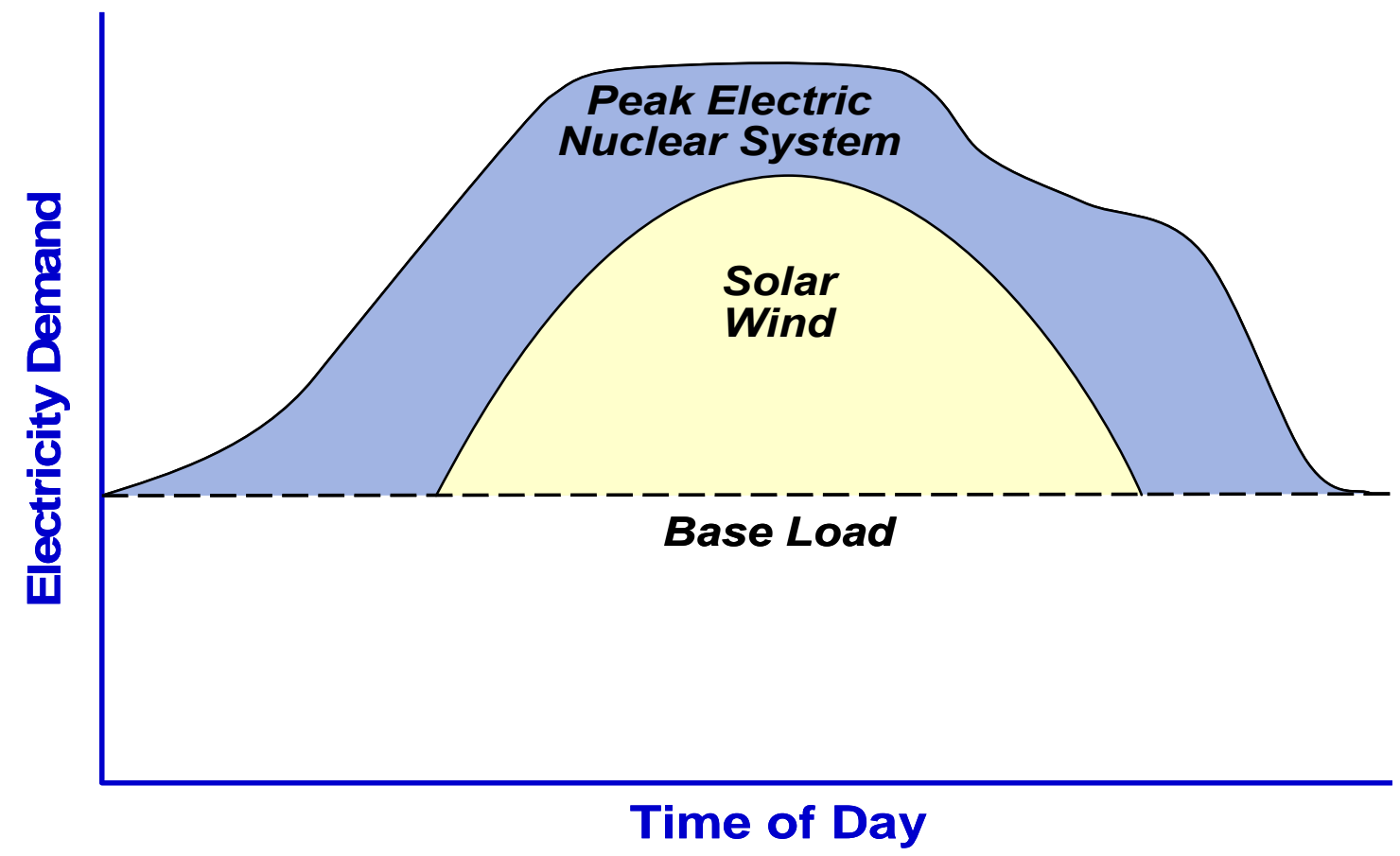

Fig. 4. Use of PENS to match electrical demand versus time with base-load electricity production and renewables electricity production

\section{Commercial Hydrogen Markets}

If economic hydrogen production is achieved, hydrogen may be used to generate electricity, provide hot water, building heating, and building cooling. Power conversion technologies produce electricity and heat. Centralized power stations produce electricity that is sold. The heat in the electric production process is dumped to the environment via cooling towers, river cooling, or seawater cooling. It is not practical to transport the low-grade heat any significant distance. If efficient, cost-effective, and smallscale fuel cell and other electrical production technologies are developed, hydrogen can be used to generate electricity on the building site with the waste heat used for hot water, heating, and cooling. In effect, the reject heat is used for beneficial purposes and avoids the need to burn fuel or use electricity for production of heat.

This is potentially a large market. However, unlike the markets above, there are many more competing technologies for stationary applications from electricity to solar heat. This application also requires the largest hydrogen distribution system. 


\section{Markets for Nuclear Hydrogen}

Table 1 listed potential hydrogen markets. Table 2, with the same categories of hydrogen markets, evaluates these markets in the context of their applicability to nuclear hydrogen production. The markets in italics are those that best match nuclear hydrogen characteristics because (1) the markets are very large, (2) centralized, and (3) have large demands for oxygen.

Table 2: Markets for Hydrogen: Implications for Nuclear Hydrogen Production

\begin{tabular}{|c|c|c|c|c|}
\hline Market & Product & Feedstock & $\mathrm{O}_{2}$ & User Size \\
\hline \multirow[t]{9}{*}{ Vehicle } & \multirow[t]{5}{*}{ Liquid Fuels } & Crude Oil & Yes & Large \\
\hline & & Heavy Oil & Yes & Large \\
\hline & & Tar Sands & Yes & Large \\
\hline & & Oil Shale & Yes & Large \\
\hline & & Coal & Yes & Large \\
\hline & \multirow{3}{*}{$\begin{array}{c}\mathrm{CO}_{2} \\
\text { Free } \\
\text { Fuels }\end{array}$} & Biomass & No & $\begin{array}{l}\text { Medium } \\
\text { Size }\end{array}$ \\
\hline & & Air & No & Large \\
\hline & & $\mathrm{H}_{2}$ Carrier & No & $\begin{array}{l}\text { Medium } \\
\text { Size }\end{array}$ \\
\hline & $\mathrm{H}_{2}$ & $\mathrm{H}_{2} \mathrm{O}$ & No & Small \\
\hline \multirow[t]{2}{*}{ Industrial } & \multicolumn{2}{|c|}{ Chemical } & No & Large \\
\hline & \multicolumn{2}{|c|}{ Steel } & No & Large \\
\hline \multirow[t]{2}{*}{ Electrical } & \multicolumn{2}{|c|}{ Variable } & No & Small \\
\hline & \multicolumn{2}{|c|}{ PENS (peak) } & Yes & Large \\
\hline Commercial & \multicolumn{2}{|c|}{ Building Heat \& Electricity } & No & $\begin{array}{l}\text { Small to } \\
\text { Medium }\end{array}$ \\
\hline
\end{tabular}

In these markets, nuclear hydrogen has an intrinsic advantage. An example can illuminate this. Consider the hydrogen market for coal liquefaction. The potentially large centralized demand for hydrogen and oxygen directly couples with the characteristics of nuclear hydrogen. In contrast, hydrogen from dispersed renewable sources in these markets has the competitive disadvantage that an infrastructure of pipelines and storage facilities would be required to collect the hydrogen and oxygen and deliver it to a coal liquefaction plant. In effect, hydrogen from renewable sources would have to have a significantly lower production cost than hydrogen from nuclear sources to be economically competitive in this market. The situation may be reversed for use of hydrogen to upgrade biomass into liquid fuels for in this case the market for hydrogen is dispersed and nuclear hydrogen may require a larger pipeline infrastructure. 
Associated with some of the markets is the need for R\&D needs to develop technologies that can take advantage of the specific characteristics of nuclear hydrogen systems. Two specific areas have been identified in this second category.

Liquid transport fuel production using hydrogen and oxygen. There are many ways to convert heavy feedstocks (heavy oil, tar sands, shale oil, and coal) into liquid transport fuels. Most require hydrogen. Some of the technologies use hydrogen and oxygen. Historically, hydrogen has been produced by steam reforming of fossil fuels - a technology that does not produce oxygen. If oxygen was required, separate processes were needed to extract oxygen from air. If nuclear hydrogen becomes available, oxygen is the coproduct with the secondary option of the nuclear reactor also providing low-cost heat. Analysis is required to determine the economic advantages of using nuclear hydrogen and taking advantage of the available low-cost coproduced oxygen. This is a unique characteristic that separates nuclear hydrogen production from other hydrogen production technologies. Any such an analysis should consider two cases: liquid transport fuels production with no constraints on carbon dioxide releases and liquid fuels production where there are constraints on carbon dioxide releases. If carbon dioxide releases are constrained, the availability of hydrogen and oxygen may enable conversion of all carbon in a feedstock to liquid fuels with no carbon dioxide releases from the fuel production facility.

An example can clarify this. For all heavy feedstocks there is processing option of thermal cracking. In this process, the heavy feedstock is heated very quickly in a special chemical reactor. The heat breaks chemical bonds producing a light hydrocarbon and a carbon residue or char. The light hydrocarbon can be refined into liquid fuels. The carbon residue is burnt to remove it from the chemical reactor. If oxygen is available, this residue can be oxidized to a relatively pure steam of carbon monoxide. If hydrogen is then added, the result is a synthesis gas that can be converted to liquid fuels using traditional technologies. The use of oxygen, rather than air, produces a relatively pure steam of carbon monoxide that is not diluted with nitrogen from the air. This substantially improves the economics of production of liquid fuels from syngas. Generally, the technologies for using hydrogen and oxygen are developed. However, because oxygen has traditionally been expensive, there have been no studies that have looked at the economics if large-scale low-cost oxygen became available.

Very large scale hydrogen and oxygen storage. Compared to other hydrogen production technologies, nuclear hydrogen systems will produce very large quantities of hydrogen and oxygen at centralized sites. There are strong economic incentives to develop large-scale low-cost storage systems for these two gases to couple centralized plant output to demand. There is limited experience in storing hydrogen on a very large scale. The status of these technologies needs to be fully understood and may require added development.

An example can clarify this. Electricity production varies by the time of day, the day of the week, and the seasons. If really low-cost large-scale hydrogen and oxygen storage can be developed, there is the potential to meet peak power demands on both a daily and weekly schedule with major reductions in the need for expensive gas turbines to meet peak electricity power demands. However, the storage technology is likely to be used only with nuclear hydrogen. Hydrogen production from fossil fuels does not produce oxygen so there is no incentive to examine large scale oxygen storage. Hydrogen and coproduct oxygen production from renewables is widely distributed. Given the cost of pipeline systems, there is little incentive to consider central storage of oxygen and hydrogen from renewable sources. 


\section{Conclusions}

Almost all future transport scenarios demand very large quantities of hydrogen; however, it is unclear whether that hydrogen will be used in vehicles or to produce a variety of liquid fuels at large industrial complexes. The hydrogen demand could equal $40 \%$ of the total energy demand if it replaces oil. The demand for peak electricity provides a second large market for hydrogen.

Nuclear hydrogen has several unique characteristics: large centralized production, coproduct production of oxygen, and the option of providing low-cost heat to industrial facilities. Somewhat surprisingly, several of the big potential markets for hydrogen (liquid fuels production and peak electric power) could also use very large quantities of oxygen. This gives nuclear hydrogen a competitive edge relative to other hydrogen production technologies for these markets. The characteristics of the markets that require both large quantities of hydrogen and oxygen need to be better understood to determine the role of nuclear hydrogen in the future and the design requirements for nuclear hydrogen facilities. Several technologies may need to be developed to fully utilize advantages from coproduction of hydrogen and oxygen in centralized facilities. 
Configuration and Technology Implications of

Page 103 of 119

Potential Nuclear Hydrogen System Applications

Appendix A

July 31,2005

\section{References}

Airbus Deutschland GmbH (2003), Liquid Hydrogen Fueled Aircraft-Systems Analysis, European Community Competitive and Sustainable Growth Subprogram (September 23).

Beychok, M. R. (1979), "Coal, Liquefaction" in Encyclopedia of Chemical Processing and Design, ed, J. J. McKetta, Marcel Dekker, Inc., New York.

Christensen, C. H., J. K. Norskeov, R. Z. Sorenson, T. Johannessen, and U. J. Quaade, April 2005, "Hydrogen Storage as Solidified Ammonia", Proc. 2005 American Institute of Chemical Engineers Spring Meeting, Atlanta, Georgia April 10-14, 2005, American Institute of Chemical Engineers, New York, NY.

Fillo, J. A., J. Powell, and M. Steinberg (1981), "Synthetic Fuels and Fusion," Nucl. Engin. and Des., 63 (2), 331-335.

Forsberg, C. W. (January 2005), Nuclear Hydrogen for Peak Electricity Production and Spinning Reserve, ORNL/TM-2004/194, Oak Ridge National Laboratory, Oak Ridge, Tennessee (January).

Gurbin, G. M. and K. H. Talbot (1994), "Nuclear Hydrogen - Cogeneration and the Transition Pathway to Sustainable Development," $9^{\text {th }}$ Pacific Basin Nuclear Conference, Trans. Am. Nucl. Soc. 70 (Suppl. 1).

Herzog, H., and D. Golumb (2004), "Carbon Capture and Storage from Fossil Fuels," in Encyclopedia of Energy, 6 vols., ed. C. J. Cleveland, Elserier, Amsterdam.

Kato Y., K. Ando, and Y. Yoshizawa (2003), "Study of a Regenerative Fuel Reformer for a ZeroEmission Vehicle System," J. of Chemical Engineering of Japan, 36, 860-866.

Marano, J. J. and J. P. Ciferno (2001), "Life-Cycle Greenhouse-Gas Emissions Inventory for FischerTropsch Fuels", Energy and Enviromental Solutions for U. S. Department of Energy National Energy Technology Laboratory.

Maiden, C. J. (1988), “The New Zealand Gas to Gasoline Project,” Chemtech 18 (1).

P. Mazza and R. Hammerschlag, June 2004. Carrying the Energy Future: Comparing Hydrogen and Electricity for Transmission, Storage, and Transportation, Institute for Lifecycle Environmental Assessment, Seattle, Washington

Steinberg, M. and V. D. Dang (1975), Use of Controlled Thermonuclear Reactor Fusion Power for the Production of Synthetic Methanol Fuel from Air and Water, BNL-20016, Brookhaven National Laboratory, Upton, New York (April).

Terry, K. B. (1995), Synthetic Fuels for Naval Applications Produced Using Shipboard Nuclear Power, Nuclear Engineer and Master of Science in Nuclear Engineering Thesis, Department of Nuclear Engineering, Massachusetts Institute of Technology, Cambridge, Massachusetts.

U.S. National Research Council (2004), The Hydrogen Economy: Opportunities, Costs, Barriers, and $R \& D$ Needs, National Academy Press, Washington, D.C. 
Configuration and Technology Implications of

Page 104 of 119

Potential Nuclear Hydrogen System Applications

Appendix A

July 31,2005

Wells, P. R. A. (Feb. 21, 2005), "Oil Supply Challenges-1: The non-OPEC decline”, Oil Gas J. 20-28.

Williams, B. (2003), "Heavy Hydrocarbons Playing Key Role in Peak-Oil Debate, Future Energy

Supply," Oil Gas J. 101 (29), 20-27. 
Potential Nuclear Hydrogen System Applications

Appendix B

July 31, 2005

\title{
Appendix B
}

\section{The Gas Reactor and Low Temperature Thermochemical Cycles for Hydrogen Production}

\author{
Richard B. Vilim, ANL \\ Michele A. Lewis, ANL \\ Proceedings of ICAPP '05 \\ Seoul, KOREA, May 15-19, 2005 \\ Paper 5480
}


July 31,2005

\title{
The Gas Reactor and Low Temperature Thermochemical Cycles for Hydrogen Production
}

\author{
Richard B. Vilim and Michele A. Lewis \\ Argonne National Laboratory \\ 9700 S. Cass Avenue \\ Argonne IL U.S.A. \\ Tel:630-252-6998,Email:rvilim@anl.gov
}

\begin{abstract}
Candidate technologies for thermochemical production of hydrogen using the Gas Reactor are examined. Adopting a goal of designing a plant with the lowest-cost product we review these technologies for their relative merits with respect to four cost-related criteria. A preliminary selection is made. This is followed by an assessment of the prospects for achieving: 1) a combined plant efficiency that is insensitive to varying the production fractions of electricity versus hydrogen and 2) absolute temperatures and temperature rates of change that are manageable from a creep and thermal stress standpoint without the need for exotic materials or extensive materials development.
\end{abstract}

\section{INTRODUCTION}

Among the many energy source, feedstock, and production technology options for producing hydrogen, the DOE Hydrogen Program [1] is focused on those that use domestic resources, avoid greenhouse gas production, and have the potential to be cost-competitive with gasoline. One such option uses nuclear energy to split water using either an electrolytic or thermochemical process. The more attractive processes among this option require very-hightemperature heat or high-efficiency electricity. In the Next Generation Nuclear Plant (NGNP) project the most promising of these will be demonstrated using the Very High Temperature Reactor (VHTR) to generate the required heat and/or electricity. A gas reactor is the leading candidate for the VHTR.

In this paper we examine the technology options that can lower the cost of producing hydrogen from the High Temperature Gas
Reactor when coupled to a thermochemical cycle. It proves helpful to arrange these choices by category. There are process options which involve 1) low temperature versus high temperature thermochemical processes and 2) hydrogen-only production versus electricity cogeneration. There are also interface options which involve 3) direct versus indirect cycle heating and 4) series versus parallel arrangement of heat loads. Generally, there is no interdependence among these categories so that the choice has four independent dimensions. The process of making design selections from among these categories provides answers to questions such as is cogeneration necessary to achieve the lowest product cost, how sensitive are the economics to providing a variable plant electricity-hydrogen output, what are the advantages of low temperature over high temperature processes, and are there overwhelming control issues for the simplest of plant configurations, the direct-cycle plant with series heat loads. 
The cost of the product depends on several plant factors including types and quality of materials used, nature of system losses, costs associated with equipment count and complexity, and design features needed for acceptable operational control. We examine how design choices from among the categories listed above affect these factors and, hence, the product cost. There are also safety implications but that is not the main focus. We conclude with a preliminary analysis of a design that should have one of the lowest product costs based an assessment with respect to the plant factors above.

\section{MAIN SYSTEM OPTIONS}

The literature contains many plant designs for producing nuclear hydrogen. Generally, each of these designs can be decomposed in a toplevel fashion into the four more or less independent categories described above. We remark on the options in each category that exist for the Gas Reactor coupled to a thermochemical cycle.

\section{II.A Process Options}

The Gas Reactor was originally conceived of as a high temperature heat source for electricity generation using a water Rankine cycle for energy conversion. The most recent concept achieves cost savings and higher plant efficiency by replacing the Rankine cycle with a Brayton cycle [2] as shown in the lower right-hand corner of Fig. 1. The reactor in this concept has a useful heat range that extends from $500 \mathrm{C}$ to as high as $1000 \mathrm{C}$. The large reactor temperature rise is related to the specific heat of helium and the need to limit coolant velocities and pumping power.

There are a variety of process options achievable with the Gas Reactor. In the 1970s the production of hydrogen using reactor outlet heat to power high-temperature thermochemical processes was studied extensively.[3] With the advent of thermochemical cycles that operate at lower temperatures new possibilities for hydrogen production arise. It is important to note, however, that the temperature range of the process heat from the Gas Reactor exceeds that which is optimal for any single thermochemical process. High temperature processes such as the sulfur-iodine cycle [3] require heat at both ends of the temperature range while low temperature processes such as copper-chlorine [4] require heat at the low end. In both cases there are idle temperature bands where the thermochemical process cannot make use of the heat. To avoid wasteful degradation of high-quality heat in situations such as these, one needs a second process to make productive use of the heat in the otherwise idle temperature band. Adding either an electric generating capability or a complimentary thermochemical process achieves this. Fig. 1 shows a matrix of possibilities for efficient use of Gas Reactor heat. The special case of hybrid thermochemical cycles where both heat and electricity are needed is covered by Fig. 1.

We use the sulfur-iodine and copper-chlorine cycles as representative of the high and low temperature thermochemical processes, respectively, in Fig. 1. The sulfur-iodine process has a well developed process flowsheet. The copper-chlorine process flowsheet is less developed but all steps of the process have been shown to proceed in the laboratory and without side reactions.[4] Both the $\mathrm{SI}$ and $\mathrm{CuCl}$ cycles lack certain process data needed for engineeringscale demonstration. [5,6] This paper adopts a simplified modeling of these thermochemical processes. They are modeled as heat loads while the hydrogen production rate is related to the heat load through an efficiency factor which we derive. The electric generation process is 
Appendix B

July 31,2005

modeled in sufficient detail that turbomachine performance curves are included.

\section{II.B Interface Options}

The interface between the primary system and the thermochemical process has important cost, operations, and safety issues associated with it. There are two independent dimensions with the basic possibilities shown in Fig. 2. The parallel and indirect options offer the potential for greater operational flexibility with respect to system isolation and control of temperature and product mix but at the expense of increased system losses and increased equipment costs.

\section{PERFORMANCE MEASURES}

As a rule of thumb, product (i.e. hydrogen/electricity) cost scales directly with the plant direct cost and inversely with plant efficiency. In turn, direct cost increases with commodities inventory, the length of the equipment list, and the quality of materials while efficiency decreases with system losses. Insight into lowering product cost is obtained by comparing, on a relative basis, the effect choices within each of the main system options has on these four measures of product cost.

\section{III.A Commodities Inventory and Equipment Count}

Generally, parallel loops each servicing a single heat load result in a longer run of pipe and with it increased commodity inventories compared to a single loop servicing the same loads. In [7] savings are claimed by going to a single heat transport loop for an application where prior state of the art called for multiple loops. Additionally, in Figs. 1 and 2 one sees heat loads at different temperatures and hence the opportunity for combining them into a single loop. This includes the obvious case of a chemical process and electric generating process but also includes two chemical processes operating at different temperatures

The cost case is even stronger for eliminating the intermediate loop in the indirect cycle in favor of a direct cycle. A heat exchanger and pump would be eliminated in addition to a run of pipe. There may, however, be a safety issue associated with eliminating a heat transport loop. A long-standing safety rule for gas reactors and liquid-metal reactors (LMR) is that primary coolant and balance of plant coolant inventories remain within their respective boundaries. While some of the simpler configurations in Fig. 2 violate this in the event of a heat exchanger tube failure, the use of double-walled heat exchangers could protect against this. This has been proposed for the LMR as a means of eliminating the intermediate loop.[8] 


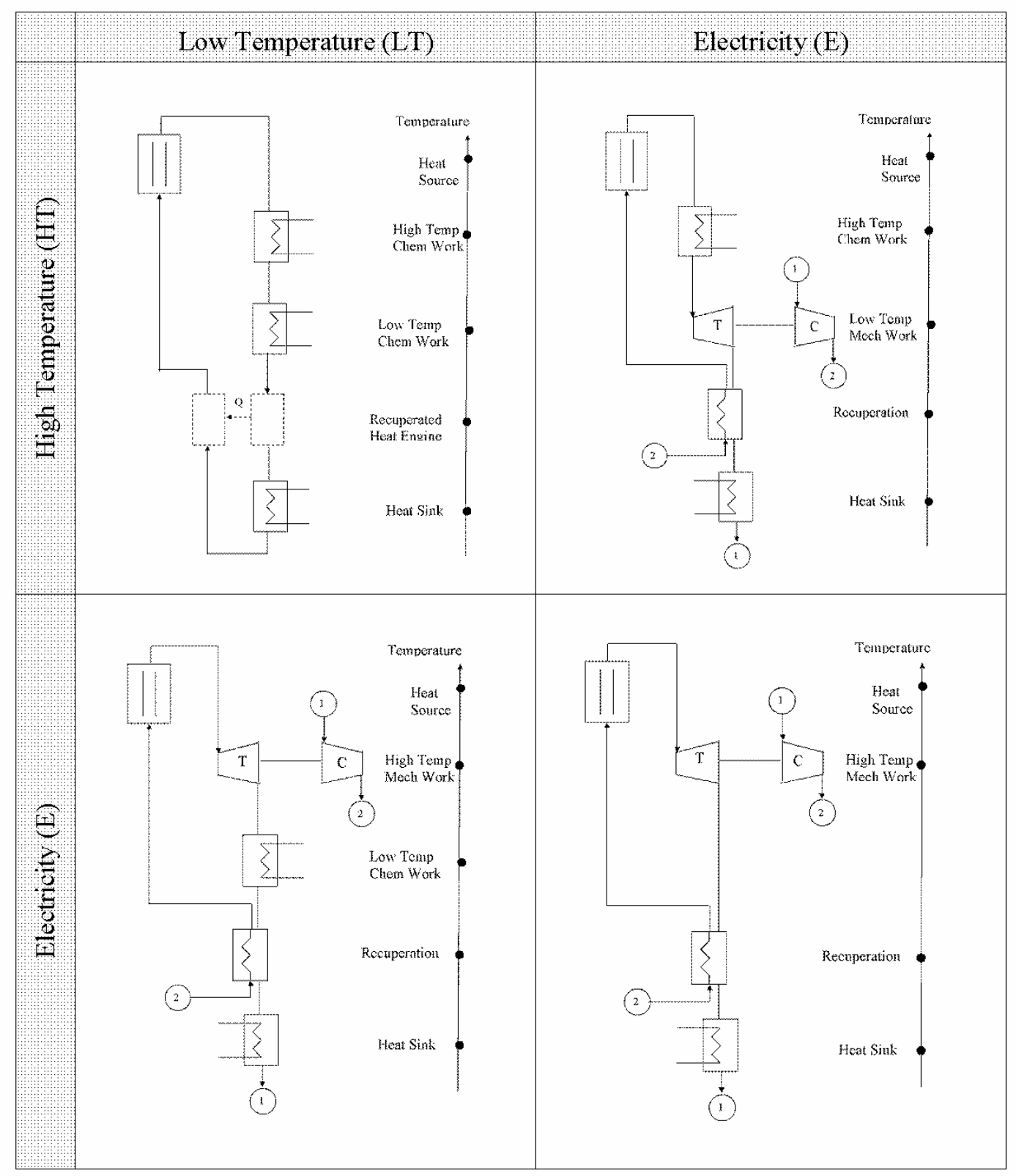

Fig. 1 Matrix of Process Options for Gas Reactor/Thermochemical Cycle Hydrogen Plant

\section{III.B Material Properties}

A major issue for nuclear production of hydrogen is materials selection for heat exchangers. So-called high-temperature thermochemical processes have a reaction that requires heat in the neighborhood of $900 \mathrm{C}$.
Additional demands may also include a corrosive chemical on the secondary side of the heat exchanger and a pressure differential of several MPa across the heat exchanger. These requirements can be daunting for metals.

One way of circumventing these material problems is to reverse the order of the turbine 
and thermochemical process from where they are usually thought of with respect to temperature. This is shown in Fig. 1 in the bottom left-hand corner where the turbine now takes the high temperature heat and a low temperature thermochemical cycle operates below it. To the first order there would be no impact on combined plant efficiency as a result of this switch. The efficiencies of the chemical process and the electrical generating processes go as the

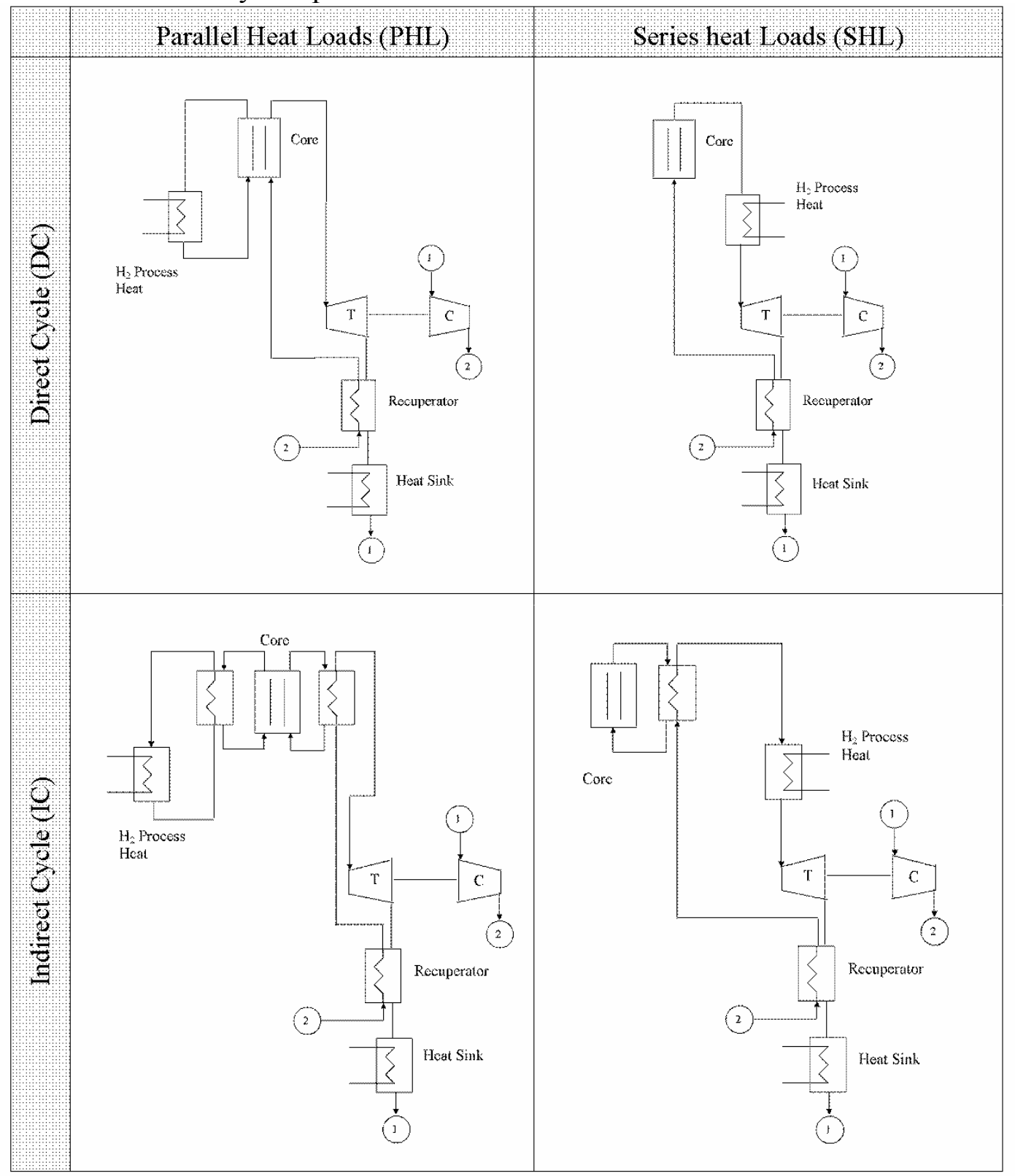

Fig. 2 Matrix of Interface Options for Gas Reactor/Thermochemical Cycle Hydrogen Plant

Carnot efficiency. Switching the processes just reverses their respective efficiencies but the combined efficiency stays the same.
The material demands are significantly reduced. First, turbine components are designed with internal cooling passages that provide 
cooling and permit the machine to run at higher gas temperatures than otherwise. Fundamentally then, for a given material, a turbine has the capability to run at a higher system temperature than a heat exchanger. The heat exchanger is tube sheet limited and the tube sheet sees the ambient coolant temperature. Second, there is no limiting stress for a turbine blade or shaft comparable to the several MPa pressure differentials across the heat exchanger tubes. Third, the corrosiveness of chemicals increases with temperature making the low temperature process better suited from the standpoint of heat exchanger longevity. A measure of the increased cost incurred in designing a heat exchanger from metals for high temperature operation is show in Fig. 3. On the ordinate we have for a material its stress rupture pressure divided by the cost of unit mass of the material. To include the benefit of increased thermal efficiency of the cycle at higher temperature we include a factor that accounts for this. The reference case in Fig. 3 is 304 stainless steel normally used for heat exchangers operating at $\sim 500 \mathrm{C}$, roughly the temperature of our low temperature thermochemical process. This is compared against Alloy 800, a candidate for high temperature thermochemical process operation at $\sim 850$ C. Fig. 3 indicates that the performance of Alloy 800 at high temperature is a factor 50 less compared to 304 stainless at low temperature.

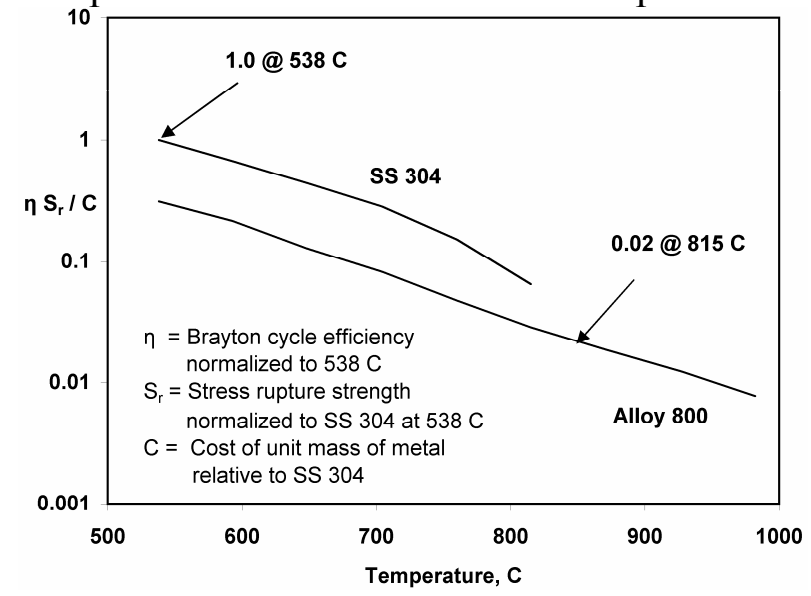

Fig. 3 Index Reflecting Cycle Efficiency, Creep Rupture Stress, and Cost Per Unit Mass as a Function of Temnerature

\section{III.C Energy Utilization}

The maximum achievable heat engine efficiency for converting heat to chemical or mechanical work is obtained only when processes are carried out via infinitesimal changes. Very small temperature and chemical gradients are required which implies low mass, energy, and momentum transfer rates. This proves uneconomical since it leads to large equipment size.

An alternative and more practical approach for minimizing losses is to minimize equipment count. Process gradients occur in equipment and so reducing the number of pieces of equipment reduces the number of points where gradients occur. Sources of irreversibility with their manifestations are: a heat exchanger and the temperature drop between hot and cold side; a pump and the compression of fluid; and mixing junctions and non-isothermal combining of fluid streams. There are some implications. Heat exchangers that must support a large pressure differential and high temperature will be structurally challenged based on Fig. 3. Tube walls will need to be thicker and so losses associated with wall temperature drop will increase. Intermediate loops that serve an isolation role will introduce losses as the result of an added pump and heat exchanger. Parallel loops that recombine fluid streams will introduce losses if the two streams recombine at different temperatures.

\section{III.D Reactor and PCU Vessel Packing}

An optimization study aimed at minimizing the cost of electricity generation for the directcycle gas reactor led to a reactor power of 600 MWt and a system configuration having two pressure vessels, one for the reactor and the other for the power conversion system (PCU).[2] Comparable electricity costs will be retained in a hydrogen cogenerating plant if we can keep this 
configuration without disrupting the vessel sizes. The main issue is whether the hydrogen process heat exchanger can be added without significantly altering the thermodynamic cycle for electricity production or perturbing the packing of the PCU vessel. We address this below.

\section{PRELIMINARY RESULTS}

We have outlined some principles that if adhered to should lead to a plant with one of the lowest product costs among all gas reactor/thermochemical cycle design possibilities. Here we apply these principles to see just what shape this plant takes. One would not expect the design to be necessarily similar to concepts proposed for NGNP demonstration of hydrogen production. There the emphasis is on component testing and assessment of technology rather than achieving lowest cost in a production setting.

\section{IV.A Low-Cost Product Plant}

The selection from interface options in Fig. 2 is strongly influenced by a cardinal rule for maximizing efficiency, that degradation in the quality or temperature of heat outside of performing mechanical or chemical work be kept to a minimum. With this in mind, no single thermodynamic cycle appears able to make effective use of the heat over the almost $500 \mathrm{C}$ temperature range for the Gas Reactor. It appears multiple heat loads are needed to avoid losses. A series arrangement of these heat loads provides for this and in conjunction with a direct cycle implementation (DC/SHL) yields the shortest equipment list and the least commodities. The direct cycle choice also allows us to retain as described below the efficient vessel packing used in the GT-MHR. It also avoids the losses associated with an intermediate loop.
The selection from process options in Fig. 1 appear limited to electricity production paired with either a high temperature (HT/E) or low temperature cycle (LT/E). Generally, a low temperature cycle has an electrolysis step so the HT /LT combination in Fig. 1 would require offsite electricity, a requirement we reject. The choice between HT/E and LT/E is strongly influenced by the need to preserve if possible the attractive economics for electricity production already achieved for the $600 \mathrm{MWt}$ GT-MHR through layout and component size selection. We can preserve this if the hydrogen process heat exchanger is placed at the outlet of the turbine, the LT/E option in Fig. 1. Then hydrogen process heat transfer area trades off one-for-one with recuperator area. The reactor inlet temperature is lowered an amount such that additional reactor power needed to raise the inlet coolant back up to the original inlet temperature equals the hydrogen process heat exchanger power. The state points for the electric generating thermodynamic cycle are unchanged so the electrical efficiency remains unchanged. However, since the reactor power was increased by an amount equal to the hydrogen process thermal power, to keep the two vessel sizes the same, the reactor power is scaled back to 600 MWt. This also requires proportionate changes in the hydrogen and electricity generating processes which is achieved by scaling back the primary flowrate by this same factor. Now for the HT/E option it is not clear that the hydrogen process heat exchanger can be added without significant disruption to the PCU. Displacing recuperator area with a high-temperature process heat exchanger at the outlet of the reactor would require shifting the Brayton cycle down in temperature. But the thermal efficiency of a closed $\mathrm{He}$ Brayton cycle falls off more quickly with heat source temperature reduction than suggested by the Carnot eficiency. Thus, there may be an efficiency penalty for the combined plant for having the thermochemical process on top rather than the electric heat engine. The 
alternative, not displacing recuperator area, would result in $29 \%$ more heat exchanger area and with it possibly the need for a third vessel. Further, there are the materials problems we described earlier for a high-temperature heat exchanger.

Our preferred design combines DC/SHL and LT/E and appears as the entry in the bottom-left corner of Fig. 1. A more complete diagram showing both coolers and a bypass valve appears in Fig. 4. The full power operating point is given in Table I. The temperatures at the hydrogen process heat exchanger were selected to power the $\mathrm{CuCl}$ hybrid cycle whose heat and electricity requirements are described in [9]. As implemented here the hydrogen process consumes 20 percent of the reactor thermal energy directly as heat for chemical reactions and another nine percent of the reactor thermal energy indirectly as electricity for the electrolysis step. The remaining reactor thermal energy is used to produce electricity for export to the electric grid. A fraction of the plant waste heat which is normally rejected by the precooler is redirected to a $\mathrm{CuCl}_{2}$ drying step. The heat on the cold side of the cooler is about $100 \mathrm{C}$ and powers a multi-effect flash evaporation process. Table I shows a $17 \%$ reduction in both the high-side system pressure and helium mass flowrate for our design compared to the GT-MHR while temperatures remain essentially unchanged. The power levels of the coolers, non- $\mathrm{H}_{2}$ process related section of the recuperator, compressors and turbine are reduced by $20 \%$ from the electricity-only plant, resulting in smaller components. This may be partially offset by the reduction in high and low system pressures which will affect the size of the turbmachines. To summarize, for the DC/SHL and LT/E combination as we have proposed it, the electrical generating efficiency remains unchanged from the GT-MHR, the PCU vessel should not see a size increase, and the material challenge associated with the intermediate heat exchanger has been eliminated since the high temperature heat is directed to the turbine.

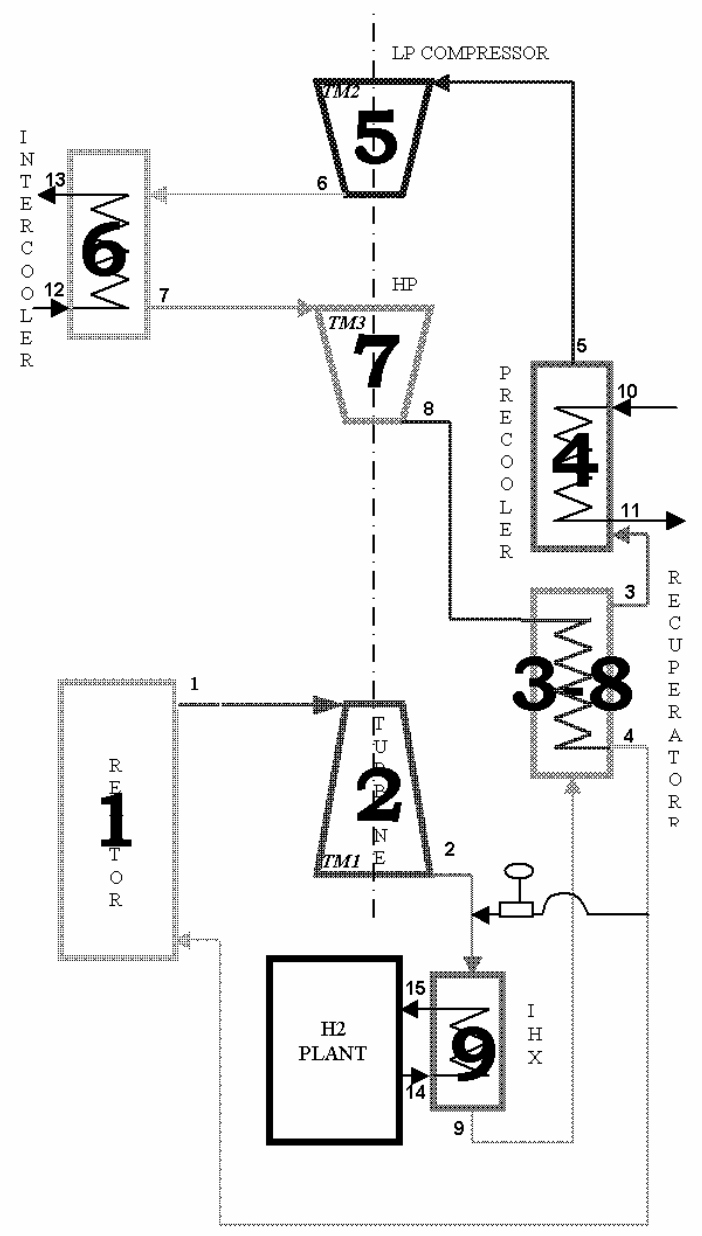

Fig. 4 Schematic of $600 \mathrm{MWt}$ Direct-Cycle Series-Arrangement Low-Temperature Thermochemical Cvcle Plant

\section{IV.B Temperatures and Efficiency with Load Change}

The short equipment list for the DC/SHL and LT/E combination implies a limited number of control actuators and with it fewer degrees of freedom to meet control objectives. Objectives include maintaining near constant temperatures for those plant components at the highest temperatures during both operational and offnormal events. Operational events would include the ability to independently vary the hydrogen 
and electricity production rates as market demands change, either diurnally or as the energy market evolves longer term. We investigated the capability of the proposed plant to meet a change in electricity demand while continuing to produce hydrogen at a constant rate and to do so without significant change in temperatures of the hottest components and without significant change in overall plant efficiency.

A description of the results requires presenting first the following definitions. The efficiency of the thermochemical process defined on a per mole basis is

$$
\eta_{\mathrm{H}_{2}}=\frac{\Delta \mathrm{H}_{\mathrm{H}_{2} \mathrm{O}(\mathrm{g})}}{\frac{\Delta \mathrm{H}}{\eta_{\mathrm{c}}}+\frac{\mathrm{W}}{\eta_{\mathrm{e}}}}
$$

where the numerator is the enthalpy required to decompose steam, also referred to as the low heating value, and is equal to $57.8 \mathrm{kcal} / \mathrm{mol} ; \Delta \mathrm{H}$ is the enthalpy change of the chemical reactions; $\eta_{\mathrm{c}}$ is the enthalpy change of the reactions divided by the actual enthalpy change for the implemented process of which the fraction 1- $\eta_{\mathrm{c}}$ represents losses; $\mathrm{W}$ in the case of a hybrid cycle is the energy input to the electrolytic cell; and $\eta_{\mathrm{e}}$ is the efficiency in converting heat to electricity.

The copper chlorine cycle described in [4] is taken as representative of a low temperature hybrid cycle. Data used to estimate the efficiency of the cycle are as follows. For the thermal steps, the theoretical enthalpy change obtained by summing the enthalpy change for each reaction at temperature is $\Delta \mathrm{H}=53.0 \mathrm{kcal} / \mathrm{mol}$.[9] This neglects the enthalpy of the drying step which is assumed to be obtained from the waste heat of the plant precooler and intercooler. An efficiency $\eta_{\mathrm{c}}=0.65$ is estimated to account for losses associated with recuperation of heat between reactions, for energy needed for chemical separations, and for energy needed to transport materials. We estimated this value from the literature for the SI cycle. In [6] an upper bound on SI cycle efficiency without irreversibilities is estimated as 0.48 . With irreversibilities the cycle efficiency is $0.28-0.34$. Hence, $\eta_{c}$ lies in the range $0.58-0.71$ for the SI cycle. We assume the midpoint (i.e. 0.65) is representative of welldeveloped thermochemical cycles and adopt this value for the $\mathrm{CuCl}$ cycle until more detailed process flowsheets are available upon which to base a more precise value. The electrochemical step involves the transfer of two electrons per molecule of hydrogen. The voltage measured in the laboratory for the electrochemical cell was $0.4 \mathrm{v}[10]$ which gives $\mathrm{W}=18.3 \mathrm{kcal} / \mathrm{mol}$. The efficiency of converting heat to electricity, $\eta_{\mathrm{e}}$, is a function of the power plant operating condition and is calculated using the GAS-PASS/H code. [11]

The efficiency of the plant is the rate of electricity and hydrogen energy production divided by the thermal power of the reactor,

$$
\eta=\frac{\eta_{\mathrm{H}_{2}} \Delta \dot{\mathrm{H}}_{\mathrm{H}_{2}}+\eta_{\mathrm{e}} \Delta \dot{\mathrm{H}}_{\mathrm{e}}}{\Delta \dot{\mathrm{H}}_{\mathrm{H}_{2}}+\Delta \dot{\mathrm{H}}_{\mathrm{e}}}
$$

where $\Delta \dot{\mathrm{H}}_{\mathrm{H}_{2}}$ and $\Delta \dot{\mathrm{H}}_{\mathrm{e}}$ are the enthalpies per unit time delivered to the hydrogen and electric generating processes, respectively.

Results are presented for the "limited regulation" control scheme described in Table II. Turbine bypass flow and rod reactivity are used to maintain constant reactor outlet temperature as the electrical power delivered to the grid is decreased while the hydrogen process heat load is held constant. Fig. 5 shows the reactor outlet temperature remains constant while the inlet temperature to the hydrogen process heat exchanger increases by $60 \mathrm{C}$ as electric power to the grid is reduced to $50 \%$ of its full power value. The thermal stress implications for the heat exchanger for this temperature rate of change 
need to be analyzed. If they are limiting, the temperature variation at the inlet to the heat exchanger could be reduced from $60 \mathrm{C}$ by taking bypass from the inlet to the recuperator rather than the outlet. The change in efficiency is shown in Fig. 6. The decrease in efficiency with decrease in power is largely due to turbine bypass flow. The turbine bypass flowrate as a fraction of reactor full power flowrate is shown in Fig. 7.

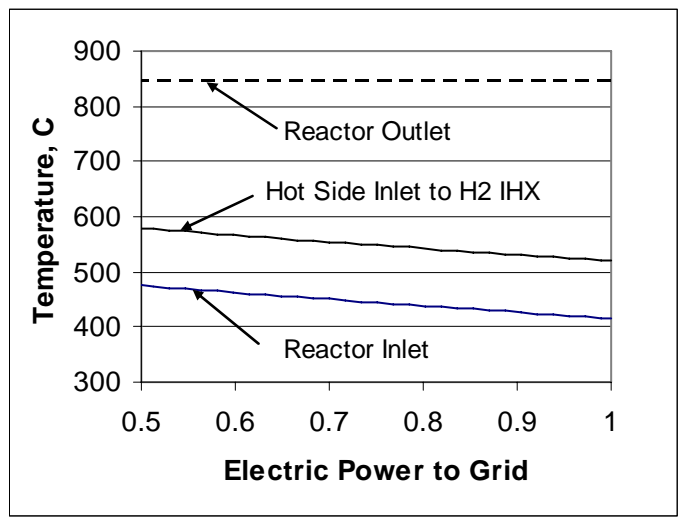

Fig. 5 Full Hydrogen-Process Power/ Partial-Load Electric Power:

Temperatures

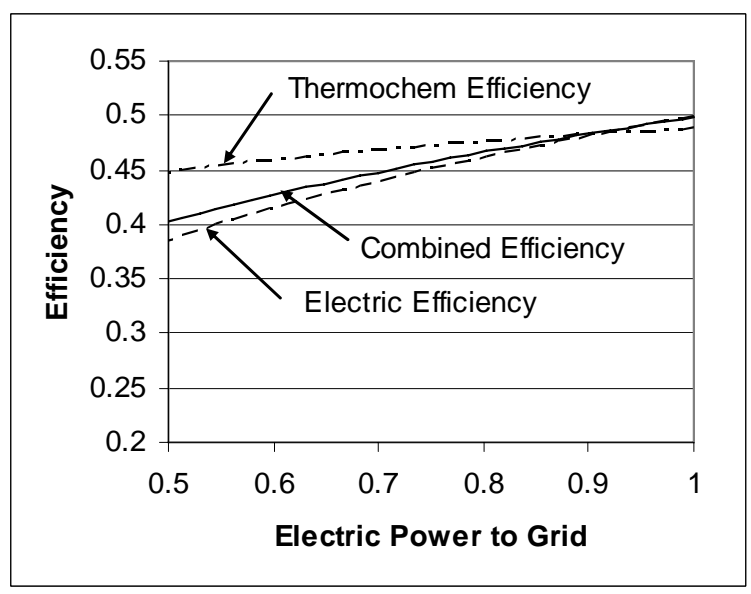

Fig. 6 Full Hydrogen-Process Power/ Partial-Load Electric Power: Efficiencies

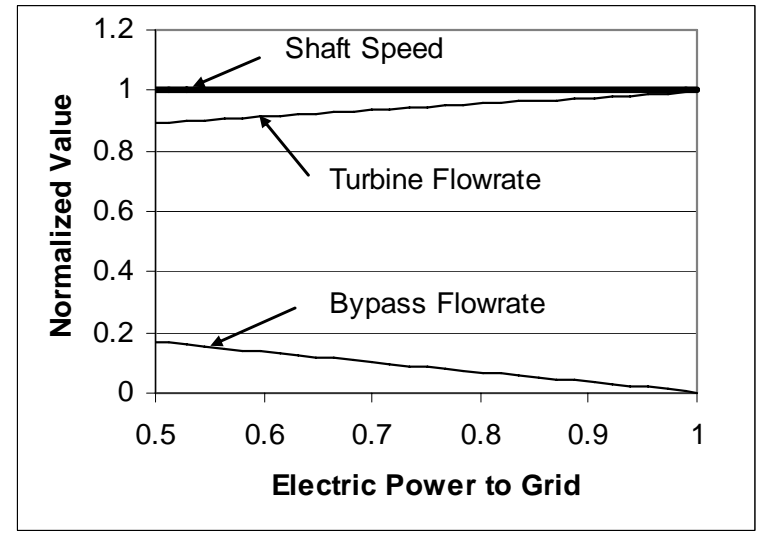

Fig. 7 Full Hydrogen-Process Power/ Partial-Load Electric Power: Flowrates

The use of the "enhanced regulation" control scheme in Table II will lead to improved results over what we have just described. Essentially, by allowing gas inventory to be an additional control variable and lifting the constraint on shaft speed, another two degrees of freedom are obtained. These can be used to reduce temperature and efficiency deviations with change in electricity production.

\section{CONCLUSIONS}

Process and interface options that give the lowest-cost product were identified for thermochemical production of hydrogen using the Gas Reactor. Several questions were posed at the outset and answers to them sought. No single thermochemical cycle appears capable of making efficient use of the almost $500 \mathrm{C}$ temperature range of heat produced by the Gas Reactor. Multiple heat loads are needed for low-cost production and for the Gas Reactor one of these should be a gas Brayton cycle for electricity generation. The change in overall plant efficiency as the hydrogen versus electricity production fractions are varied in a plant depends on whether bypass flow is used as a means for regulating temperatures in the hot components. Best results will be obtained if gas inventory is used in place of bypass flow. In any case, a plant 
design that provides for a variable energy mix will have idle production capacity and this will adversely affect the product cost. One can make a strong case related to materials cost and availability in favor of a low-temperature rather than high-temperature thermochemical cycle. It was shown that acceptable temperatures can be obtained for this low-cost plant even when one includes the goal of being able to produce varying fractions of electricity and hydrogen.

This work establishes the basic viability of a plant combining a direct cycle with two heat loads in series, a low temperature thermochemical process and a Brayton cycle, for producing low-cost hydrogen and electricity. More complete characterization requires further research to investigate how one should perform startup, recover from upsets in one of the plants, and isolate one of the plants when needed. Additional studies are needed to determine the best control strategy for normal operation. More detailed modeling of the low temperature processes is needed including a process flowsheet of sufficient detail to yield a good estimate for thermochemical cycle efficiency. Also of interest are the incremental product costs incurred by building in capability to deliver a variable mix of electricity and hydrogen product.

\section{REFERENCES}

1. Nuclear Hydrogen R\&D Plan, Draft, Office of Nuclear Energy, Science and Technology, U.S. Department of Energy, 2005.

2. Gas Turbine-Modular Helium Reactor (GTMHR) Conceptual Design Description Report, General Atomics, report number 910720, July 1996.

3. J.L. Russell and J.R. Schuster, "Thermochemical Water Splitting at General Atomic," Proc of 8th Synth Pipeline Gas Symp, p. 335-361, Chicago, IL, October 1976.
4. M.A. Lewis, M. Serban and J.K. Basco, "Hydrogen Production at $<550^{\circ} \mathrm{C}$ Using a Low Temperature Thermochemical Cycle," Proceedings of the ANS/ENS 2003 Global International Conference on Nuclear Technology, New Orleans, LA, November 16-23, 2003.

5. R.B. Vilim, "Commodity Inventories and Equipment Sizes for a Low Temperature Nuclear-Chemical Plant for the Production of Hydrogen," AIChE 2004 Spring National Meeting, New Orleans, LA, April 2004.

6. S.Goldstein , X.Vitart and J.M.Borgard, "General comments about the efficiency of the Iodine_Sulphur cycle coupled to a High Temperature Gas Cooled Reactor," Second Information Exchange Meeting on Nuclear Production of Hydrogen, Argonne National Laboratory, October 2003.

7. Y. Shimakawa, "An Innovative Concept of a Sodium-Cooled Reactor to Pursue High Economic Competitiveness," Nuclear Technology, 140, 2002.

8. Description of Candidate Liquid-MetalCooled Rector Systems Report, Generation IV Roadmap, Nuclear Energy Research Advisory Committee, GIF-017-00, December 2002.

9. R.B. Vilim, A. Miron, and E. Feldman, "Nuclear-Chemical Plant for Low Temperature Hydrogen Production," Global 2003, New Orleans, LA, November 16-23, 2003.

10. R. Remick, unpublished data, Gas Technology Institute, Chicago, IL, March 2004. 
Potential Nuclear Hydrogen System Applications Appendix B

July 31,2005

11. R.B. Vilim, "ATWS Events and Control System Design for the Gas Fast Reactor," International Congress on Advances in Nuclear Power Plants, Seoul, Korea, May 2005. 
Potential Nuclear Hydrogen System Applications

Appendix B

July 31,2005

Table I Full Power Condition for Direct-Cycle Single-Shaft 600 MWt Gas Reactor

\begin{tabular}{|c|c|c|}
\hline & Electricity Only & Electricity and $\mathrm{H}_{2}$ \\
\hline $\begin{array}{l}\text { Reactor } \\
\text { Core Power, MW(t) } \\
\text { Core Inlet/Outlet Temperatures, }{ }^{\circ} \mathrm{C} /{ }^{\circ} \mathrm{C} \\
\text { Helium Mass Flow Rate, } \mathrm{kg} / \mathrm{s}\end{array}$ & $\begin{array}{c}600 \\
490 / 850 \\
320\end{array}$ & $\begin{array}{c}600 \\
415 / 850 \\
264\end{array}$ \\
\hline $\begin{array}{l}\text { Turbomachinery } \\
\text { Turbine Inlet/Outlet Temperatures, } \\
{ }^{\circ} \mathrm{C} /{ }^{\circ} \mathrm{C} \\
\text { Turbine Inlet/Outlet Pressures, } \\
\mathrm{MPa} / \mathrm{MPa} \\
\text { Compressor Inlet/Outlet } \\
\text { Temperatures, }{ }^{\circ} \mathrm{C} /{ }^{\circ} \mathrm{C} \\
\text { Compressor Overall Pressure Ratio }\end{array}$ & $\begin{array}{c}850 / 510 \\
7.02 / 2.65 \\
33 / 112 \\
2.82\end{array}$ & $\begin{array}{c}850 / 519 \\
5.8 / 2.2 \\
29 / 110 \\
2.70\end{array}$ \\
\hline $\begin{array}{l}\text { Recuperator } \\
\text { Hot Side Inlet/Outlet Temperatures, } \\
{ }^{\circ} \mathrm{C} /{ }^{\circ} \mathrm{C} \\
\mathrm{Cold} \text { Side Inlet/Outlet Temperatures, } \\
{ }^{\circ} \mathrm{C} /{ }^{\circ} \mathrm{C}\end{array}$ & $\begin{array}{l}510 / 131 \\
112 / 490\end{array}$ & $\begin{array}{l}432 / 127 \\
110 / 415\end{array}$ \\
\hline $\begin{array}{l}\mathbf{H}_{2} \text { Heat Exchanger } \\
\text { Power, MW(t) } \\
\text { Mass Flow Rate, } \mathrm{kg} / \mathrm{s} \\
\text { Hot Side Inlet/Outlet Temperatures, } \\
{ }^{\circ} \mathrm{C} /{ }^{\circ} \mathrm{C}\end{array}$ & $\begin{array}{l}- \\
- \\
-\end{array}$ & $\begin{array}{c}120 \\
264 \\
519 / 432\end{array}$ \\
\hline $\begin{array}{l}\text { Precooler } \\
\text { Power, MW(t) } \\
\text { Inlet/Outlet Temperatures, }{ }^{\circ} \mathrm{C} /{ }^{\circ} \mathrm{C}\end{array}$ & $\begin{array}{c}163 \\
131 / 33 \\
\end{array}$ & $\begin{array}{c}135 \\
127 / 28 \\
\end{array}$ \\
\hline $\begin{array}{l}\text { Intercooler } \\
\text { Power, } \mathrm{MW}(\mathrm{t}) \\
\text { Inlet/Outlet Temperatures, }{ }^{\circ} \mathrm{C} /{ }^{\circ} \mathrm{C}\end{array}$ & $\begin{array}{c}131 \\
112 / 33 \\
\end{array}$ & $\begin{array}{c}104 \\
105 / 29 \\
\end{array}$ \\
\hline $\begin{array}{l}\text { Generator } \\
\text { Power, MW(t) } \\
\text { Grid } \\
\text { Electrolysis } \\
\end{array}$ & $\begin{array}{c}306 \\
306 \\
-\end{array}$ & $\begin{array}{c}240 \\
27 \\
213 \\
\end{array}$ \\
\hline
\end{tabular}


Potential Nuclear Hydrogen System Applications

Appendix B

July 31,2005

Table II Regulation of Cogenerating Direct Cycle/Series Plant: Full Hydrogen-Process Power, Partial Electric-Generator Power

\begin{tabular}{|c|c|c|c|}
\hline \multirow{2}{*}{ Process Variable } & \multirow{2}{*}{$\begin{array}{l}\text { Full Generator } \\
\text { Power }\end{array}$} & \multicolumn{2}{|c|}{ Partial Generator Power } \\
\hline & & $\begin{array}{c}\text { Scheme A - } \\
\text { Limited Regulation }\end{array}$ & $\begin{array}{c}\text { Scheme B - } \\
\text { Enhanced } \\
\text { Regulation } \\
\end{array}$ \\
\hline Reactor Power & $\bullet$ & $\mathrm{CV}$ & $\mathrm{CV}$ \\
\hline $\mathrm{H}_{2}$ Process Power & - $(100 \%)$ & - $(100 \%)$ & - $(100 \%)$ \\
\hline $\begin{array}{l}\text { Precooler Secondary } \\
\text { Flowrate and Inlet } \\
\text { Temp }\end{array}$ & $\bullet \bullet$ & $\bullet \bullet$ & $\bullet \bullet$ \\
\hline $\begin{array}{l}\text { Intercooler Secondary } \\
\text { Flowrate and Inlet } \\
\text { Temp }\end{array}$ & $\bullet \bullet$ & $\bullet \bullet$ & $\bullet \bullet$ \\
\hline Shaft Speed & $\bullet$ & $\bullet$ & $\mathrm{CV}$ \\
\hline Bypass Flowrate & $\bullet(=0)$ & $\mathrm{CV}$ & $\mathrm{CV}$ \\
\hline Reactor Outlet Temp & $\bullet$ & $\bullet$ & $\bullet$ \\
\hline Reactivity & $\mathrm{CV}$ & $\mathrm{CV}$ & $\mathrm{CV}$ \\
\hline Generator Power & CV $(100 \%)$ & - $(<100 \%)$ & - $(<100 \%)$ \\
\hline Coolant Inventory & $\mathrm{CV}$ & $\bullet$ & $\mathrm{CV}$ \\
\hline $\begin{array}{l}\mathrm{H}_{2} \text { Plant Hot Side Inlet } \\
\text { Temp }\end{array}$ & $\mathrm{CV}$ & $\mathrm{CV}$ & $\bullet$ \\
\hline $\begin{array}{l}\mathrm{H}_{2} \text { Plant Hot Side } \\
\text { Outlet Temp }\end{array}$ & $\mathrm{CV}$ & $\mathrm{CV}$ & $\bullet$ \\
\hline $\begin{array}{l}\text { Total, Controlled } \\
\text { Variables }\end{array}$ & 9 & 9 & 9 \\
\hline
\end{tabular}

- = Regulated Variable, assign its value; $\mathrm{CV}=$ Control Variable, value implied by values of Regulated Variables; Shaded region indicates regulated variable with important equipment implication 